August 30, 2012

Mr. Luis S. Cruz

Military Sealift Fleet Support Command

Naval Station Norfolk

Norfolk, VA 23511

\title{
SUBJECT: PHASE II CHARACTERIZATION SURVEY OF THE USNS BRIDGE (T-AOE 10), MILITARY SEALIFT FLEET SUPPORT COMMAND, NAVAL STATION, NORFOLK, VIRGINIA DCN 5180-SR-01-0
}

Dear Mr. Cruz:

Oak Ridge Associated Universities is pleased to provide the enclosed final report. The report details the Phase II results of the USNS Bridge characterization surveys. Comments from the draft report have been incorporated.

Please feel free to contact me via my information below, or Tim Vitkus at 865.576.5073, if you have any questions.

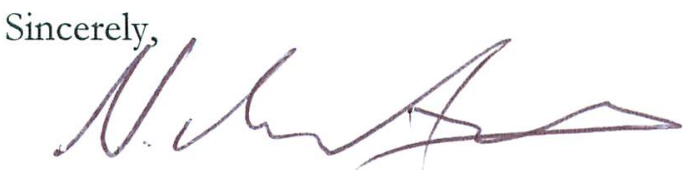

Nick A. Altic

Health Physicist,

Survey Projects

NAA:fr

Enclosure

$$
\text { cc: D. Hanson/MSFSC }
$$

File/5180

electronic distribution:
S. Roberts, ORAU
T. Vitkus, ORAU

E. Bailey, ORAU 


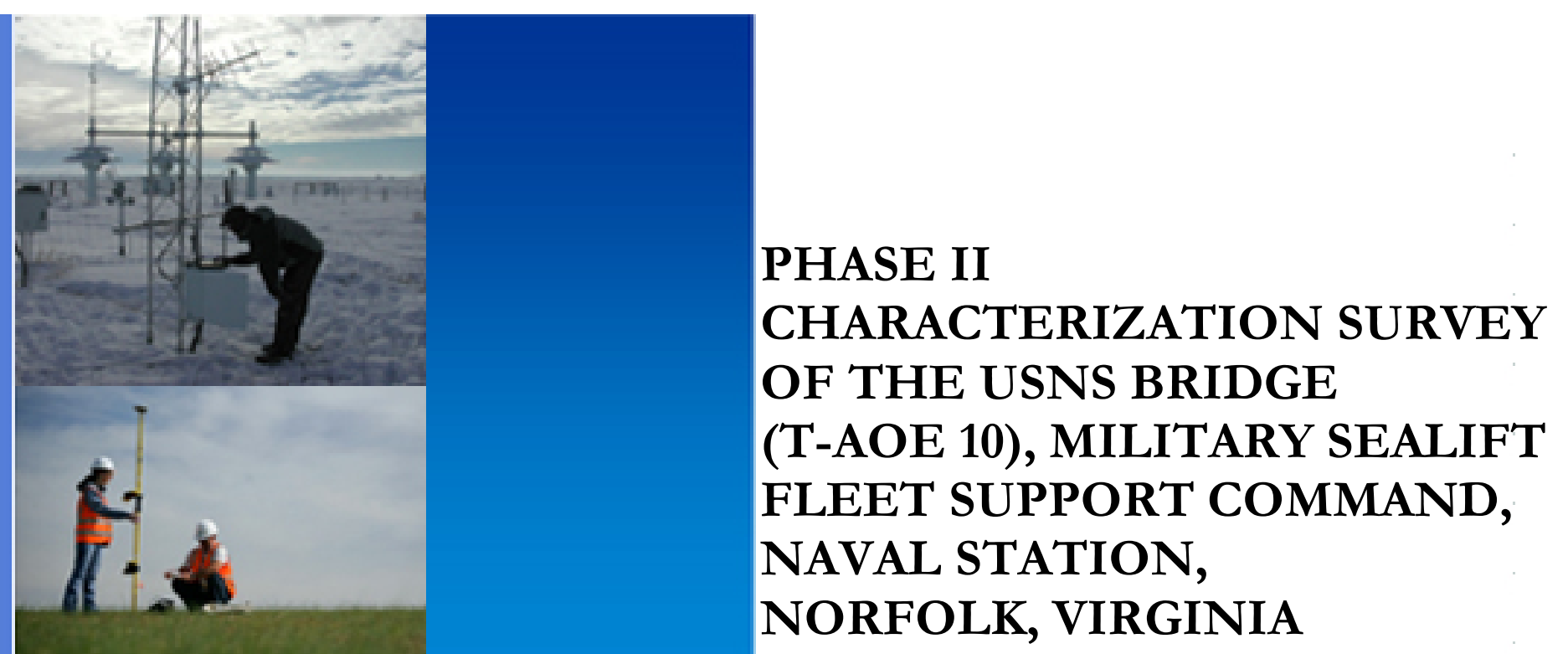

Nick A. Altic

Prepared for the

Military Sealift Fleet Support Command
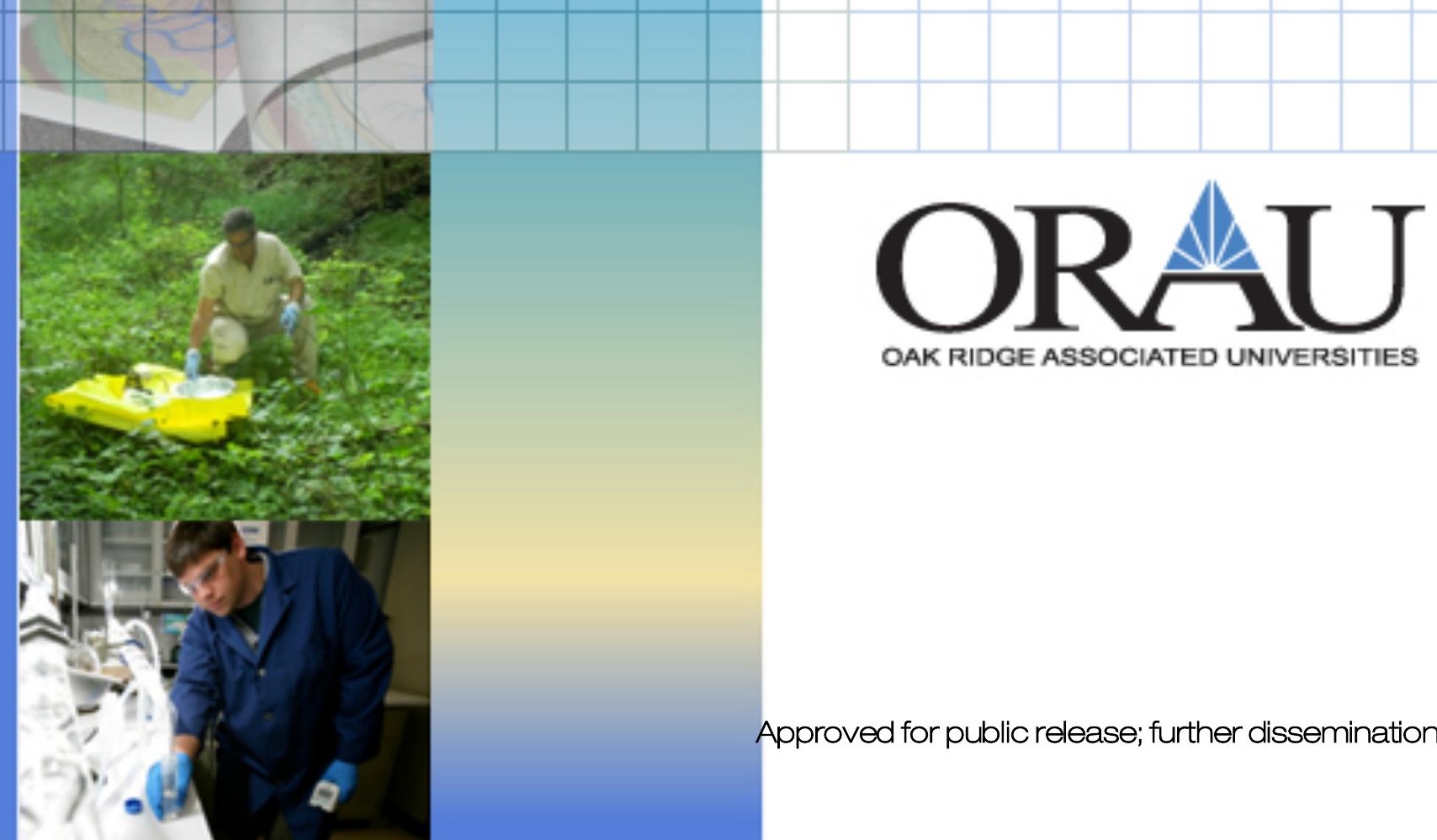

Approved for public release; further dissemination unlimited. 
Oak Ridge Associated Universities manages the Oak Ridge Institute for Science and Education (ORISE) contract for the U.S. Department of Energy. ORISE focuses on scientific initiatives to research health risks from occupational hazards, assess environmental cleanup, respond to radiation medical emergencies, support national security and emergency preparedness, and educate the next generation of scientists.

\section{NOTICES}

The opinions expressed herein do not necessarily reflect the opinions of the sponsoring institutions of Oak Ridge Associated Universities.

This report was prepared as an account of work sponsored by the United States Government. Neither the United States Government nor the U.S. Department of Energy, nor any of their employees, makes any warranty, expressed or implied, or assumes any legal liability or responsibility for the accuracy, completeness, or usefulness of any information, apparatus, product, or process disclosed, or represents that its use would not infringe on privately owned rights. Reference herein to any specific commercial product, process, or service by trade name, mark, manufacturer, or otherwise, does not necessarily constitute or imply its endorsement or recommendation, or favor by the U.S. Government or any agency thereof. The views and opinions of authors expressed herein do not necessarily state or reflect those of the U.S. Government or any agency thereof. 


\title{
PHASE II CHARACTERIZATION SURVEY OF THE USNS BRIDGE (T-AOE 10), MILITARY SEALIFT FLEET SUPPORT COMMAND, NAVAL STATION, NORFOLK, VIRGINIA
}

\author{
Prepared by \\ N. A. Altic

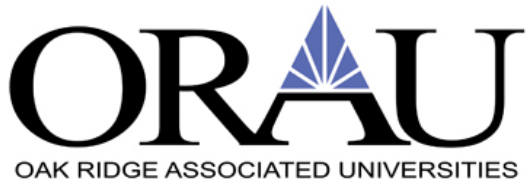 \\ Independent Environmental Assessment and Verification Program \\ Oak Ridge Associated Universities \\ Oak Ridge, Tennessee \\ Prepared for the \\ Military Sealift Fleet Support Command
}

FINAL REPORT

AUGUST 2012 
THIS PAGE INTENTIONALLY LEFT BLANK

Bridge - Phase II 


\section{ORAU}

PHASE II CHARACTERIZATION SURVEY OF THE USNS BRIDGE (T-AOE 10), MILITARY SEALIFT FLEET SUPPORT

COMMAND, NAVAL STATION, NORFOLK, VIRGINIA

Prepared by:

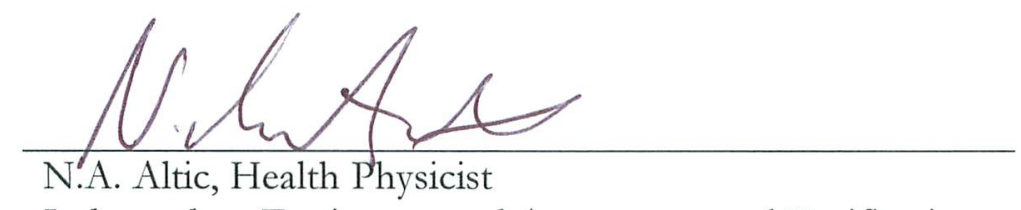

Date:

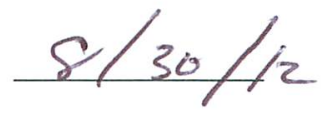

Independent Environmental Assessment and Verification

Reviewed by:

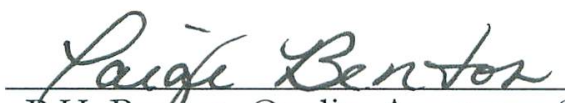

P.H. Berfon, Quality Assurance Specialist

Independent Environmental Assessment and Verification

Date:

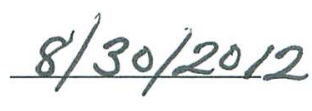

Reviewed and approved for release by:
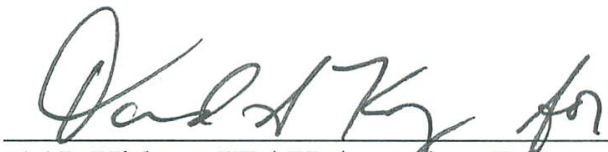

Date: $8 / 30 / 2012$

T.J. Vitkus, IEAV Assqeiate Director

Director Survey Projects

Independent Environmental Assessment and Verification

FINAL REPORT

AUGUST 2012 
THIS PAGE INTENTIONALLY LEFT BLANK

Bridge - Phase II 


\section{CONTENTS}

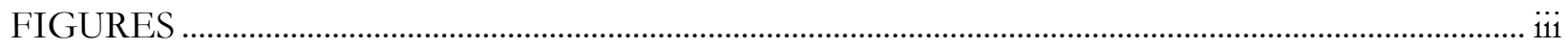

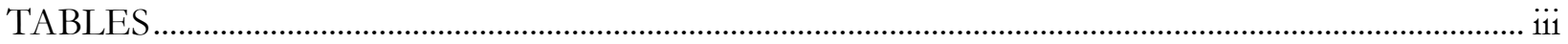

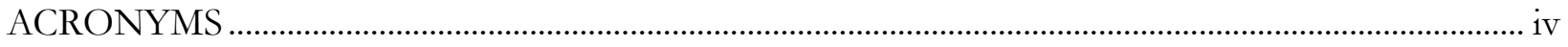

1. GENERAL INFORMATION AND RADIOLOGICAL HISTORY ……………............................. 1

1.1 Source of Radioactivity ................................................................................................................. 2

2. CONTROLS USED WHILE PERFORMING RADIOLOGICAL WORK …................................... 3

2.1 Control of Radioactive Surface Contamination ............................................................................. 3

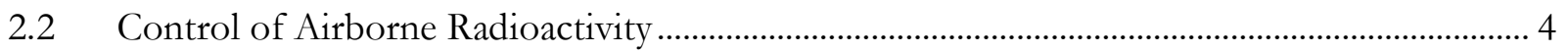

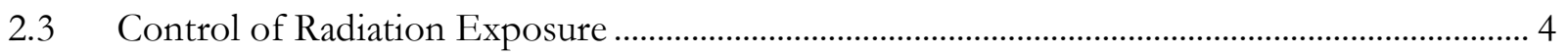

3. RADIOLOGICAL SURVEY PLAN ……............................................................................................. 4

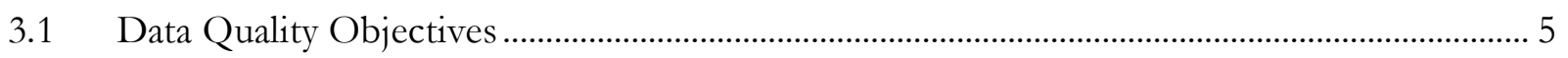

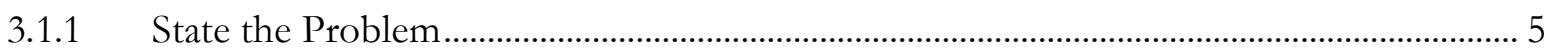

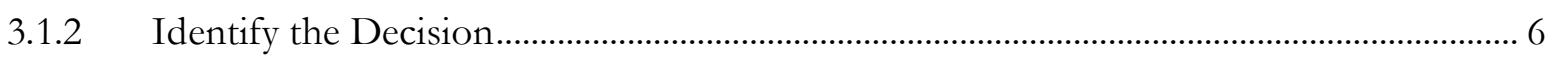

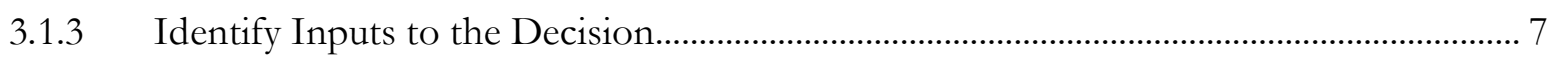

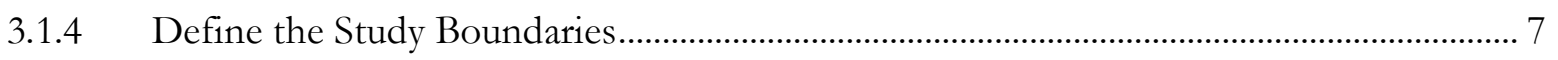

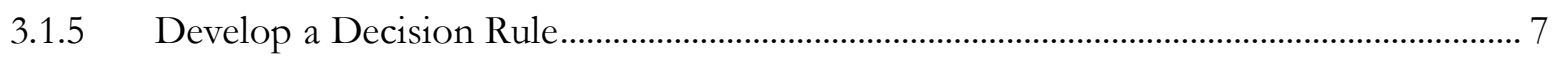

3.1.6 Specify Limits on Decision Errors ...................................................................................... 7

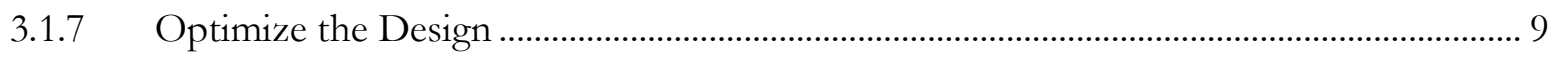

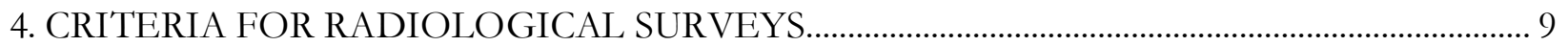

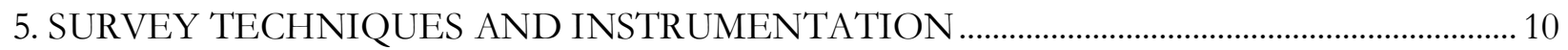

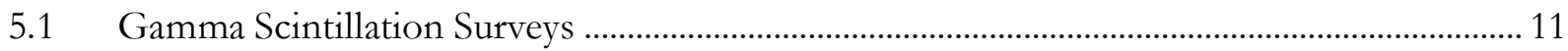

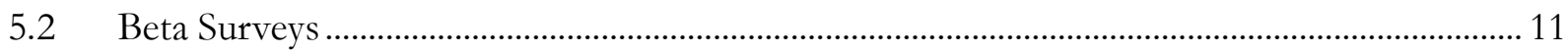

5.3 Explanation of Data Presentation............................................................................................ 13

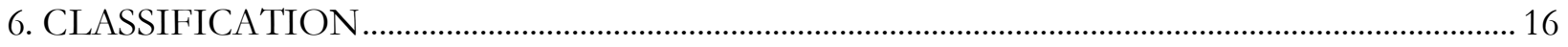

7. QUALITY ASSURANCE DURING RADIOLOGICAL SURVEYS ............................................. 17

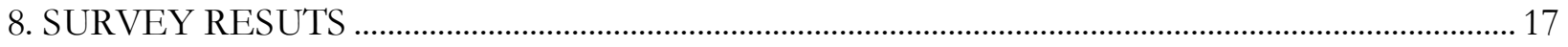

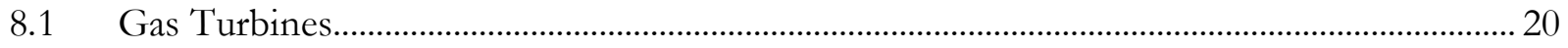

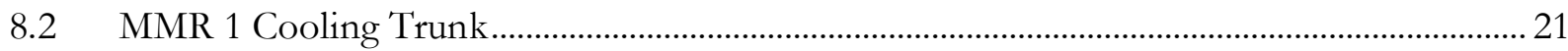

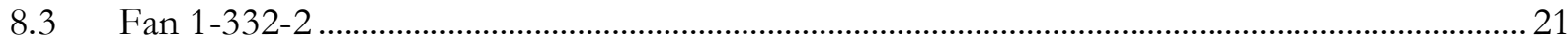

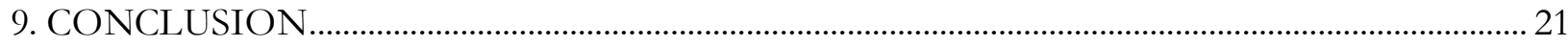

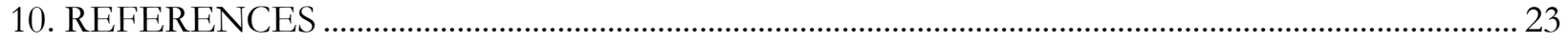

APPENDIX A: ITEMS REQUIRING INVESTIGATION APPENDIX B: DATA PACKAGES 


\section{FIGURES}

Fig. 5.1. Example Q-Q Plot to Illustrate Background Distribution and Simulated Contamination

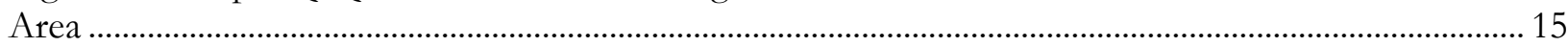

Fig. 8.1. Textured Surface on the Interior of the Power Turbine Casing .......

\section{TABLES}

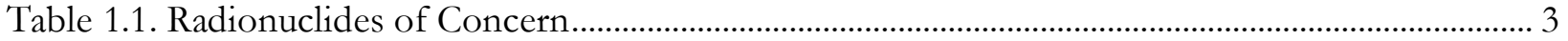

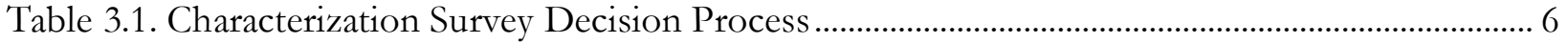

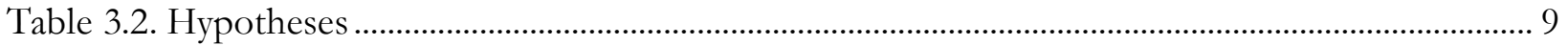

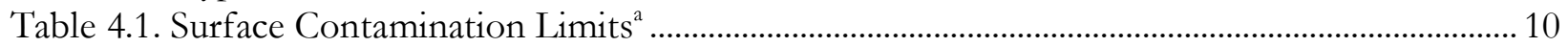

Table 8.1 Summary of Direct Measurements ........................................................................................ 19

Table 8.2. Summary of GTRB Measurements Above the Release Limit ................................................. 20

Table A-1. Areas of Investigation........................................................................................................... 


\section{ACRONYMS}

\begin{tabular}{|c|c|}
\hline $\mathrm{AA}$ & alternate action \\
\hline Bridge & USNS Bridge \\
\hline $\mathrm{Ci}$ & curie \\
\hline cpm & counts per minute \\
\hline ccpm & corrected counts per minute \\
\hline CPS & collective protective system \\
\hline Cs-137 & cesium-137 \\
\hline dpm & disintegrations per minute \\
\hline DQO & data quality objective \\
\hline GM & Geiger-Muller \\
\hline GTRB & gas turbine \\
\hline $\mathrm{H}_{0}$ & null hypothesis \\
\hline $\mathrm{H}_{\mathrm{A}}$ & alternative hypothesis \\
\hline HVAC & heating, ventilation, and air conditioning \\
\hline IEAV & Independent Environmental Assessment and Verification \\
\hline $\mathrm{MeV}$ & million electron volts \\
\hline MDC & minimum detectable concentration \\
\hline MMR & main machinery room \\
\hline MSFSC & Military Sealift Fleet Support Command \\
\hline $\mathrm{NaI}$ & sodium iodide \\
\hline NAVSEA & Naval Sea Systems Command \\
\hline NRC & U.S. Nuclear Regulatory Commission \\
\hline NORM & naturally-occurring radioactive material \\
\hline PSP & project-specific plan \\
\hline Q-Q & quantile-quantile \\
\hline ORAU & Oak Ridge Associated Universities \\
\hline ORISE & Oak Ridge Institute for Science and Education \\
\hline $\mathrm{pCi}$ & picocurie \\
\hline PPE & principal port engineer \\
\hline PSQ & principal study question \\
\hline S & substantial difference \\
\hline SSDG & ship service diesel generator \\
\hline UCL & upper confidence limit \\
\hline USN & United States Navy \\
\hline
\end{tabular}


THIS PAGE INTENTIONALLY LEFT BLANK

Bridge - Phase II 


\section{PHASE II CHARACTERIZATION SURVEY OF THE USNS BRIDGE (T-AOE 10), MILITARY SEALIFT FLEET SUPPORT COMMAND, NAVAL STATION, NORFOLK, VIRGINIA}

\section{GENERAL INFORMATION AND RADIOLOGICAL HISTORY}

The USNS Bridge (Bridge) is the fourth ship in the Supply class of fast combat support ships, commissioned on August 5, 1998 as a warship. On June 29, 2004 the Bridge was formally decommissioned and transferred from the United States Navy (USN) to the Military Sealift Fleet Support Command (MSFSC). The Bridge's displacement is approximately 48,800 tons, with a length of $755 \mathrm{ft}(230 \mathrm{~m})$, and a beam of $107 \mathrm{ft}(33 \mathrm{~m})$. Propulsion is via four 26,250 hp General Electric gas turbine engines, coupled to two propellers. The crew consists of $180+$ civilian personnel. The ship has five levels beneath the main deck, containing crew facilities, cargo holds, fuel holds, machinery rooms, and other support areas. The superstructure above the main deck consists of five levels and contains the pilot house together with other navigational and support areas. Crew living areas and offices are contained within the boundary of the ship's collective protective system (CPS), which filters the air with chemical, biological, and radiological filters.

In March 2011, the ship was deployed off northeastern Honshu, Japan with the carrier USS Ronald Reagan to assist with relief efforts after the 2011 Tōhoku earthquake and tsunami. During that time, the Bridge was exposed to air-borne radioactive materials leaking from the damaged Fukushima I Nuclear Power Plant. The proximity of the Bridge to the air-borne impacted area resulted in the contamination of the ship's air-handling systems and the associated components, as well as potential contamination of other ship surfaces due to either direct intake/deposition or inadvertent spread from crew/operational activities. Preliminary surveys in the weeks after the event confirmed low-level contamination within the heating, ventilation, and air conditioning (HVAC) ductwork and systems, and engine and other auxiliary air intake systems. Some partial decontamination was performed at that time.

In response to the airborne contamination event, MSFSC contracted Oak Ridge Associated Universities (ORAU), under provisions of the Oak Ridge Institute for Science and Education (ORISE) contract, to assess the radiological condition of the Bridge. ORAU performed Phase I of the radiological characterization surveys aboard the Bridge between July 11 and July 27, 2011. 
Phase I identified contamination within the CPS filters, ventilation systems, miscellaneous equipment, and other suspect locations that could not accessed at that time (ORAU 2011b). Because the Bridge was underway during the characterization, all the potentially impacted systems/spaces could not be investigated. As a result, MSFSC contracted with ORAU to perform Phase II of the characterization, specifically to survey systems/spaces previously inaccessible. During Phase II of the characterization, the ship was in port to perform routine maintenance operations, allowing access to the previously inaccessible systems/spaces.

\subsection{SOURCE OF RADIOACTIVITY}

On March 11, 2011, a 9.0 magnitude earthquake occurred near the coast of mainland Japan (Honshu). The seismic event triggered the automatic shutdown of three of the Fukushima I (Dai-ichi) Power Plant's six reactors, and all four of the Fukushima II (Dai-Ni) Power Plant's reactor units. The subsequent earthquake-induced tsunami damaged Fukushima I station's backup diesel generators and battery banks, resulting in a power station systems blackout. The power outage led to partial core damage at the Fukushima I facility. After several hydrogen explosions, reactor-based radionuclides were released into the atmosphere from the reactor and spent fuel pools as atmospheric plumes. Cooling liquids contaminated with radionuclides were also released into the ocean and land. Atmospheric plumes from the damaged Fukushima Dai-ichi reactor affected surrounding areas with low level radioactive fallout.

Naval activities and vessels located downwind of the event were exposed to these low levels of radioactive fallout and potentially water-borne oceanic contamination; the Bridge was one of several impacted or potentially impacted ships. Following the event, Naval Sea Systems Command (NAVSEA) provided specific radiological control requirements (NAVSEA 2012a) that were to be instituted prior to performing maintenance on ships' equipment and systems that were potentially affected by radioactivity from the Fukushima Dai-ichi reactor plants.

Table 1.1 lists the radionuclides of concern from fallout for compartments and systems aboard the Bridge. Due to its relatively short half life, iodine 131 (I-131) which initially was the primary radionuclide of concern, will not be present after approximately eight weeks following the reactor accident, and therefore has been deselected from further radiological survey requirements. 
Table 1.1. Radionuclides of Concern

\begin{tabular}{|c|c|c|c|c|}
\hline Radionuclide & Ratio to Cs-137 & Half Life & $\begin{array}{c}\text { Gamma Energy } \\
\text { (keV) }\end{array}$ & $\begin{array}{c}\text { Beta Max Energy } \\
\text { (keV) }\end{array}$ \\
\hline \multirow{2}{*}{ Cs-137 } & $1: 1$ & $30 \mathrm{yr}$ & 662 & 514 \\
\hline Cs-134 & $0.9: 1$ & $2.065 \mathrm{yr}$ & 605 & 658 \\
& $0.01: 1$ & $29.12 \mathrm{yr}(\mathrm{Sr})$ & None & $546(\mathrm{Sr})$ \\
\hline \multirow{2}{*}{ Sr-90/Y-90 } & $64.1 \mathrm{hr}(\mathrm{Y})$ & $2283(\mathrm{Y})$ \\
\hline
\end{tabular}

The primary radionuclide of concern is cesium-137 (Cs-137), with lesser quantities of Cs-134. The beta-only emitting radionuclides, strontium-90 (Sr-90), and yttrium-90 (Y-90), may also be present at very low concentrations relative to the cesium isotopes. Both of these radionuclides (Sr-90, parent/Y-90, daughter) establish equilibrium in a short period of time and for the purpose of radiological survey data reporting, they are evaluated together as a single radionuclide. The Table 1.1 ratios are based on evaluation of air sample data collected soon after the reactor accident. The values were adjusted to account for the decay of the short lived radionuclides no longer present. The NAVSEA Release Plan (NAVSEA 2012b) has established the ratio of Sr-90/Y-90 in relation to Cs-137. The Cs-137 to Sr-90/Y-90 ratio may then be used to establish a gross beta radioactivity action level that will account for the potential mixture of activity concentrations during the release surveys.

\section{CONTROLS USED WHILE PERFORMING RADIOLOGICAL WORK}

\subsection{Control of Radioactive Surface Contamination}

General work practices were established and invoked when performing surveys to mitigate potential cross-contamination. These general work practices were based on the potential for contamination. General work practices consisted of use of disposable surfaces to capture debris, wipe down equipment to minimize the buildup of radioactivity, and to minimize dust-producing operations.

Radiological protective clothing was specified in addition to the normal personal protective equipment. Depending on the contamination levels encountered, protective clothing requirements consisted of surgical/rubber gloves, a tyvek suit, cloth hood, and plastic shoe covers. A basic 
requirement for contamination control is the monitoring of all personnel leaving any area where radioactive contamination can be present. Workers would monitor (i.e., frisk) themselves prior to leaving a contamination area. Frisking the entire body for radioactivity was required, using sensitive handheld friskers.

\subsection{CONTROL OF Airborne Radioactivity}

Normal work practices and engineered controls prevented exceeding the limit for airborne radioactivity. All surveys were performed in areas or on equipment where the removable contamination levels were less than the 100 corrected counts per minute (ccpm) per $100 \mathrm{~cm}^{2}$ action level that would have required air monitoring.

\subsection{CONTROL OF RADIATION EXPOSURE}

Collection of waste can act as a concentrator of radioactivity. Only one item was collected by the ORAU survey team that was classified as waste. That item was double-bagged and stored in a locked case accessible only by the ORAU survey team, away from the ship's crew, until a time it could be properly disposed.

\section{RADIOLOGICAL SURVEY PLAN}

The Phase II characterization surveys were performed during the period of May 23-31 and June 8-16, 2012 in accordance with the project-specific plan (PSP) submitted to the MSFSC, the ORAU/ORISE Survey Procedures Manual, and the ORAU Quality Program Manual (ORISE 2011a, ORAU 2012a, and ORAU 2012b). Survey activities included gamma and beta scan surveys, direct measurements, and the collection of removable contamination smears.

NAVSEA issued the release plan after characterization surveys were completed. A cross-check was completed between the characterization survey plan and the release plan. It was determined that the data collected during characterization would meet the requirements of the release plan. 


\subsection{DATA QuAlity OBJECTIVES}

The data quality objectives (DQO) process provides a formalized method for planning the radiation surveys, improving the survey efficiency and effectiveness, and ensuring that the type, quality, and quantity of data collected were adequate for the intended decision applications. The characterization survey was designed using a graded approach. The level of survey effort was directly correlated with the radiological contamination potential. Where contamination was identified or suspected, the survey was also to define the boundaries and the extent of contaminated areas, quantify the levels of contamination for comparison to various action limits, and provide estimates of the level of effort required for decontamination. Where appropriate, these data may also be used for radiological release decisions.

The seven steps of the DQO process are as follows.

1. State the problem.

2. Identify the decision/objective.

3. Identify inputs to the decision/objective.

4. Define the study boundaries.

5. Develop a decision rule.

6. Specify limits on decision errors.

7. Optimize the design for obtaining data.

The preliminary USN survey results were reviewed and initial DQOs developed for the radiological characterization survey. Additionally, research was performed to determine the primary airborne radionuclides of concern released from the Fukushima I Nuclear Power Plant as discussed in Section 2. The DQOs followed radiological characterization industry accepted guidance (HPS 2008).

\subsubsection{State the Problem}

All of the Bridge's potentially impacted systems, equipment, and structural surfaces could not be characterized due to the ship being underway at the time of characterization. Additional characterization efforts were required to investigate these previously inaccessible areas. 


\subsubsection{Identify the Decision}

The second step in the DQO process identified the principal study questions (PSQs) and alternate actions (AAs), developed a decision statement, and organized multiple decisions, as appropriate. This was done by specifying AAs that could result from a "yes" response to a given PSQ and combining that PSQ and the AAs into a decision statement. Table 3.1 presents the PSQs and AAs combined into the decision statements.

\begin{tabular}{|c|c|}
\hline \multicolumn{2}{|c|}{ Table 3.1. Characterization Survey Decision Process } \\
\hline Principal Study Questions & Alternate Actions \\
\hline $\begin{array}{l}\text { 1. Is radiological contamination present } \\
\text { within air intake systems? }\end{array}$ & $\begin{array}{l}\text { Yes: Radiation count rates are in excess } \\
\text { of the background distribution. The } \\
\text { system/area is confirmed Class } 1 \\
\text { impacted and requires further } \\
\text { investigation and characterization. } \\
\text { Quantify levels for comparison to } \\
\text { total and removable surface activity } \\
\text { release criteria. }\end{array}$ \\
\hline $\begin{array}{l}\text { 2. Is radiological contamination present } \\
\text { on structural surfaces or other } \\
\text { system surfaces due to direct or } \\
\text { cross contamination events? }\end{array}$ & $\begin{array}{l}\text { No: Radiation count rates are comparable } \\
\text { to the background distribution. The } \\
\text { system/area is either non-impacted by } \\
\text { the airborne release event or there is a } \\
\text { low probability of residual } \\
\text { contamination being present. Perform } \\
\text { judgmental surveys to demonstrate } \\
\text { uncontaminated conditions or that } \\
\text { levels are less than the release criteria. }\end{array}$ \\
\hline \multicolumn{2}{|c|}{ Decision Statements } \\
\hline \multicolumn{2}{|c|}{$\begin{array}{l}\text { 1. When contamination is identified, determine if the levels exceed the NAVSEA } \\
\text { allowable surface contamination limits. }\end{array}$} \\
\hline \multicolumn{2}{|c|}{$\begin{array}{l}\text { 2. If the NAVSEA release limits are exceeded, determine the total contaminated } \\
\text { area requiring remediation through robust survey coverage. }\end{array}$} \\
\hline $\begin{array}{l}\text { 3. When contamination is not identified, } \\
\text { and smear samples to document radic } \\
\text { radiological release limits. }\end{array}$ & $\begin{array}{l}\text { collect judgmental direct measurements, } \\
\text { logical status. Compare data to the }\end{array}$ \\
\hline
\end{tabular}




\subsubsection{Identify Inputs to the Decision}

Previous characterization results were used as the initial input to classify known contaminated or previously contaminated systems/areas. For all other areas, the preliminary classification was based on Ship's Force interviews, areas where contamination may have accumulated, or the results of the initial judgmental surface scanning. Direct beta surface scans and/or static measurements were made at locations identified during preliminary surveys to make the quantitative determination as to whether contamination was present or further investigation was required. Contamination was defined as beta or gamma count rates in excess of the 95\% upper confidence limit (UCL) of material-specific and/or area-specific background distributions. This differential is referred to as the background mean plus a substantial difference (background $+\mathrm{S}$ ).

\subsubsection{Define the Study Boundaries}

Specific items not assessed in the initial characterization are listed in Table A-1. Some of the items were remediated or replaced between Phase II and the issuance of Table A-1; therefore, per the principal port engineer (PPE), these items were not investigated. Study boundaries, or survey areas, were limited to each specific item on Table A-1.

\subsubsection{Develop a Decision Rule}

The primary decision rule, as introduced in Table 3.1, is the contaminated/uncontaminated decision. The 95\% UCL of the background gamma and beta radiation count rate was established both for ambient conditions and for certain types of materials found on the ship, most notably the rubber decking material. Count rates in excess of this level were investigated to determine if contamination was present or the elevated count rates were the result of naturally occurring radioactive material (NORM). When contamination was confirmed, outlier data points were compared with the NAVSEA release criteria (Table 4.1) surface contamination limits (NAVSEA 2012b).

\subsubsection{Specify Limits on Decision Errors}

Three orders of control were established to limit decision errors. These decision errors are defined as Type I (also known as $\alpha$ error or a false positive) and Type II (also known as a $\beta$ error or false negative) errors. The manner in which the error is specifically stated is a function of the base condition being evaluated. For individual measurements, a Type I error occurs when a given 
radiation count rate is deemed background when it is actually contamination. Conversely, a Type II (false negative) error occurs when a given radiation count rate is deemed contamination when it is actually background. Errors were controlled for both scanning surveys and quantitative surveys. The initial control was the establishment of an a priori scan minimum detectable concentration (MDC) that was calculated for this survey to ensure a true positive detection proportion of 0.90 and a false positive proportion of no more than 0.25 (NRC 2000). The second limit established was the 0.95 UCL of background beta and gamma count rates. In other words, there is no more than a 0.05 probability of a Type I error when a measurement exceeds this threshold. Type II errors are controlled at the 0.05 significance level via the static measurement MDC. That is, there is a 0.95 probability that measurements above this threshold are contamination.

The final control was through the performance of a non-parametric two-sample hypothesis test. The data sets evaluated were from a background reference area and a survey area. Survey areas were evaluated via the Wilcoxon Mann-Whitney test. The null hypothesis $\left(\mathrm{H}_{0}\right)$, or assumed base condition, was that the survey area mean beta and/or gamma radiation count rate of direct measurements collected from a survey area were greater than the mean count rate from the background reference area population plus a substantial difference (S) of 2 times the background sample population standard deviation. The alternative hypothesis $\left(\mathrm{H}_{\mathrm{A}}\right)$ was that the survey unit was less than or equal to the background plus S. The original survey plan intended to compare quantitative static direct measurements of beta for this evaluation. However, once onboard it was determined that this method could not be readily implemented while maintaining the project schedule. Therefore, the plan was modified to compare the surface scan data from each survey area to an appropriate background scan data set. For most detector and material types, the selected background data set was an ambient, in-air background. Only the rubber decking required a material-specific detector background.

Specific information as to the confidence level $(1-\alpha)$ and the power $(1-\beta)$ were established once additional ship-specific information was known. Hypothesis tests were conducted for each survey area. The outcome of the test determined whether the null hypothesis could be rejected and the alternative hypothesis accepted or if there was insufficient evidence to reject the null hypothesis and conclude contamination was present. 
The null $\left(\mathrm{H}_{0}\right)$ and alternative $\left(\mathrm{H}_{\AA}\right)$ hypotheses are shown in Table 3.2 (EPA 2002).

\begin{tabular}{|c|c|c|}
\hline & $\mathbf{H}_{0}$ & $\mathbf{H}_{\mathrm{A}}$ \\
\hline $\begin{array}{l}\mathrm{H}_{0} \text { : site is greater than or equal to background }+\mathrm{S} \text {; } \\
\text { vs. } \\
\mathrm{H}_{\mathrm{A}} \text { : site is less than or from the same population as background } \\
+\mathrm{S} \text { (One-tailed, Test Form } 2)\end{array}$ & $\mu \mathrm{s}>\mu \mathrm{b}+\mathrm{S}$ & $\mu \mathrm{s} \leq \mu \mathrm{b}+\mathrm{S}$ \\
\hline
\end{tabular}

Cases where the survey area data failed to reject the $\mathrm{H}_{0}$ did not necessarily provide evidence that remediation was required. This decision was based on comparison of the contamination activity levels to the NAVSEA limits. All data were also evaluated for outliers, both in real time as the surveyor performed the scans and after processing and plotting the data. Because the Mann-Whitney test is a non-parametric test, it does not rely upon the assumption of a normal distribution and as such is not as sensitive to outliers. Therefore, because a given survey area data test might reject $\mathrm{H}_{0}$ with outliers present, evaluation of outliers was considered a critical function for identifying localized suspect contamination.

\subsubsection{Optimize the Design}

Details of the survey procedures are provided in Section 5.

\section{CRITERIA FOR RADIOLOGICAL SURVEYS}

The contamination limits for unrestricted release are based on the U.S. Nuclear Regulatory Commission (NRC) Regulatory Guide 1.86, and are more restrictive than the limits identified in the American National Standards Institute/Health Physics Society (ANSI/HPS) N13.12-1999 (R2010), Surface and Volume Radioactivity Standards for Clearance (NAVSEA 2012b). Contamination below the Regulatory Guide 1.86 limits will ensure that formerly contaminated platforms and material do not present any adverse health effects to personnel or a cross-contamination risk and, if achievable, will provide for the full, unrestricted operations of formerly contaminated platforms by any unprotected personnel, including the general public. 
All Phase II surface activity measurements were compared against the gross activity surface contamination limit presented in Table 4.1. The limits in Table 4.1, stated in units of disintegrations per minute per 100 square centimeters $\left(\mathrm{dpm} / 100 \mathrm{~cm}^{2}\right)$, allow for unrestricted release of ship components per Regulatory Guide 1.86. Using the Sr-90/Y-90 to Cs-137 ratio in Table 1.1 a gross activity surface contamination limit can be calculated by:

$$
\text { Gross Activity Limit }=\frac{1}{\frac{f_{S r}}{\text { Limit } S r_{S r}}+\frac{f_{C S}}{\text { Limit } C S}}
$$

Where:

$$
\begin{aligned}
& \mathrm{f}_{\mathrm{sr}}=\text { fraction of Sr-90/Y-90 present, } 0.01 \\
& \mathrm{f}_{\mathrm{Cs}}=\text { fraction of Cs-137 present, } 0.99 \\
& \text { Limit }_{\text {Sr }}=\text { Sr-90/Y-90 surface activity limit } \\
& \text { Limit }_{\mathrm{Cs}}=\text { Cs-137 surface activity limit }
\end{aligned}
$$

\begin{tabular}{|c|c|c|c|}
\hline \multicolumn{3}{|c|}{ Table 4.1. Surface Contamination Limits } \\
\hline Radionuclide & $\begin{array}{c}\text { Removable } \\
\left(\mathbf{d p m} / \mathbf{1 0 0} \mathbf{~ c m}^{\mathbf{2}}\right)\end{array}$ & $\begin{array}{c}\text { Total } \\
\text { (Fixed }+ \text { Removable) } \\
\left(\mathbf{d p m} / \mathbf{1 0 0} \mathbf{c m}^{\mathbf{2}}\right)\end{array}$ & $\begin{array}{c}\text { Maximum Allowable } \\
\text { (Fixed + Removable) }^{\mathrm{b}} \\
\left(\mathbf{d p m} / \mathbf{1 0 0} \mathbf{c m}^{\mathbf{2}}\right)\end{array}$ \\
\hline $\begin{array}{c}\text { Fission Product } \\
\text { beta/gamma } \\
\text { emitters }\end{array}$ & 1,000 & 5,000 & 15,000 \\
\hline $\begin{array}{c}\text { Sr-90/Y-90 } \\
\text { Gross Activity }\end{array}$ & 200 & 1,000 & 3,000 \\
\hline
\end{tabular}

${ }^{a}$ To convert from disintegrations per minute $(\mathrm{dpm})$ per $100 \mathrm{~cm}^{2}$ to $\mathrm{pCi} / 100 \mathrm{~cm}^{2}$, multiply table values by 0.45 .

bA small spot cannot exceed this maximum allowable level and the average contamination levels over 1 square meter do not exceed the total contamination level (fixed + removable).

cGross activity surface contamination limits were calculated using a Sr-90/Y-90 to Cs-137 ratio of 0.01:1.

\section{SURVEY TECHNIQUES AND INSTRUMENTATION}

The survey equipment and techniques used while performing release surveys for the Bridge are discussed below. 


\subsection{Gamma Scintillation SuRVEYS}

Gamma scintillation surveys were performed using a Ludlum Model 44-10 gamma scintillation detector coupled to a Ludlum Model 2221 ratemeter-scaler. The model 44-10 consists of a 2 -inch $\times$ 2-inch sodium iodide $(\mathrm{NaI})$ crystal. Data loggers were coupled to the ratemeter/detector combination during scans to collect the scanning count rate data at one-second intervals; this allows for evaluations of the electronically captured data distributions, possible outliers, or comparisons with other data sets.

Direct gamma radiation surface scans were performed by passing the detector slowly over the surface of the item under investigation. The distance between the detector and surface was maintained at a minimum. The gamma scintillation scans were primarily performed to assess the potential for internal system contamination. A specific scan MDC for the scintillation detector was not determined as the instrument was used solely as a qualitative means to identify elevated gamma radiation levels in excess of background. Identification of elevated radiation levels that could exceed the surface contamination limits were determined based on an increase in the audible signal from the ratemeter-scaler. Instrument calibration and daily operational checks were performed according to the ORAU/ORISE survey procedures manual (ORAU 2012a).

\subsection{Beta Surveys}

Direct surface scans for beta radiation were performed using either a Ludlum Model 44-9 "pancake" Geiger-Muller (GM) or a Ludlum Model 44-142 beta scintillator detector. Both detectors were coupled to Ludlum Model 2221 ratemeter-scalers. Data loggers were only used when scanning large surface areas (engine surfaces, walls, floors, etc.). The count rates are recorded directly from the digital readout of the ratemeter. The digital readout is a rolling average of the number of counts per second recorded in 31 -second intervals. The firmware then multiplies this value by 60 and records the result as cpm. Because the recorded results are based on 1-second counts, there is a large counting error associated with the value, upwards of 70\%. For example, if the detector response was such that the instantaneous rolling average was 3 per second, the digital readout would be $180 \mathrm{cpm}$. However, the random property of radioactive decay requires that the error of the counting statistics also be understood. For the $180 \mathrm{cpm}$ example, the result would be expressed as $180 \pm 104$ (1 sigma) cpm if the counting error were to be included. Therefore, there will be values in the recorded 
scanning data that are above the count rate action level that corresponds to $4,800 \mathrm{dpm} / 100 \mathrm{~cm}^{2}$. Action levels were determined a priori by back-calculating an instrument response required to reach the surface contamination limits. A static direct measurement MDC was determined for each detector type and is as follows:

- $1,600 \mathrm{dpm} / 100 \mathrm{~cm}^{2}$ for the $44-9$

- $250 \mathrm{dpm} / 100 \mathrm{~cm}^{2}$ for the $44-142$

Surface scans were performed by maintaining the detector-to-surface distance at a minimum and passed slowly over the surface of the item under investigation. A scan MDC was determined for each detector type prior to survey efforts and is as follows:

- $1,200 \mathrm{dpm} / 100 \mathrm{~cm}^{2}$ for the $44-9$

- $\quad 980 \mathrm{dpm} / 100 \mathrm{~cm}^{2}$ for the $44-142$

Static surface activity measurements were performed at locations above the action level or at judgmental locations where instrument response was at a maximum. Direct measurements were performed over a period of one minute. Surface activity was calculated based on Equation 5.1. Ambient background was subtracted as opposed to a material-specific background as the two were not appreciably different. If contamination was identified, measurements were taken with a portable isotope identifier (SAM-940). Instrument calibration and daily operational checks were performed according to the ORAU/ORISE survey procedures manual (ORAU 2012a).

$$
\text { Surface Activity }\left(\mathrm{dpm} / 100 \mathrm{~cm}^{2}\right)=(\mathrm{R}-\mathrm{B}) /\left(\mathrm{G}^{*} \boldsymbol{\varepsilon}_{\mathrm{tot}}\right) \quad \text { (Equation 5.1) }
$$

Where:

$$
\begin{aligned}
& \mathrm{R}=\text { Instrument Response }(\mathrm{cpm}) \\
& \mathrm{B}=\text { Ambient Background }(\mathrm{cpm}) \\
& \mathrm{G}=\text { Geometry Factor (normalizes to } 100 \mathrm{~cm}^{2} \text { ) } \\
& \varepsilon_{\mathrm{tot}}=\text { Total Instrument Efficiency }
\end{aligned}
$$

The Ludlum model 44-142 is more efficient than the DT-304 frisker referenced in the NAVSEA manuals. Therefore, static direct measurements were also reported in DT-304 equivalent corrected 
counts per minute (ccpm), for comparison with the limits in the Radiological Controls Manual (NAVSEA 2012a)

Smears for removable activity were collected at all direct measurement locations. Removable activity samples were collected using numbered filter paper disks, $47 \mathrm{~mm}$ in diameter. Moderate pressure was applied to the smear and approximately $100 \mathrm{~cm}^{2}$ of the surface was wiped. Smears were placed in labeled envelopes with the location and other pertinent information recorded. Smears were field counted with a 44-142 in the same location to minimize the impact to the calculated ccpm that could be introduced by variable backgrounds. Corrected count rates were then converted to units of activity.

\subsection{Explanation of Data Presentation}

Appendix B of this report provides data packages for each item in Table A-1, except where noted. The data package for each of the survey areas investigated contains:

1. Raw summary statistics for each survey unit, including number of observations (n), sample mean and standard deviation, minimum and maximum observation, and median

2. Quantile-quantile (Q-Q) plots (additional details to follow) of each item's direct gamma radiation measurement data compared with a representative background radiation measurement data population

3. Hypothesis tests for scan data, when appropriate

4. Direct measurement results, as well as removable surface activity. This report uses disintegrations per minute $(\mathrm{dpm})$ as the unit of radioactivity (i.e., the number of nuclear transformations per minute) for comparison with the guidelines. Another unit commonly used in the nuclear industry is the curie (Ci), and is defined as the amount of any radionuclide that undergoes exactly $3.7 \times 10^{10} \mathrm{dpm}$, which was the historic best-estimate of the amount of radioactivity in 1 gram of pure radium-226. For this report, in addition to the $\mathrm{dpm}$, activity is also presented using the picocurie $\left(10^{-12} \mathrm{Ci}\right)$.

5. Pictures identifying the item investigated

The Q-Q plot is a graphical technique for determining if two data sets come from populations with a common distribution. The advantages of utilizing the Q-Q plot are as follows. 
1. The sample sizes do not need to be equal.

2. Population distributional aspects can be evaluated simultaneously. The aspects that can all be detected include:
a. Shifts in scale
b. Changes in symmetry (skewness of the data)
c. The presence of outliers

3. The Q-Q plot also answers the following questions:
a. Do two data sets come from populations with a common distribution?
b. Do two data sets have common location and scale?
c. Do two data sets have similar distributional shapes?
d. Do two data sets have similar tail behavior (left or right skew, i.e., outliers)?

Q-Q plots were generated by uploading the appropriate background data and survey area data into the U.S. Environmental Protection Agency's ProUCL software. In viewing the Q-Q plots provided in Appendix B, the $\mathrm{Y}$-axis represents uncorrected instrument response (in cpm). The $\mathrm{X}$-axis represents the data quantiles about the mean value. A normal distribution that is not skewed by outliers - a background radiation population-will appear as a straight line, with the slope of the line subject to the degree of variability among the data population, while a larger slope indicates a greater variability in the data population. Values less than the mean are represented in the negative quantiles and the values greater than the mean are represented in the positive quantiles. Background levels were not significantly different between Phase I and Phase II of the characterization. Therefore, background data sets for the $\mathrm{NaI}$ detector (44-10) and hand-held beta scintillator (44-142) from Phase I were applied to all logged data collected in Phase II.

More than one distribution, such as background plus contamination or other outliers, will appear as a step function. Figure 5.1 illustrates a Q-Q plot of a floor background and a second population of simulated contamination on the same floor. For this plot, a radiological Sr-90 check source was randomly placed beneath the detector to simulate contamination while conducting a scan survey. The green-coded plot shows the data for background population. The blue-coded plot shows the floor beta survey data plus the intermittent source. The floor survey data closely follows that of the 
background. The outlier data, representing the simulated contamination from the Sr-90 check source placement, are clearly represented in the steep step function.

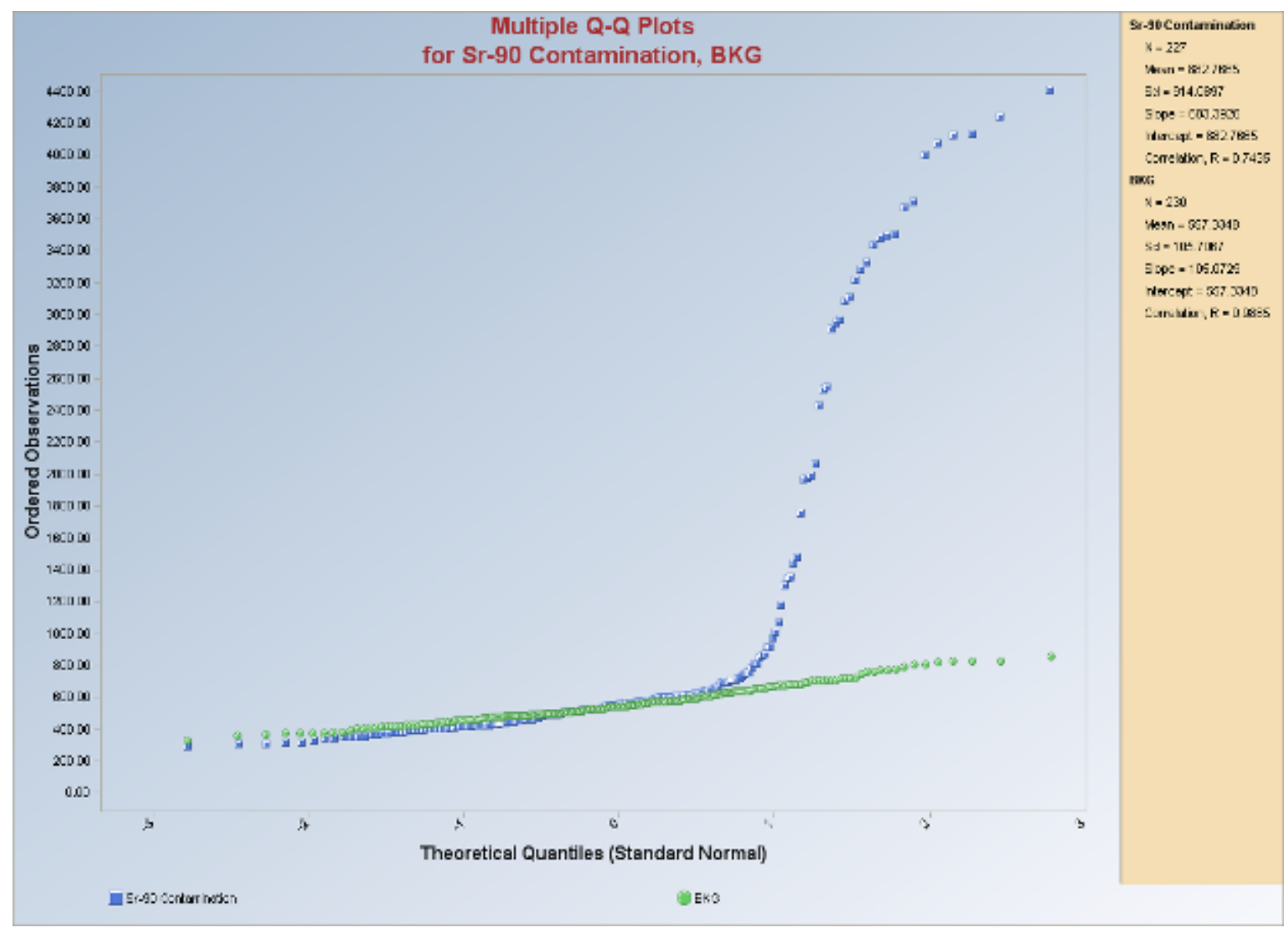

Fig. 5.1. Example Q-Q Plot to Illustrate Background Distribution and Simulated Contamination Area

Survey area results for gamma and beta radiation levels, if collected, are plotted separately with their appropriate background populations. Survey area results from non-impacted locations will closely mirror those of the background distribution, although slight variability in local area background relative to the nominal background may result in the survey area data appearing slightly above or below the background distribution. Outlier measurements that indicate the presence of contamination or locations that otherwise required further investigation will be apparent in the upper-right quadrant of the charts, as in Fig. 5.1. Survey area results with two differing material types will show the characteristic shallow step function of the two populations. To the degree possible, 
efforts were made to minimize combining material types with differing backgrounds, so as not to adversely impact the statistical data evaluations.

\section{CLASSIFICATION}

The spaces and systems of the ship are classified into four categories based on the potential for fallout contamination: Class 1, Class 2, Class 3, and non-impacted.

Class 1 spaces and systems have:

- Highest potential for radionuclide concentration from fallout contamination above the release limits

- Highest potential for small areas of elevated radionuclide concentration

- Insufficient evidence to support reclassification as Class 2 or Class 3 spaces or systems

Class 2 spaces or systems have:

- Low potential for radionuclide concentration from fallout contamination above the release limit

- Little or no potential for small areas of elevated radionuclide concentration or radioactivity

Class 3 spaces or systems have:

- Little or no potential for radionuclide concentration above background

- Insufficient evidence to support categorization as non-impacted

Non-impacted spaces and systems have:

- No potential for contamination

All of the spaces/systems in Table A-1 were treated as Class 1 because these systems were outside of the CPS boundary and no documentation exists to prove otherwise. For Class 1 spaces, high-density scans consisting of up to $100 \%$ of accessible surfaces were performed. If instrument response was above the action level, the contamination was bounded and a judgmental direct measurement was taken. 
For Class 1 systems, access ports near concentrators were opened and high-density scans consisting of up to $100 \%$ of the accessible surfaces were performed. Direct measurements were taken on at least one concentrator (e.g., fan blade) and at least one non-concentrator (e.g., plenum). Smears for removable activity were also collected at each direct measurement location, post measurement.

\section{QUALITY ASSURANCE DURING RADIOLOGICAL SURVEYS}

All applicable aspects of the radiological survey for the Bridge were independently reviewed to ensure that document preparation and data standards were maintained. Survey activities were conducted in accordance with procedures from the following IEAV program documents:

- Survey Procedures Manual (ORAU 2012a)

- Quality Program Manual (ORAU 2012b)

The procedures contained in these manuals were developed to meet the requirements of U.S. Department of Energy order 414.1D.

Quality control procedures include:

- Daily instrument background and check-source measurements to confirm equipment operation is within acceptable statistical fluctuations

- Calibration of all field instruments was performed with sources/standards traceable to the National Institute of Standards and Technology

- Training and certification of all individuals performing the surveys

- Review of survey documentation by senior personnel

\section{SURVEY RESUTS}

The Bridge was evaluated based on potential for exposure to fallout contamination associated with Fukushima Dai-ichi reactor accidents. Table 8.1 provides a summary of all measurements taken during Phase II of the characterization. Individual data packages for the items listed in Table A-1 are presented in Appendix B and grouped by their location (excluding the gas turbines). Four items had 
measurements that were above the $4,800 \mathrm{dpm} / 100 \mathrm{~cm}^{2}$ radiological release limit for total contamination specified in Table 4.1. Those items were: gas turbine (GTRB) 1B and 2B, main machinery room (MMR) 1 cooling trunk, and fan 1-332-2. Each item is discussed in the subsections below. Based on the scans being roughly uniform over the fan blades, it is not justifiable to compare the measurements to the maximum allowable hot spot gross activity radiological release limit of $15,000 \mathrm{dpm} / 100 \mathrm{~cm}^{2}$. However, all measurements taken were below the 2,250 pCi/probe limit as prescribed in the Radiological Controls Manual (NAVSEA 2012a). Additionally, all smear samplesincluding those collected from the four items discussed above-were below the gross activity radiological release limit for removable contamination.

While investigating fan 1-269-2 in compartment 1-265-4-Q, a rag was discovered inside the fan housing. The readings on the rag were approximately $350 \mathrm{cpm}$ with a pancake GM detector, well above the action level. The rag was removed and packaged for disposal. Extensive scans were performed upstream from the rag and did not identify areas above the limits.

Exterior gamma scans with a NaI detector were performed on the No. 4 Ship Service Diesel Generator (SSDG) turbocharger and surrounding area. NaI response was elevated compared to background $(\sim 3,000 \mathrm{cpm})$; however, this could not be attributed to contamination without scanning the interior with a GM or similar probe. These readings were similar to the turbochargers investigated during Phase I (ORAU 2011b). The unit could not be opened for investigation. SAM-940 measurements were taken at the three highest locations and did not identify Cs-137. 


\begin{tabular}{|c|c|c|c|c|}
\hline \multirow{2}{*}{ Location } & \multicolumn{2}{|c|}{ Highest Surface Activity } & \multicolumn{2}{|c|}{ Highest Removable } \\
\hline & $\mathrm{dpm} / 100 \mathrm{~cm}^{2}$ & Item/Description & $\mathrm{dpm} / 100 \mathrm{~cm}^{2}$ & Item/Description \\
\hline 01-205-AA & 4,100 & —a/Fan blade & 340 & - / in fan housing \\
\hline 1-225-1-AA & 310 & $\begin{array}{c}\text { Fan } 1-257-1 / \text { in fan } \\
\text { housing }\end{array}$ & 110 & $\begin{array}{c}\text { Fan } 1-244-1 / \text { inside fan } \\
\text { housing }\end{array}$ \\
\hline 1-265-4-Q & 4,200 & Fan 1-268-2/fan blade & 300 & Fan 1-269-2/ fan blade \\
\hline 1-330-4-Q & 4,800 & Fan 1-332-2/fan blade & 210 & Fan 1-336-2/ fan blade \\
\hline $1-395-2-Q$ & 2,400 & $\begin{array}{l}\text { Fan 1-399-2 \& 1-398-2/fan } \\
\text { blade }\end{array}$ & 200 & Fan 1-398-2/fan blade \\
\hline $\begin{array}{l}\text { GTRB 1A } \\
\text { Enclosure }\end{array}$ & 460 & $\begin{array}{l}\text { Engine surface/power } \\
\text { turbine casing }\end{array}$ & $\mathrm{n} / \mathrm{a}$ & $\mathrm{n} / \mathrm{a}$ \\
\hline $\begin{array}{l}\text { GTRB 1A } \\
\text { Exhaust }\end{array}$ & 950 & Large fin/ $\mathrm{n} / \mathrm{a}$ & 88 & Large fin/ $\mathrm{n} / \mathrm{a}$ \\
\hline $\begin{array}{c}\text { GTRB 1A } \\
\text { Power Turbine }\end{array}$ & 1,600 & $\begin{array}{l}\text { Vein between } 5^{\text {th }} \text { and } 6^{\text {th }} \\
\text { stage }\end{array}$ & 65 & $6^{\text {th }}$ stage blade \\
\hline $\begin{array}{l}\text { GTRB 1B } \\
\text { Enclosure }\end{array}$ & 770 & $\begin{array}{c}\text { Engine } \\
\text { surface/compressor }\end{array}$ & $\mathrm{n} / \mathrm{a}$ & $\mathrm{n} / \mathrm{a}$ \\
\hline $\begin{array}{l}\text { GTRB 1B } \\
\text { Exhaust }\end{array}$ & 3,200 & Large fin/ $\mathrm{n} / \mathrm{a}$ & 56 & $\begin{array}{l}\text { Shaft/casing covering } \\
\text { drive shaft }\end{array}$ \\
\hline $\begin{array}{c}\text { GTRB 1B } \\
\text { Power Turbine }\end{array}$ & 8,600 & $\begin{array}{l}\text { Inside casing } \\
\text { (see Figure 8.1) }\end{array}$ & 84 & $\begin{array}{l}\text { Inside casing } \\
\text { (see Figure 8.1) }\end{array}$ \\
\hline $\begin{array}{l}\text { GTRB 2A } \\
\text { Enclosure }\end{array}$ & 170 & $\begin{array}{c}\text { Engine surface/exhaust } \\
\text { duct }\end{array}$ & $\mathrm{n} / \mathrm{a}$ & $\mathrm{n} / \mathrm{a}$ \\
\hline $\begin{array}{l}\text { GTRB 2A } \\
\text { Exhaust }\end{array}$ & 770 & Large fin/ $\mathrm{n} / \mathrm{a}$ & 130 & Large fin/ $\mathrm{n} / \mathrm{a}$ \\
\hline $\begin{array}{c}\text { GTRB 2A } \\
\text { Power Turbine }\end{array}$ & 1,700 & Vein between $3^{\text {rd }} / 4^{\text {th }}$ stage & 73 & $\begin{array}{l}\text { Vein between } 3^{\text {rd }} / 4^{\text {th }} \\
\text { stage }\end{array}$ \\
\hline $\begin{array}{l}\text { GTRB 2B } \\
\text { Enclosure }\end{array}$ & 1,200 & $\begin{array}{l}\text { Anti-rotation bin/post } \\
\text { removal }\end{array}$ & $\mathrm{n} / \mathrm{a}$ & $\mathrm{n} / \mathrm{a}$ \\
\hline $\begin{array}{l}\text { GTRB 2B } \\
\text { Exhaust }\end{array}$ & 2,200 & Wall/ n/a & 120 & Large fin/ $\mathrm{n} / \mathrm{a}$ \\
\hline $\begin{array}{c}\text { GTRB 2B } \\
\text { Power Turbine }\end{array}$ & 8,100 & $\begin{array}{l}\text { Inside casing } \\
\text { (see Figure 8.1) }\end{array}$ & 98 & $6^{\text {th }}$ stage blade \\
\hline $\begin{array}{l}\text { MMR1 Cooling } \\
\text { Trunk }\end{array}$ & 6,500 & $\begin{array}{l}\text { 2B enclosure cooling/fan } \\
\text { blade }\end{array}$ & 98 & $\begin{array}{c}\text { 2B enclosure } \\
\text { cooling/fan blade }\end{array}$ \\
\hline $\begin{array}{l}\text { MMR2 Cooling } \\
\text { Trunk }\end{array}$ & 4,400 & $\begin{array}{c}1 \mathrm{~B} \text { enclosure } \\
\text { cooling/inside plenum }\end{array}$ & 79 & $\begin{array}{c}1 \mathrm{~B} \text { enclosure } \\
\text { cooling/inside plenum }\end{array}$ \\
\hline
\end{tabular}




\subsection{GAS TURBINES}

Contamination was not identified on any of the engine surfaces or engine compartment surfaces.

The contamination identified on GTRBs $1 \mathrm{~B}$ and $2 \mathrm{~B}$ was determined to be contained within internal engine components. Cs-137 was identified inside of the power turbine casing and contamination levels between the two GTRBs were similar. The highest recorded surface activity was on the inside of the power turbine casing and had a value of $8,600 \mathrm{dpm} / 100 \mathrm{~cm}^{2}(170 \mathrm{ccpm} /$ probe DT-304 equivalent). Table 8.2 provides a summary of the measurements taken on the power turbine that were above the limit.

\section{Table 8.2. Summary of GTRB Measurements Above the Release Limit}

\begin{tabular}{|c|c|c|c|c|c|}
\hline \multirow{2}{*}{ GTRB } & \multirow{2}{*}{ Location } & \multicolumn{2}{|c|}{ Total Beta Activity } & \multicolumn{2}{c|}{ Removable Beta Activity } \\
\cline { 2 - 5 } & $\mathbf{c c p m} / \mathbf{p r o b e}^{\mathbf{a}}$ & $\mathbf{d p m} / \mathbf{1 0 0} \mathbf{c m}^{\mathbf{2}}$ & $\mathbf{c c p m}$ & $\mathbf{d p m} / \mathbf{1 0 0} \mathbf{c m}^{\mathbf{2}}$ \\
\hline 1B & $4^{\text {th }}$ stage blade & 93 & 4,800 & -4 & -17 \\
\hline 1B & $\begin{array}{c}\text { Casing between 5 } \\
\text { veins }\end{array}$ & 170 & 8,600 & 18 & 84 \\
\hline 2B & 6 $^{\text {th }}$ stage blade & 120 & 5,900 & 21 & 98 \\
\hline 2B & $2^{\text {thd }}$ stage vein & 100 & 5,200 & 14 & 65 \\
\hline 2B & $\begin{array}{c}\text { Casing between 5th } \\
\text { veins }\end{array}$ & 160 & 8,100 & 8 & 39 \\
\hline
\end{tabular}

${ }^{a}$ Values are DT-304 equivalent

The inside of the turbine casing is textured (Fig. 8.1), which can act as a concentrator by collecting material between the grooves. Due to maintenance schedules, the fan blades on the compressor were not able to be investigated. However, they are suspected to be contaminated as well, possibly at levels higher than the power turbine as they are upstream. 


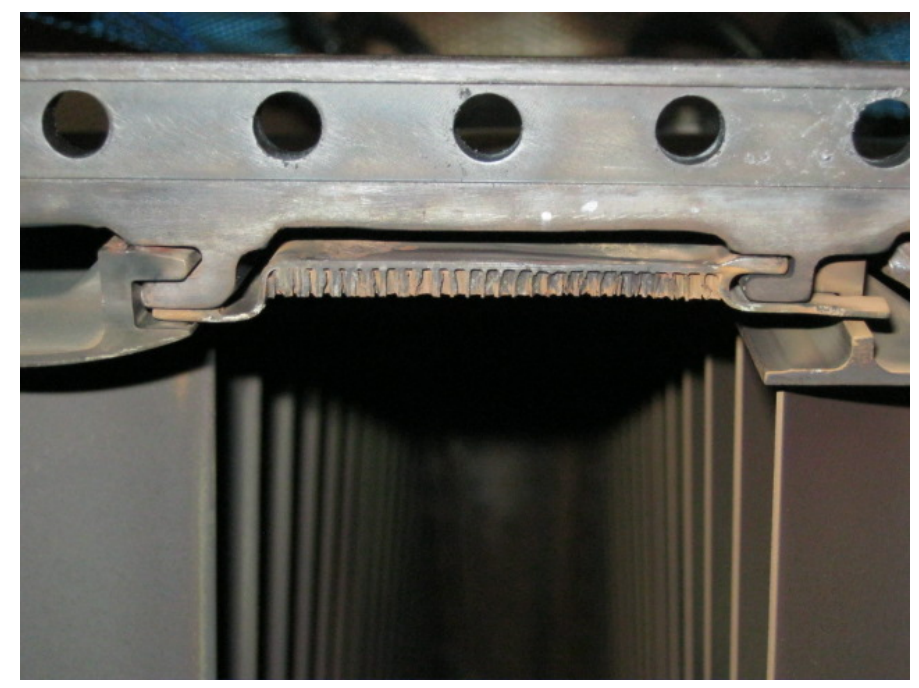

Fig. 8.1. Textured Surface on the Interior of the Power Turbine Casing

\subsection{MMR 1 COOLING TRUNK}

The MMR cooling trunk provides cooling to engine enclosures (i.e., diesel generators, GTRBs). Elevated levels of radioactivity were found on fans providing cooling to the GTRB enclosures. Only one measurement was above the gross activity limit. This measurement was located on a fan blade supplying cooling to enclosure $2 \mathrm{~B}$ and had a surface activity level of $6,500 \mathrm{dpm} / 100 \mathrm{~cm}^{2}$ (130 ccpm/probe). Cs-137 contamination was confirmed using the SAM 940.

\subsection{FAN 1-332-2}

A direct measurement taken from a blade on fan 1-332-2 in space 1-330-4-Q was equal to the gross activity guideline $\left(4,800 \mathrm{dpm} / 100 \mathrm{~cm}^{2}\right)$. However, this measurement is below the $500 \mathrm{ccpm} /$ probe and 2,250 pCi/probe limit for total contamination listed in the Radiological Controls Manual. Cs-137 contamination could not be confirmed.

\section{CONCLUSION}

GTRBs $1 \mathrm{~B}$ and $2 \mathrm{~B}$ were found to have levels of Cs-137 contamination above the gross activity release limit in Table 4.1. These engines would require some level of decontamination to reduce the surface activity levels such that the engines could be removed from radiological control, based on the NAVSEA Release Plan. Alternatively, measurements could be compared to NRC's conservative 
screening level guideline for uniform Cs-137 provided in NUREG-1757 (NRC 2006). The Cs-137 screening level in NUREG-1757 is 28,000 dpm/100 cm $\mathrm{cm}^{2}$ The $28,000 \mathrm{dpm} / 100 \mathrm{~cm}^{2}$ is a dose-based limit-equivalent to 25 millirem per year-and represents the average activity level that may be present on floors, walls, and ceilings for a building occupancy scenario. The modeled scenario includes direct and indirect exposure durations of 2,000 hours annually. This criterion is considered protective of human health and the environment. Any potential exposure during engine maintenance or overhaul would be expected to be well below the modeled scenario of 2,000 hours and these limits should therefore be considered very conservative from potential dose consequence and therefore protective. All measurements taken are well below this level. If these engines are to be remediated or replaced, a cost-benefit-analysis could be performed to assess the benefit (i.e., reduction in radiation absorbed dose) of said actions or alternatively a dose assessment performed using the measured activity levels as inputs as well as inputs that represent maintenance activity exposure durations and any additional sensitive parameters.

Per the PPE, the fan providing cooling to enclosure $2 \mathrm{~B}$ was scheduled to be remediated shortly after the characterization survey was completed. Once remediation is complete, the remediation contractor should provide documentation that the surface activity levels on the fan are below the limits.

Fan 1-332-2 in compartment 1-330-4-Q had a single measurement located on the fan blade equal to the gross activity limit, 4,800 dpm/100 $\mathrm{cm}^{2}$ (93 ccpm/probe). The fan blade should be replaced or remediated to a value below the limit.

The turbocharger on SSDG\#4 should be scanned internally with a GM, or equivalent, probe during the next scheduled maintenance operations to assess contamination levels.

All other items investigated were below both the limits in Table 4.1 and the Radiological Controls Manual and satisfied the requirements for release from radiological control. 


\section{REFERENCES}

EPA 2002. Guidance for Comparing Background and Chemical Concentrations in Soil for CERCLA Sites. EPA 540-R-01-003, OSWER 9285.7-41. U.S. Environmental Protection Agency. Washington, D.C. September.

HPS 2008. Characterization in Support of Decommissioning Using the Data Quality Objectives Process. American National Standard Institute (ANSI) Standard N13.59. Health Physics Society. McLean, Virginia.

NAVSEA 2012a. Radiological Controls Manual for Fukushima Dai-ichi Fallout. Naval Sea Systems Command. Washington, DC. February 3.

NAVSEA 2012b. Release Plan for Naval Vessels Under Radiological Controls Associated With Fukushima Dai-ichi Reactor Accidents. Naval Sea Systems Command. Washington, DC. June 15.

NRC 2000. Multi-Agency Radiation Survey and Site Investigation Manual. NUREG-1575, EPA 402-R-97-016, DOE/EH-0624. U.S. Nuclear Regulatory Commission. Washington, D.C. August.

NRC 2006. NUREG-1757 Consolidated Decommissioning Guidance. Vol. 2, Rev. 1. U.S. Nuclear Regulatory Commission. Washington, D.C. September.

ORAU 2011a. Project-specific Characterization Survey Plan for the USNS Bridge, Military Sealift Support Command, Naval Station, Norfolk, Virginia. DCN 03-PL -01-1. Oak Ridge Associated Universities. Oak Ridge, Tennessee; July 7.

ORAU 2011b. Characterization Survey of the USNS Bridge (T-AOE 10), Military Sealift Fleet Support Command, Naval Station, Norfolk, Virginia; DCN 5150-SR-01-0. Oak Ridge Associated Universities. Oak Ridge, Tennessee; September 30.

ORAU 2012a. Survey Procedures Manual for the Independent Environmental Assessment and Verification Program. Oak Ridge Associated Universities. Oak Ridge, Tennessee. June 1.

ORAU 2012b. Quality Program Manual for the Independent Environmental Assessment and Verification Program. Oak Ridge Associated Universities. Oak Ridge, Tennessee. June 28. 
THIS PAGE INTENTIONALLY LEFT BLANK

Bridge - Phase II 
APPENDIX A

SURVEY AREAS 
THIS PAGE INTENTIONALLY LEFT BLANK

Bridge - Phase II 


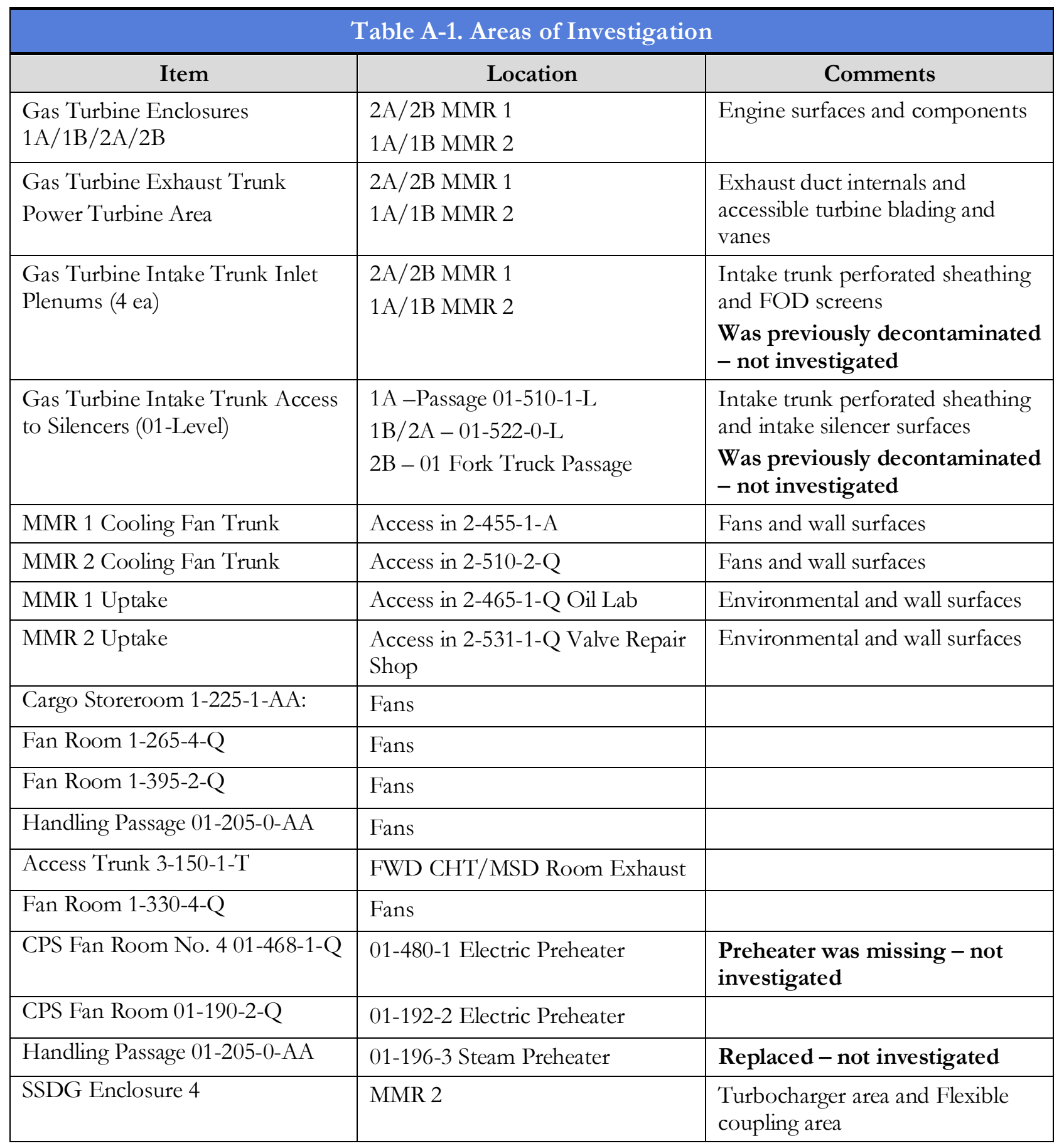


THIS PAGE INTENTIONALLY LEFT BLANK

Bridge - Phase II 
APPENDIX B

DATA PACKAGES 
THIS PAGE INTENTIONALLY LEFT BLANK

Bridge - Phase II 


\section{1-205-0-AA}

Includes:

Fan 01-431-2 


\section{1-205-0-AA}
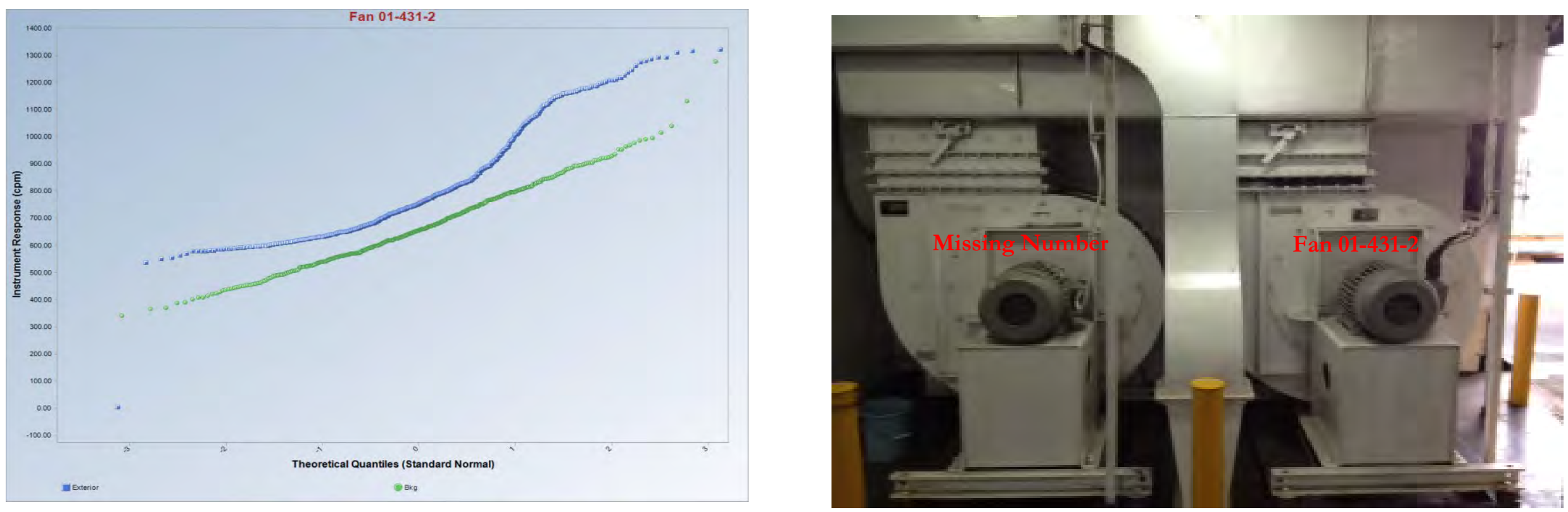

\begin{tabular}{|c|c|c|c|c|c|}
\hline \multicolumn{5}{|c|}{ Exterior Gamma Scan of Fan 01-431-2 Exterior } \\
\hline $\mathbf{n}$ & Min & Max & Mean & Median & SD \\
\hline \multirow{4}{*}{703} & \multicolumn{5}{|c|}{$c$ m } \\
\cline { 2 - 6 } & 5 & 1,322 & 799 & 754 & 180 \\
\cline { 2 - 6 } & \multicolumn{5}{|c|}{$c c p m$} \\
\cline { 2 - 6 } & -661 & 656 & 133 & 88 & 180 \\
\hline
\end{tabular}

Surface Activity Measurements from Fan 01-431-2

\begin{tabular}{|c|l|c|c|c|c|}
\hline \multicolumn{5}{|c|}{ Surface Activity Measurements from Fan 01-431-2 } \\
\hline Fan & Measurement & \multicolumn{3}{|c|}{ Total } & \multicolumn{2}{c|}{ Removable } \\
\cline { 3 - 6 } Number & Location & ccpm/probe & $\mathrm{dpm} / 100 \mathrm{~cm}^{2}$ & $\mathrm{ccpm}$ & $\mathrm{dpm} / 100 \mathrm{~cm}^{2}$ \\
\hline $01-431-2$ & Blade & 14 & 710 & 0 & 0 \\
\hline $01-431-2$ & Inside housing & -3 & -170 & 3 & 23 \\
\hline-- & Blade & 4 & -180 & 18 & 140 \\
\hline-- & Inside Housing & 79 & 4,100 & 44 & 340 \\
\hline
\end{tabular}




\section{1-205-0-AA}

Wilcoxon-Mann-Whitney Site vs Background Comparison Test for Full Data Sets without NDs User Selected Options

From File

Full Precision

Confidence Coefficient

Substantial Difference

Selected Null Hypothesis

Alternative Hypothesis

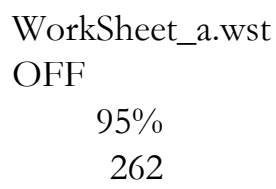

Site or AOC Mean/Median $>=$ Background Mean/Median Plus Substantial Difference, $\mathrm{S}$ (Form 2)

Site or AOC Mean/Median Less Than Background Mean/Median Plus Substantial Difference, S

Area of Concern Data: Exterior

Background Data: Bkg

Raw Statistics

Number of Valid Observations

$\begin{array}{rc}\text { Site } & \text { Background } \\ 703 & 600 \\ 398 & 351 \\ 5 & 341 \\ 1322 & 1278 \\ 799.4 & 667 \\ 754 & 655.5 \\ 179.6 & 130.6 \\ 6.775 & 5.334\end{array}$

Number of Distinct Observations

Minimum

Maximum

Mean

Median

SD

6.775

5.334

Wilcoxon-Mann-Whitney (WMW) Test

H0: Mean/Median of Site or AOC >= Mean/Median of Background +262

Site Rank Sum W-Stat 353248

WMW Test U-Stat

WMW Critical Value (0.050)

P-Value

Conclusion with Alpha $=0.05$

P-Value $<$ alpha (0.05) 


\section{1-225-1-AA}

Includes:

Fan 1-244-1

Fan 1-257-1 

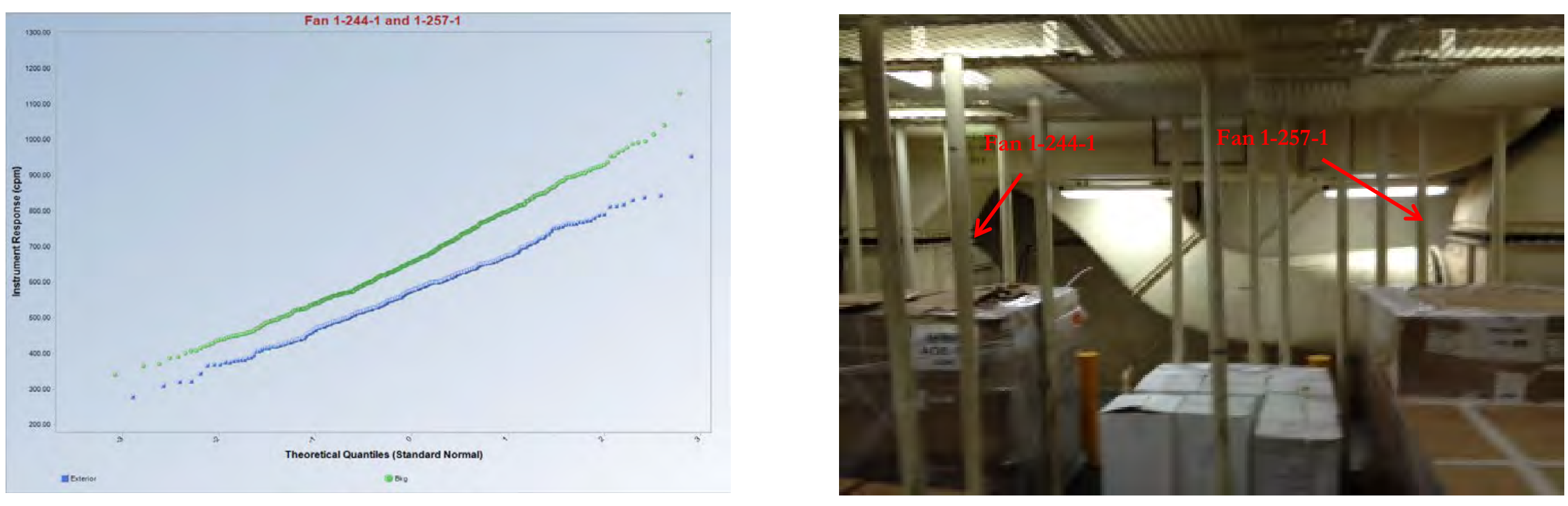

\begin{tabular}{|c|c|c|c|c|c|}
\hline \multicolumn{5}{|c|}{ Exterior Gamma Scan of Fans 1-244-1 and 1-257-1 Exterior } \\
\hline $\mathbf{n}$ & Min & Max & Mean & Median & SD \\
\hline \multirow{3}{*}{331} & \multicolumn{5}{|c|}{$c p m$} \\
\cline { 2 - 6 } & 278 & 954 & 574 & 576 & 108 \\
\cline { 2 - 6 } & \multicolumn{5}{|c|}{$c c p m$} \\
\cline { 2 - 6 } & -388 & 288 & -92 & -90 & 108 \\
\hline
\end{tabular}

\begin{tabular}{|c|l|c|c|c|c|}
\hline \multicolumn{5}{|c|}{ Surface Activity Measurements from Fans 1-244-1 and 1-257-1 } \\
\hline Fan & Measurement & \multicolumn{2}{|c|}{ Total } & \multicolumn{2}{c|}{ Removable } \\
\cline { 3 - 6 } Number & Location & $\mathrm{ccpm} /$ probe & $\mathrm{dpm} / 100 \mathrm{~cm}^{2}$ & $\mathrm{ccpm}$ & $\mathrm{dpm} / 100 \mathrm{~cm}^{2}$ \\
\hline $1-244-1$ & Blade & 1 & 60 & -1 & -5 \\
\hline $1-244-1$ & Inside housing & 0 & -9 & 14 & 110 \\
\hline $1-257-1$ & Blade & -2 & -93 & 4 & 33 \\
\hline $1-257-1$ & Inside Housing & 6 & 310 & 1 & 9 \\
\hline
\end{tabular}




\section{1-225-1-AA}

Wilcoxon-Mann-Whitney Site vs Background Comparison Test for Full Data Sets without NDs User Selected Options

From File

Full Precision

Confidence Coefficient

Substantial Difference

Selected Null Hypothesis

Alternative Hypothesis

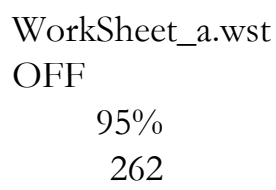

Site or AOC Mean/Median >= Background Mean/Median Plus Substantial Difference, $\mathrm{S}$ (Form 2)

Site or AOC Mean/Median Less Than Background

Area of Concern Data: Exterior

Background Data: Bkg

Raw Statistics

Number of Valid Observations Site Background

Number of Distinct Observations

$229 \quad 351$

Minimum

$278 \quad 341$

Maximum

$954 \quad 1278$

Mean

$573.7 \quad 667$

Median

$576 \quad 655.5$

$\mathrm{SD}$

$108.3 \quad 130.6$

SE of Mean

$5.952 \quad 5.334$

Wilcoxon-Mann-Whitney (WMW) Test

H0: Mean/Median of Site or AOC >= Mean/Median of Background +262

Site Rank Sum W-Stat 57827

WMW Test U-Stat

$-24.55$

WMW Critical Value (0.050)

P-Value

Conclusion with Alpha $=0.05$

P-Value $<$ alpha (0.05) 


\section{1-265-4-Q}

Includes:

Fan 1-268-2

Fan 1-269-2 


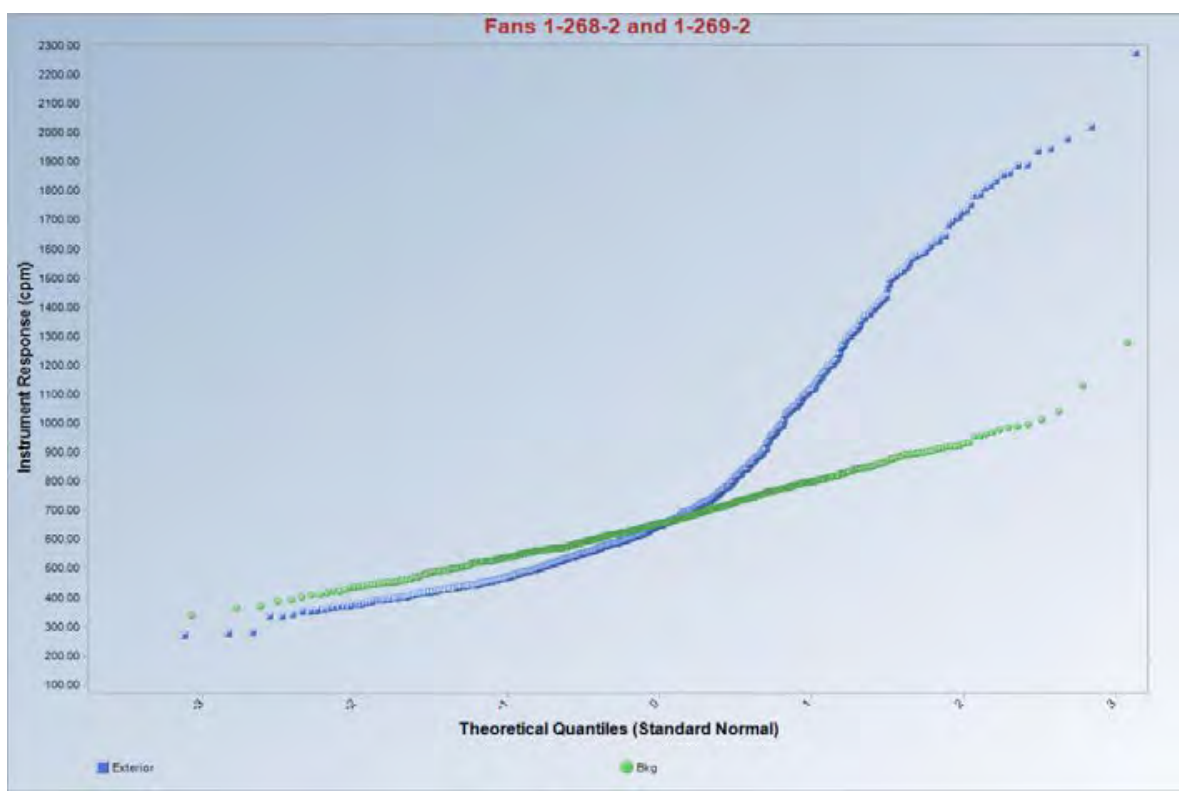

\begin{tabular}{|c|c|c|c|c|c|}
\hline \multicolumn{5}{|c|}{ Exterior Gamma Scan of Fans 1-244-1 and 1-257-1 } \\
\hline $\mathbf{n}$ & Min & Max & Mean & Median & SD \\
\hline \multirow{3}{*}{707} & \multicolumn{5}{|c|}{$c$ m } \\
\cline { 2 - 6 } & 272 & 2,275 & 768 & 650 & 354 \\
\cline { 2 - 6 } & \multicolumn{5}{|c|}{$c$ cpm } \\
\cline { 2 - 6 } & -394 & 1,609 & 102 & -16 & 354 \\
\hline
\end{tabular}

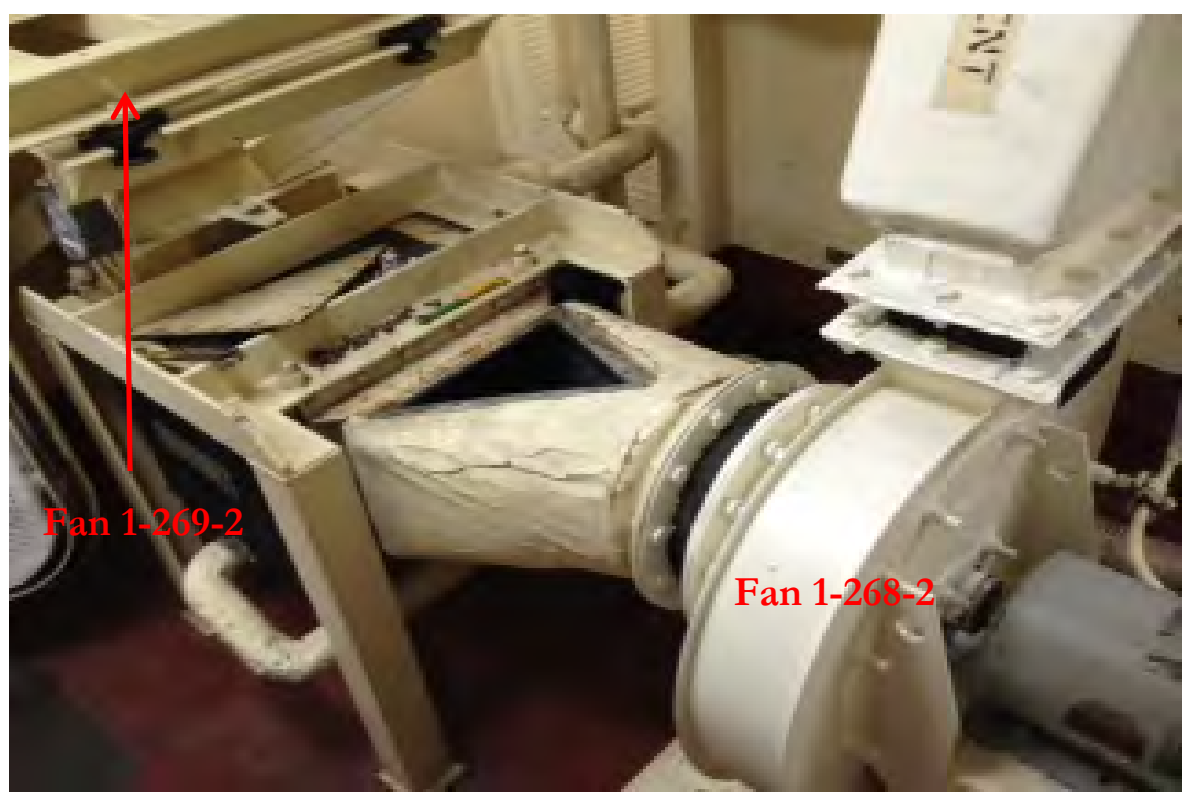




\section{1-265-4-Q}
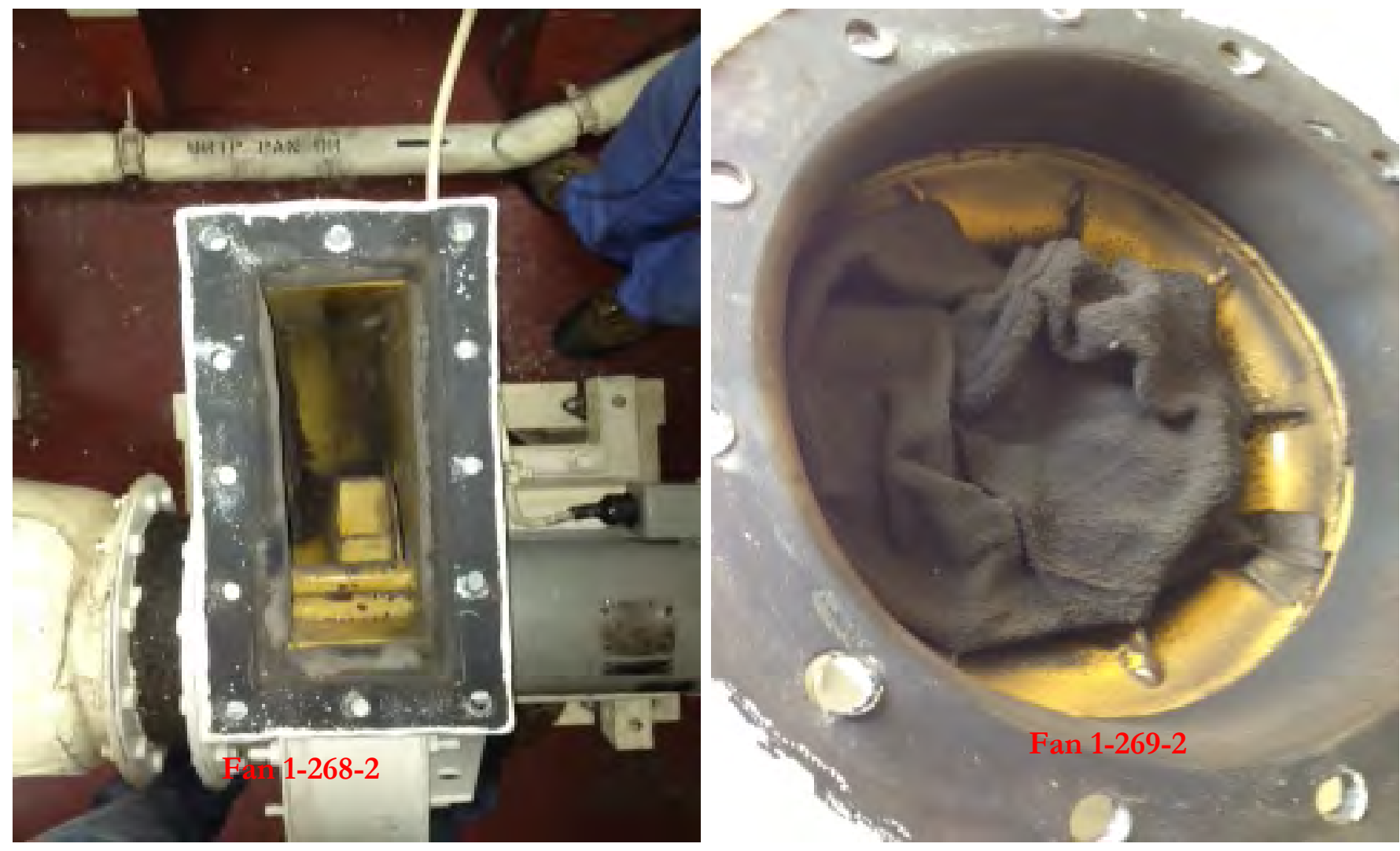

\begin{tabular}{|c|l|c|c|c|c|}
\hline \multicolumn{5}{|c|}{ Surface Activity Measurements from Fans 1-244-1 and 1-257-1 } \\
\hline \multirow{2}{*}{ Fan Number } & \multirow{2}{*}{$\begin{array}{c}\text { Measurement } \\
\text { Location }\end{array}$} & \multicolumn{3}{|c|}{ Total } & \multicolumn{2}{c|}{ Removable } \\
\cline { 3 - 6 } & & ccpm/probe & $\mathrm{dpm} / 100 \mathrm{~cm}^{2}$ & $\mathrm{ccpm}$ & $\mathrm{dpm} / 100 \mathrm{~cm}^{2}$ \\
\hline $1-268-2$ & Fan Blade & 81 & 4,200 & 0 & 0 \\
\hline $1-268-2 / 1-269-2$ & $\begin{array}{l}\text { Inside plenum } \\
\text { between fans }\end{array}$ & 3 & 150 & -1 & -9 \\
\hline $1-268-2 / 1-269-2$ & Filter & 16 & 820 & na & na \\
\hline $1-269-2$ & Fan Blade & 13 & 670 & 39 & 300 \\
\hline
\end{tabular}




\section{$1-265-4-Q$}

Wilcoxon-Mann-Whitney Site vs Background Comparison Test for Full Data Sets without NDs User Selected Options

From File

Full Precision

Confidence Coefficient

Substantial Difference

Selected Null Hypothesis

Alternative Hypothesis

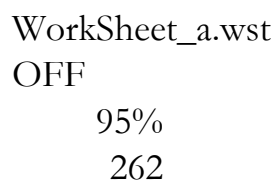

Site or AOC Mean/Median >= Background Mean/Median Plus Substantial Difference, $\mathrm{S}$ (Form 2)

Site or AOC Mean/Median Less Than Background

Area of Concern Data: Exterior

Background Data: Bkg

Raw Statistics

Number of Valid Observations Site $\quad$ Background

Number of Distinct Observations

$479 \quad 351$

Minimum

$272 \quad 341$

Maximum

$2275 \quad 1278$

Mean

$768.3 \quad 667$

Median

$650 \quad 655.5$

SD

$354.2 \quad 130.6$

SE of Mean

$13.32 \quad 5.334$

Wilcoxon-Mann-Whitney (WMW) Test

H0: Mean/Median of Site or AOC $>=$ Mean/Median of Background +262

Site Rank Sum W-Stat

357324

WMW Test U-Stat

$-15.45$

WMW Critical Value (0.050)

P-Value

Conclusion with Alpha $=0.05$

\section{Reject H0, Conclude Site $<$ Background +262.00}

P-Value $<$ alpha (0.05) 


\section{1-330-4-Q}

Includes:

Fan 1-332-2

Fan 1-336-2

Fan 1-337-2 


\section{$1-330-4-Q$}
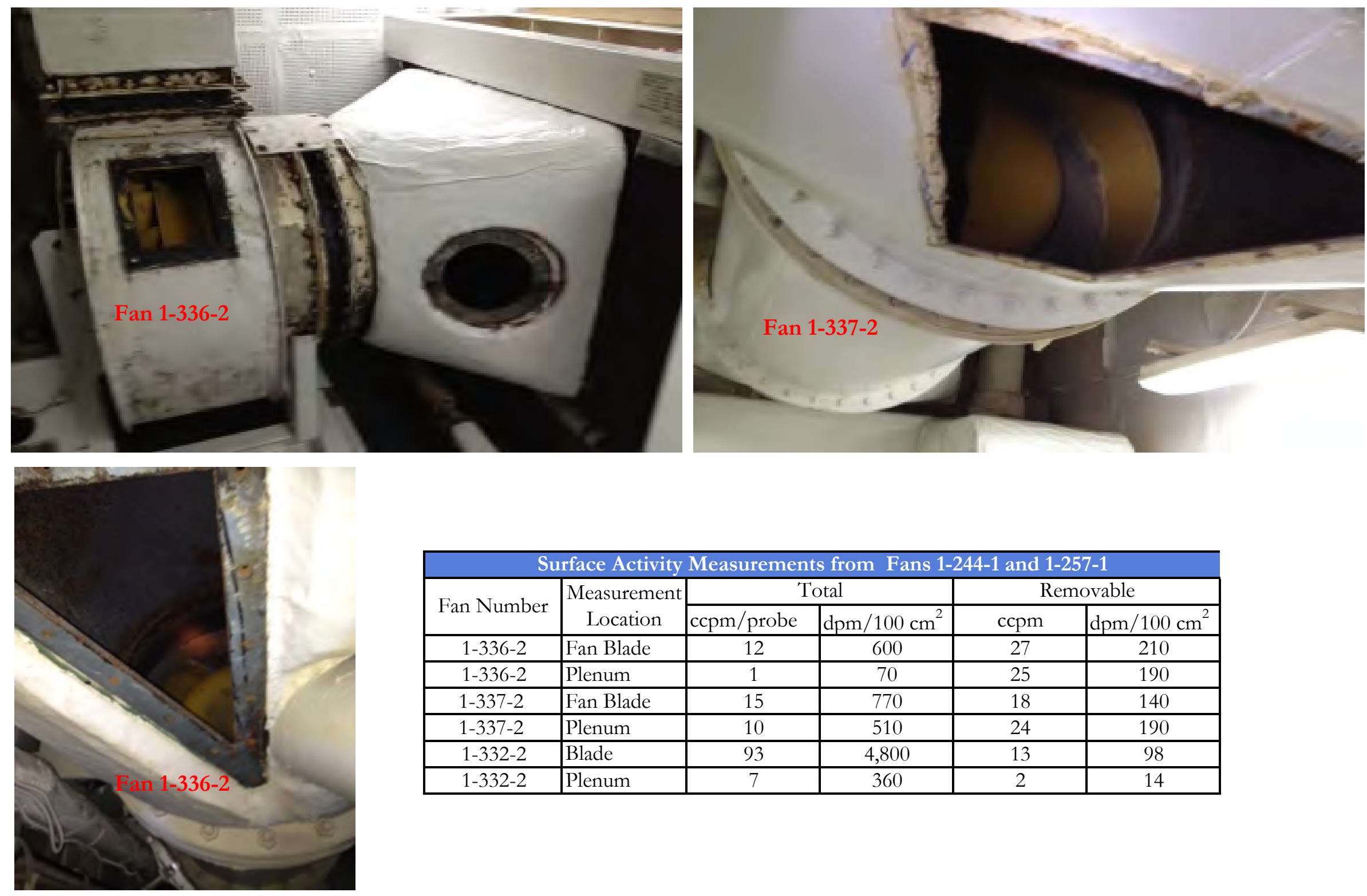

Surface Activity Measurements from Fans 1-244-1 and 1-257-1

\begin{tabular}{|c|l|c|c|c|c|}
\hline \multicolumn{5}{|c|}{ Surface Activity Measurements from Fans 1-244-1 and 1-257-1 } \\
\hline \multirow{2}{*}{ Fan Number } & Measurement & \multicolumn{2}{|c|}{ Total } & \multicolumn{2}{c|}{ Removable } \\
\cline { 3 - 6 } & Location & $\mathrm{ccpm} /$ probe & $\mathrm{dpm} / 100 \mathrm{~cm}^{2}$ & $\mathrm{ccpm}$ & $\mathrm{dpm} / 100 \mathrm{~cm}^{2}$ \\
\hline $1-336-2$ & Fan Blade & 12 & 600 & 27 & 210 \\
\hline $1-336-2$ & Plenum & 1 & 70 & 25 & 190 \\
\hline $1-337-2$ & Fan Blade & 15 & 770 & 18 & 140 \\
\hline $1-337-2$ & Plenum & 10 & 510 & 24 & 190 \\
\hline $1-332-2$ & Blade & 93 & 4,800 & 13 & 98 \\
\hline $1-332-2$ & Plenum & 7 & 360 & 2 & 14 \\
\hline
\end{tabular}




\section{1-395-2-Q}

Includes:

Fan 1-397-2

Fan 1-398-2

Fan 1-399-2

Fan 1-400-2 
1-395-2-Q

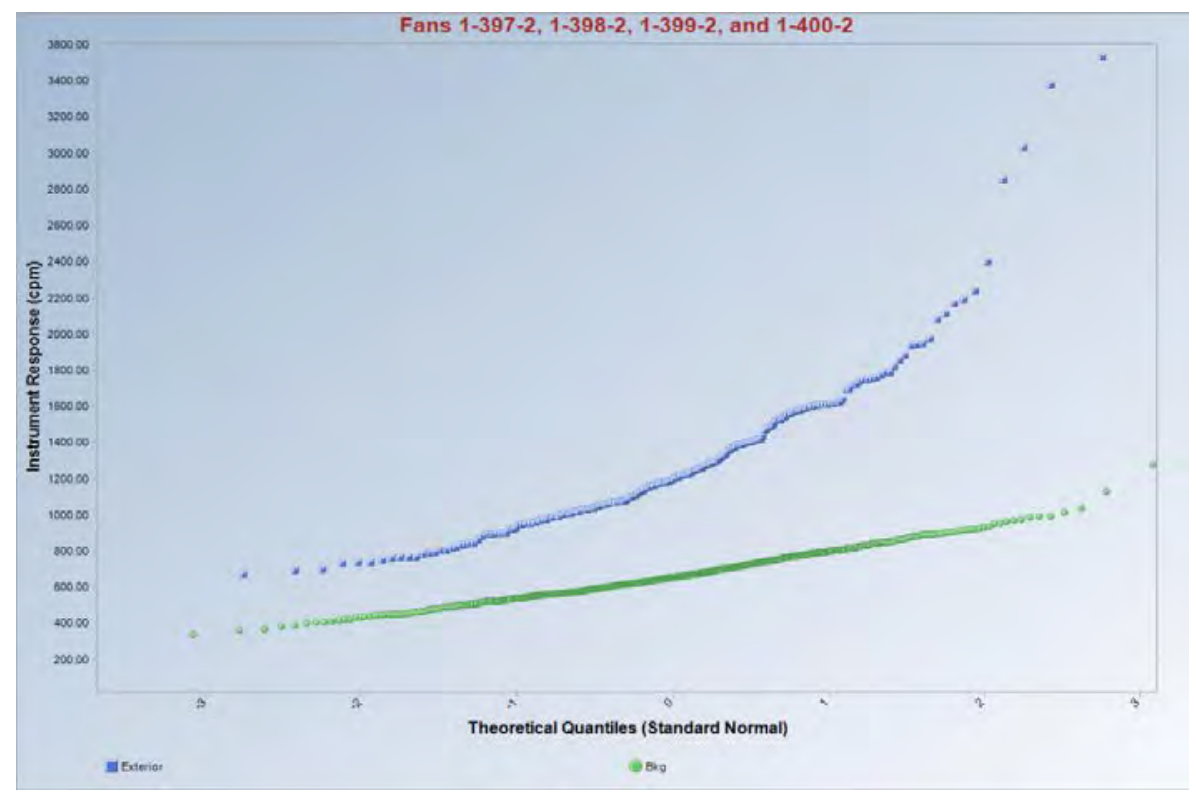

\begin{tabular}{|c|c|c|c|c|c|}
\hline \multicolumn{5}{|c|}{ Exterior Gamma Scan of Fans 1-244-1 and 1-257-1 } \\
\hline $\mathbf{n}$ & Min & Max & Mean & Median & SD \\
\hline \multirow{3}{*}{214} & \multicolumn{5}{|c|}{$c$ m } \\
\cline { 2 - 6 } & 674 & 3,536 & 1,291 & 1,200 & 432 \\
\cline { 2 - 6 } & \multicolumn{5}{|c|}{$c c p m$} \\
\cline { 2 - 6 } & 8 & 2,870 & 625 & 534 & 432 \\
\hline
\end{tabular}
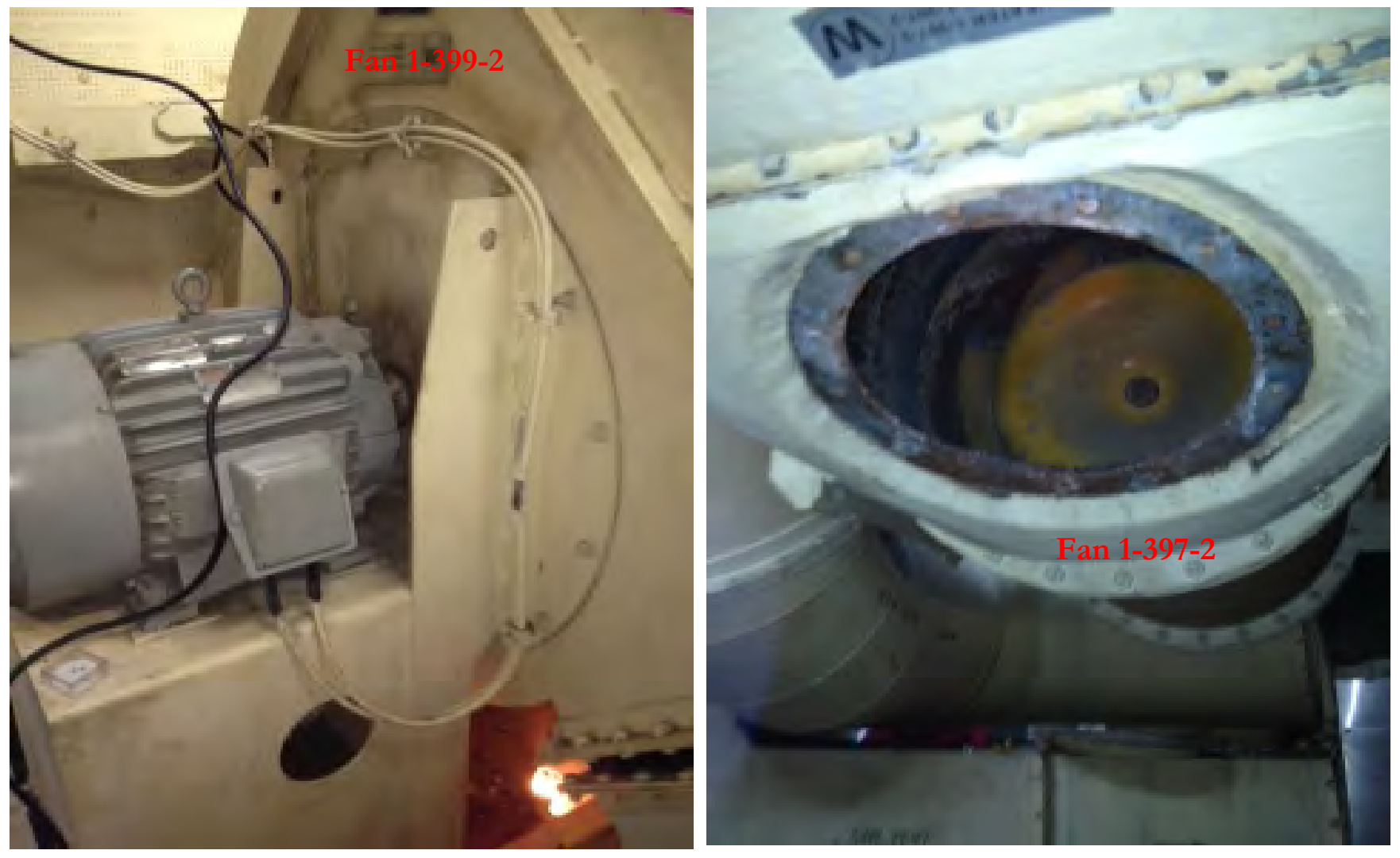
1-395-2-Q

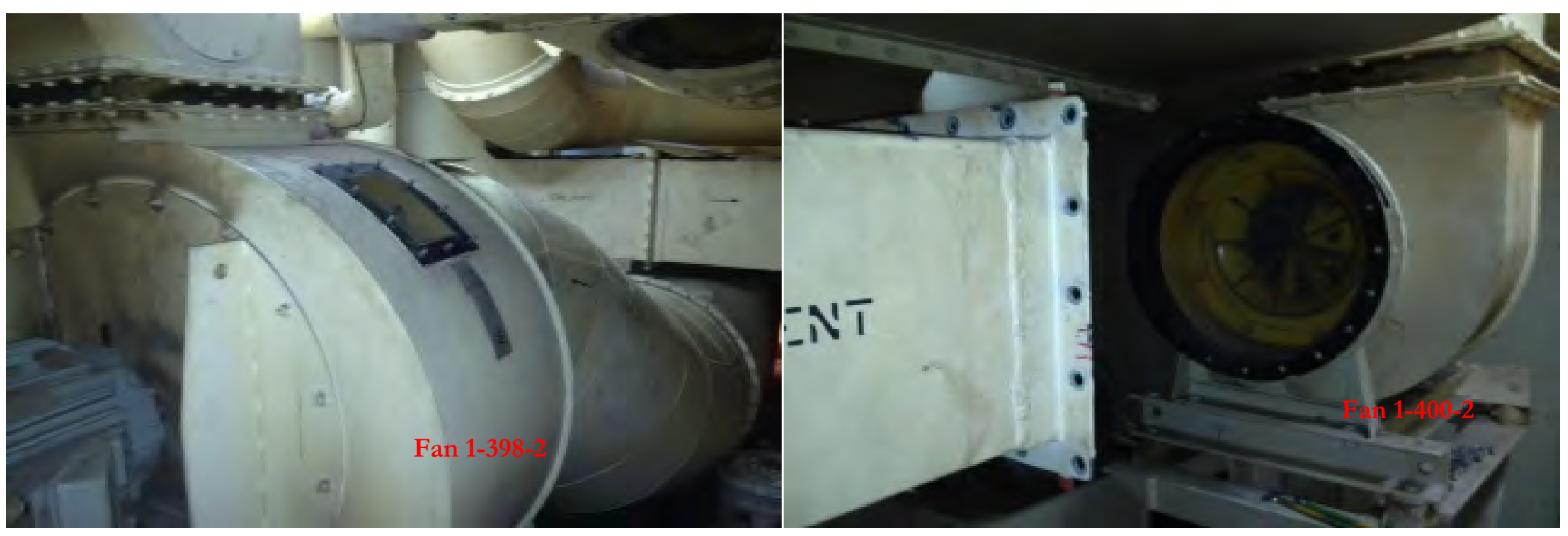

\begin{tabular}{|c|l|c|c|c|c|}
\hline \multicolumn{5}{|c|}{ Surface Activity Measurements from Fans 1-244-1 and 1-257-1 } \\
\hline \multirow{2}{*}{ Fan Number } & \multirow{2}{*}{$\begin{array}{c}\text { Measurement } \\
\text { Location }\end{array}$} & \multicolumn{2}{|c|}{ Total } & \multicolumn{2}{c|}{ Removable } \\
\cline { 3 - 6 } & ccpm/probe & $\mathrm{dpm} / 100 \mathrm{~cm}^{2}$ & $\mathrm{ccpm}$ & $\mathrm{dpm} / 100 \mathrm{~cm}^{2}$ \\
\hline Fan 1-397-2 & Blade & 8 & 410 & 13 & 98 \\
\hline Fan 1-397-2 & Plenum & -3 & -154 & 24 & 181 \\
\hline Fan 1-400-2 & Blade & 17 & 872 & 14 & 107 \\
\hline Fan 1-400-2 & Inside Housing & -3 & -154 & 7 & 51 \\
\hline Fan 1-398-2 & Plenum & 5 & 256 & 15 & 112 \\
\hline Fan 1-398-2 & Blade & 47 & 2,410 & 26 & 200 \\
\hline Fan 1-399-2 & Blade & 47 & 2,410 & 12 & 93 \\
\hline Fan 1-399-2 & Inside Housing & -7 & -359 & 5 & 42 \\
\hline
\end{tabular}




\section{$1-395-2-Q$}

Wilcoxon-Mann-Whitney Site vs Background Comparison Test for Full Data Sets without $\mathrm{N}$ User Selected Options

From File

Full Precision

Confidence Coefficient

Substantial Difference

Selected Null Hypothesis

Alternative Hypothesis

WorkSheet.wst
OFF
\[ 5 \% \]
262

Site or AOC Mean/Median >= Background Mean/Median Plus Substantial Difference, S (Form 2)

Site or AOC Mean/Median Less Than Background Mean/Median Plus Subs1

Area of Concern Data: Exterior

Background Data: Bkg

Raw Statistics

Number of Valid Observations

Number of Missing Values

\begin{tabular}{rr} 
Site & \multicolumn{2}{c}{ Background } \\
214 & 600 \\
0 & 1 \\
188 & 351 \\
674 & 341 \\
3536 & 1278 \\
1291 & 667 \\
1200 & 655.5 \\
431.5 & 130.6 \\
29.5 & 5.334
\end{tabular}

Number of Distinct Observations

Minimum

Wilcoxon-Mann-Whitney (WMW) Test

H0: Mean/Median of Site or AOC $>=$ Mean/Median of Background +262

Site Rank Sum W-Stat

127710

WMW Test U-Stat

WMW Critical Value (0.050)

P-Value

Conclusion with Alpha $=0.05$

Do Not Reject H0, Conclude Site $>=$ Background +262.00

P-Value $>=$ alpha (0.05) 
MMR 1 Uptake 


\section{MMR 1 Uptake}

\begin{tabular}{|c|c|c|c|c|c|}
\hline \multicolumn{6}{|c|}{ Beta Scan of MMR 1 Uptake } \\
\hline $\mathbf{n}$ & Min & Max & Mean & Median & SD \\
\hline \multirow{4}{*}{1012} & \multicolumn{5}{|c|}{$c$ m } \\
\cline { 2 - 7 } & 21 & 609 & 170 & 155 & 79 \\
\cline { 2 - 6 } & \multicolumn{5}{|c|}{$c c p m / p r o b e$} \\
\cline { 2 - 6 } & -133 & 455 & 16 & 1 & 79 \\
\cline { 2 - 6 } & \multicolumn{5}{|c|}{$d$ m $/ 100 \mathrm{~cm}^{2}$} \\
\cline { 2 - 6 } & -605 & 2068 & 71 & 5 & 361 \\
\hline
\end{tabular}

Gamma Scan of MMR 1 Uptake

\begin{tabular}{|c|c|c|c|c|c|}
\hline \multicolumn{6}{|c|}{ Gamma Scan of MMR 1 Uptake } \\
\hline $\mathbf{n}$ & Min & Max & Mean & Median & SD \\
\hline \multirow{3}{*}{884} & \multicolumn{5}{|c|}{$c$ m } \\
\cline { 2 - 7 } & 2 & 4,712 & 1,626 & 1,389 & 812 \\
\cline { 2 - 6 } & \multicolumn{5}{|c|}{$c$ cpm } \\
\cline { 2 - 6 } & -664 & 4,046 & 960 & 723 & 812 \\
\hline
\end{tabular}

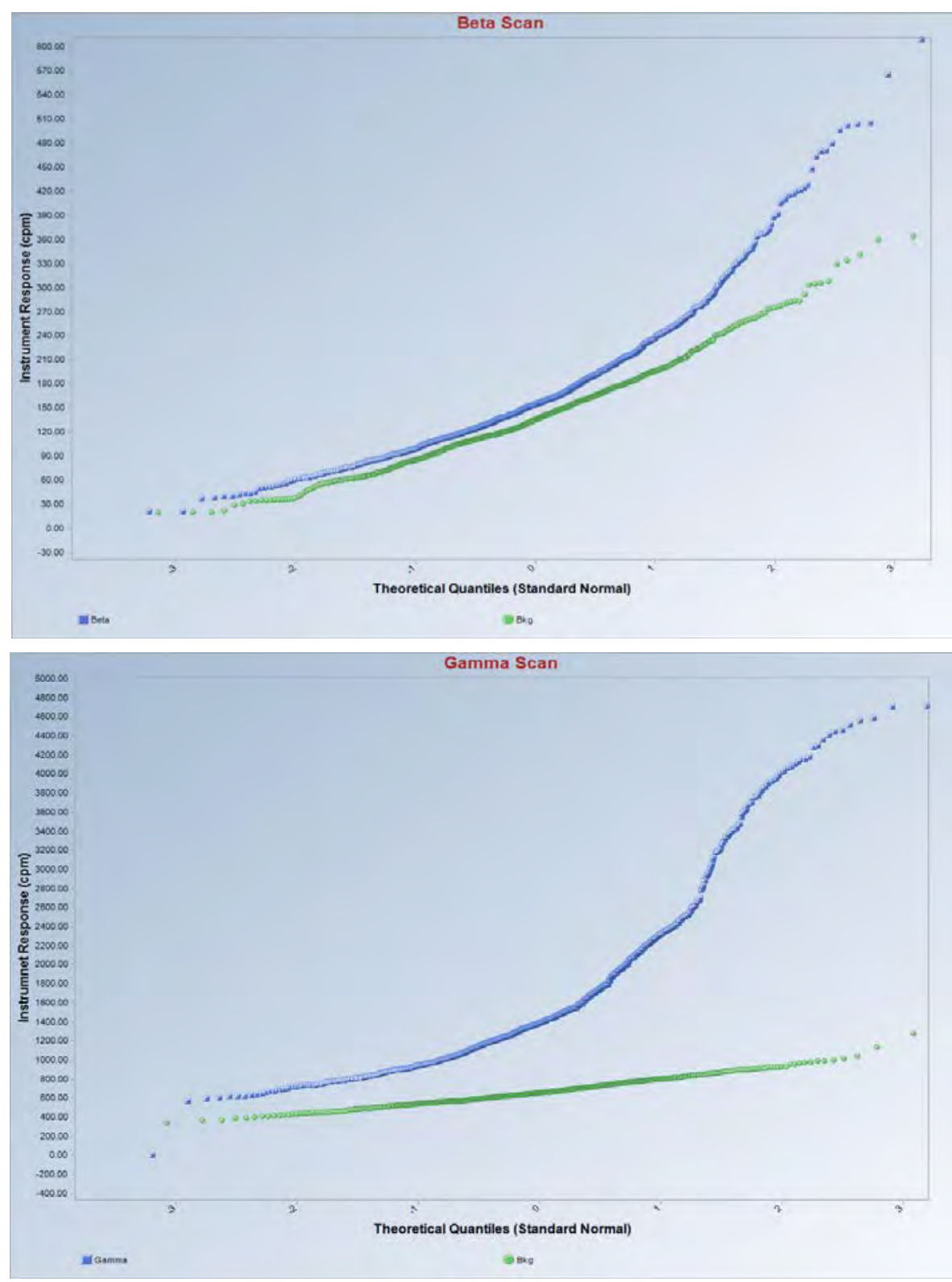




\section{MMR 1 Uptake Beta Scan}

Wilcoxon-Mann-Whitney Site vs Background Comparison Test for Full Data Sets without NDs

User Selected Options

From File

Full Precision

Confidence Coefficient

Substantial Difference

Selected Null Hypothesis

Alternative Hypothesis

WorkSheet.wst
OFF
\[ 5 \% \]
112

Site or AOC Mean/Median >= Background Mean/Median Plus Substantial Difference, S (Form 2)

Site or AOC Mean/Median Less Than Background Mean/Median Plus Substantial Difference, S

Area of Concern Data: Beta

Background Data: Bkg

Raw Statistics

Number of Valid Observations

$\begin{array}{rc}\text { Site } & \text { Background } \\ 1012 & 783 \\ 294 & 232 \\ 21 & 20 \\ 609 & 365 \\ 169.7 & 141.6 \\ 155 & 136 \\ 79.33 & 57.52 \\ 2.494 & 2.056\end{array}$

Number of Distinct Observations

20

Minimum

Wilcoxon-Mann-Whitney (WMW) Test

H0: Mean/Median of Site or AOC $>=$ Mean/Median of Background +112

Site Rank Sum W-Stat $\quad 643898$

WMW Test U-Stat $\quad-24.32$

WMW Critical Value (0.050) $\quad-1.645$

P-Value

Conclusion with Alpha $=0.05$

Reject H0, Conclude Site $<$ Background +112.00

P-Value $<$ alpha $(0.05)$ 


\section{MMR 2 Uptake}




\section{MMR 2 Uptake}

\begin{tabular}{|c|c|c|c|c|c|}
\hline \multicolumn{6}{|c|}{ Beta Scan of MMR 2 Uptake } \\
\hline $\mathrm{n}$ & Min & Max & Mean & Median & SD \\
\hline \multirow{6}{*}{852} & \multicolumn{5}{|c|}{$c p m$} \\
\hline & 17 & 592 & 189 & 176 & 88 \\
\hline & \multicolumn{5}{|c|}{ ccpm/probe } \\
\hline & -137 & 438 & 35 & 22 & 88 \\
\hline & \multicolumn{5}{|c|}{$\frac{1}{d p m / 100 \mathrm{~cm}^{2}}$} \\
\hline & -623 & 1991 & 161 & 100 & 402 \\
\hline
\end{tabular}

Gamma Scan of MMR2 Uptake

\begin{tabular}{|c|c|c|c|c|c|}
\hline \multicolumn{6}{|c|}{ Gamma Scan of MMR2 Uptake } \\
\hline $\mathbf{n}$ & Min & Max & Mean & Median & SD \\
\hline \multirow{3}{*}{889} & \multicolumn{5}{|c|}{$c$ m } \\
\cline { 2 - 6 } & 13 & 3,228 & 1,371 & 1,274 & 505 \\
\cline { 2 - 6 } & \multicolumn{5}{|c|}{$c c p m$} \\
\cline { 2 - 6 } & -653 & 2,562 & 705 & 608 & 505 \\
\hline
\end{tabular}
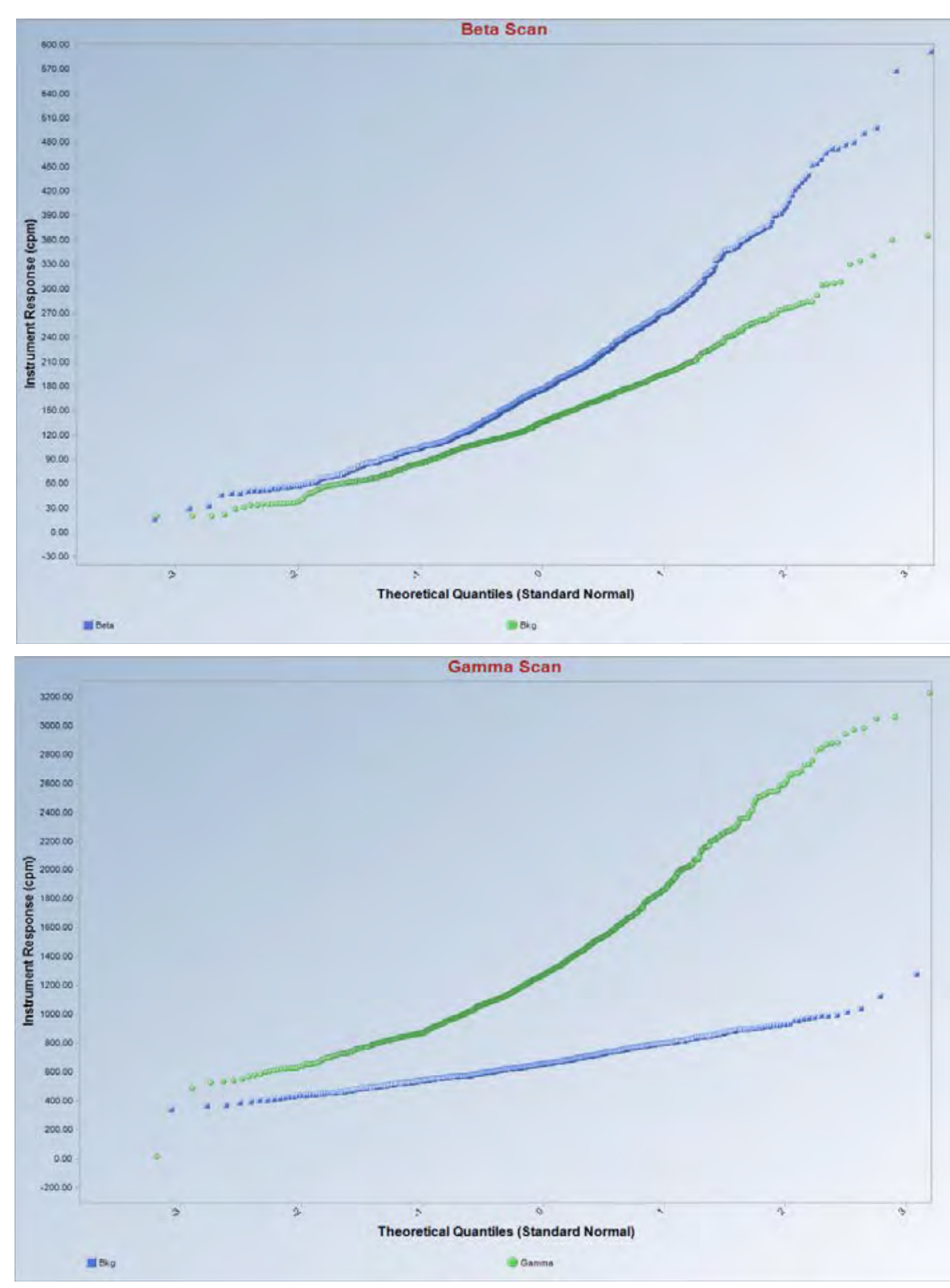


\section{MMR 2 Uptake Beta Scan}

Wilcoxon-Mann-Whitney Site vs Background Comparison Test for Full Data Sets without NDs User Selected Options

From File

Full Precision

Confidence Coefficient

Substantial Difference

Selected Null Hypothesis

Alternative Hypothesis

WorkSheet.wst
OFF
\[ 5 \% \]
112

Site or AOC Mean/Median >= Background Mean/Median Plus Substantial Difference, S (Form 2)

Site or AOC Mean/Median Less Than Background Mean/Median Plus Substantial Difference, $\mathrm{S}$

Area of Concern Data: Beta

Background Data: Bkg

Raw Statistics

Number of Valid Observations

$\begin{array}{rc}\text { Site } & \text { Background } \\ 1012 & 783 \\ 294 & 232 \\ 21 & 20 \\ 609 & 365 \\ 169.7 & 141.6 \\ 155 & 136 \\ 79.33 & 57.52 \\ 2.494 & 2.056\end{array}$

Number of Distinct Observations

20

Minimum

Wilcoxon-Mann-Whitney (WMW) Test

H0: Mean/Median of Site or AOC $>=$ Mean/Median of Background +112

Site Rank Sum W-Stat $\quad 643898$

WMW Test U-Stat $\quad-24.32$

WMW Critical Value (0.050) $\quad-1.645$

P-Value

Conclusion with Alpha $=0.05$

Reject H0, Conclude Site $<$ Background +112.00

P-Value $<$ alpha $(0.05)$ 
MMR 1 Cooling Trunk 


\section{MMR 2 Cooling Trunk}

\begin{tabular}{|c|c|c|c|c|c|}
\hline \multicolumn{7}{|c|}{ Beta Scan of MMR 1 Cooling Trunk } \\
\hline n & Min & Max & Mean & Median & SD \\
\hline \multirow{4}{*}{591} & \multicolumn{5}{|c|}{$c$ m } \\
\cline { 2 - 7 } & 22 & 705 & 161 & 130 & 113 \\
\cline { 2 - 6 } & \multicolumn{5}{|c|}{$c \mathrm{pm} /$ probe } \\
\cline { 2 - 6 } & -20 & 83 & 1 & -4 & 17 \\
\cline { 2 - 6 } & \multicolumn{5}{|c|}{$d p \mathrm{~m} / 100 \mathrm{~cm}^{2}$} \\
\cline { 2 - 6 } & -90 & 375 & 5 & -16 & 77 \\
\hline
\end{tabular}

\begin{tabular}{|c|c|c|c|c|c|}
\hline \multicolumn{6}{|c|}{ Gamma Scan of MMR 1 Cooling Trunk } \\
\hline $\mathbf{n}$ & Min & Max & Mean & Median & SD \\
\hline \multirow{3}{*}{1323} & \multicolumn{5}{|c|}{$c p m$} \\
\cline { 2 - 7 } & 336 & 2,268 & 826 & 768 & 303 \\
\cline { 2 - 7 } & \multicolumn{5}{|c|}{$c c p m$} \\
\cline { 2 - 6 } & -330 & 1,602 & 160 & 102 & 303 \\
\hline
\end{tabular}
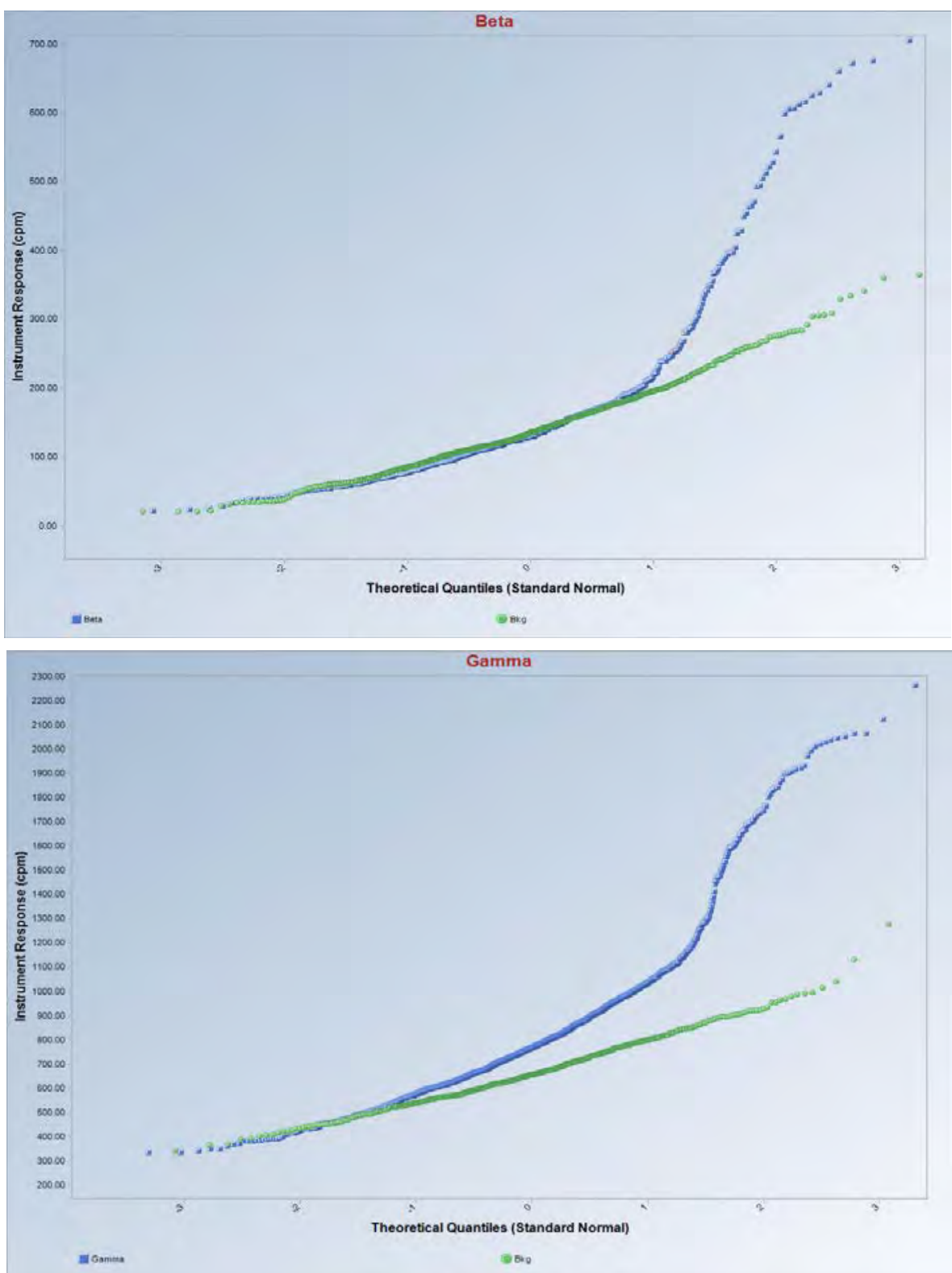


\section{MMR 1 Cooling Trunk}

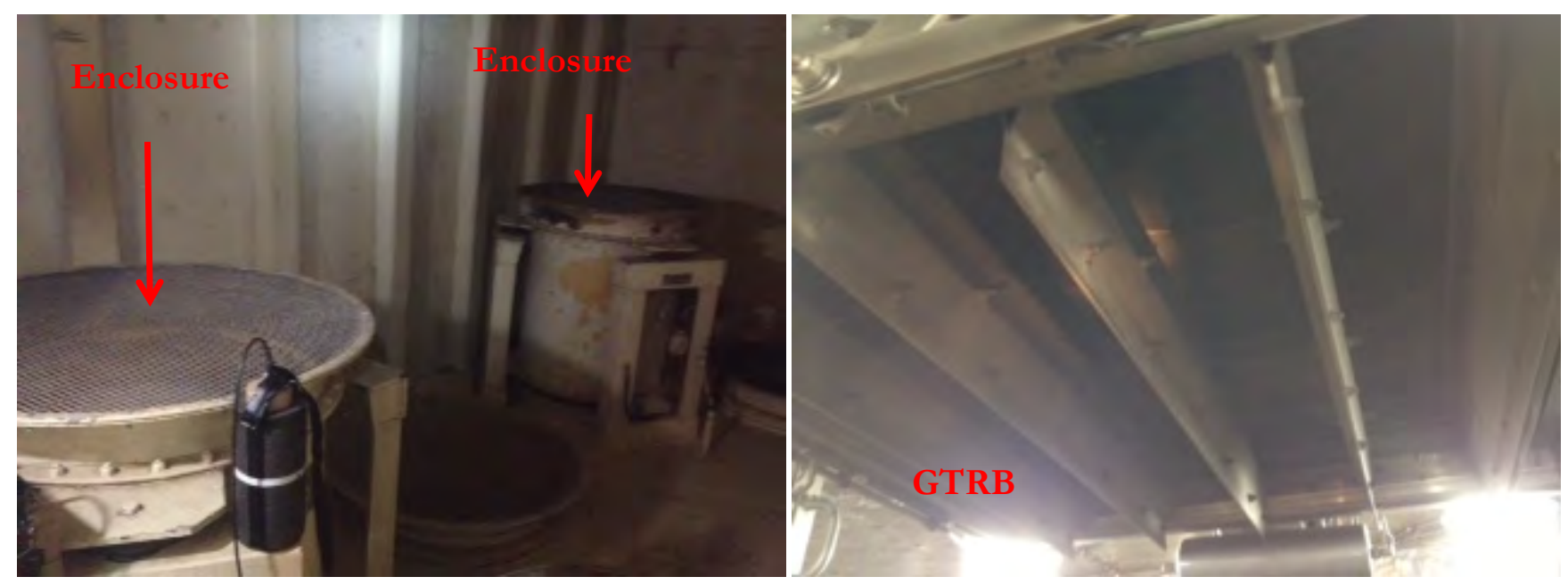

\begin{tabular}{|c|c|c|c|}
\hline \multicolumn{4}{|c|}{ MMR 2 Cooling Trunk Direct Measurements } \\
\hline GTRB & Item & ccpm /probe & $\mathbf{d p m} / \mathbf{1 0 0} \mathbf{~ c m}^{\mathbf{2}}$ \\
\hline 2A & Fan blade & 9 & 470 \\
\hline 2A & Plenum & 2 & 93 \\
\hline 2A & Plenum (accessed from enclosure) & -4 & -223 \\
\hline 2B & Fan blade & 126 & 6,500 \\
\hline 2B & Plenum & 39 & 2,009 \\
\hline 2B & Plenum (accessed from enclosure) & 13 & 670 \\
\hline
\end{tabular}




\section{MMR 1 Cooling Trunk Beta Scan}

Wilcoxon-Mann-Whitney Site vs Background Comparison Test for Full Data Sets without NDs

User Selected Options

From File

Full Precision

Confidence Coefficient

Substantial Difference

Selected Null Hypothesis

WorkSheet.wst

OFF

$95 \%$

112

Site or AOC Mean/Median >= Background Mean/Median Plus Substantial Difference, S (Form 2)

Site or AOC Mean/Median Less Than Background Mean/Median Plus

Alternative Hypothesis

Substantial Difference, $\mathrm{S}$

Area of Concern Data: Beta

Background Data: Bkg

Raw Statistics

Number of Valid Observations

Site Background

Number of Distinct Observations

$591-783$

Minimum

$246 \quad 232$

Maximum

$22 \quad 20$

Mean

$705 \quad 365$

Median

$161.1 \quad 141.6$

SD

$130 \quad 136$

SE of Mean

$113.2 \quad 57.52$

$4.655 \quad 2.056$

Wilcoxon-Mann-Whitney (WMW) Test

H0: Mean/Median of Site or AOC > = Mean/Median of Background +112

Site Rank Sum W-Stat

241957

WMW Test U-Stat

$-22.57$

WMW Critical Value (0.050)

$-1.645$

P-Value

Conclusion with Alpha $=0.05$

Reject H0, Conclude Site < Background +112.00

P-Value $<$ alpha (0.05) 
MMR 2 Cooling Trunk 


\section{MMR 2 Cooling Trunk}

\begin{tabular}{|c|c|c|c|c|c|}
\hline \multicolumn{7}{|c|}{ Beta Scan of MMR 2 Cooling Trunk } \\
\hline $\mathbf{n}$ & Min & Max & Mean & Median & SD \\
\hline \multirow{4}{*}{753} & \multicolumn{5}{|c|}{$c$ m } \\
\cline { 2 - 7 } & 15 & 613 & 144 & 129 & 76 \\
\cline { 2 - 6 } & \multicolumn{5}{|c|}{$c \mathrm{cpm} /$ probe } \\
\cline { 2 - 6 } & -21 & 46 & -2 & -4 & 10 \\
\cline { 2 - 6 } & \multicolumn{5}{|c|}{$d \mathrm{~m} / 100 \mathrm{~cm}^{2}$} \\
\cline { 2 - 6 } & -95 & 210 & -10 & -17 & 44 \\
\hline
\end{tabular}

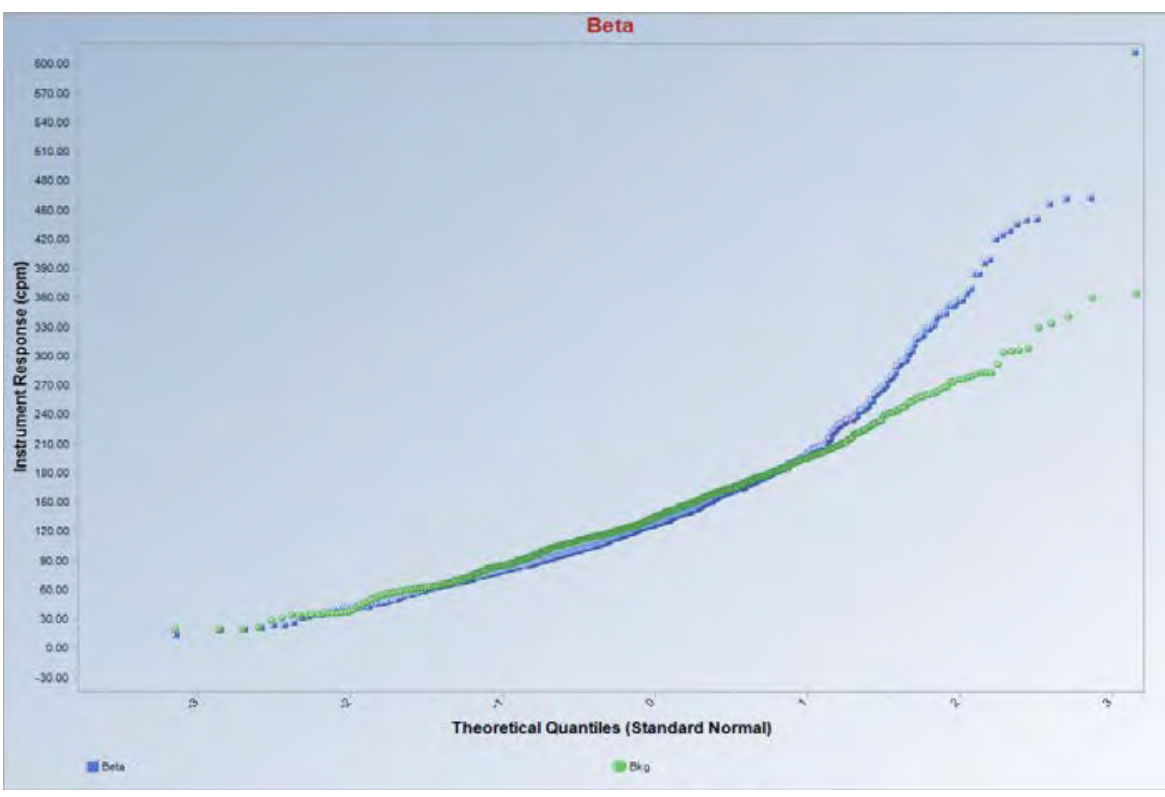

Gamma Scan of MMR 2 Cooling Trunk

\begin{tabular}{|c|c|c|c|c|c|}
\hline $\mathbf{n}$ & Min & Max & Mean & Median & SD \\
\hline \multirow{4}{*}{241} & \multicolumn{5}{|c|}{$c$ pm } \\
\cline { 2 - 6 } & 496 & 2,955 & 1,002 & 902 & 419 \\
\cline { 2 - 6 } & \multicolumn{5}{|c|}{$c c p m$} \\
\cline { 2 - 6 } & -170 & 2,289 & 336 & 236 & 419 \\
\hline
\end{tabular}

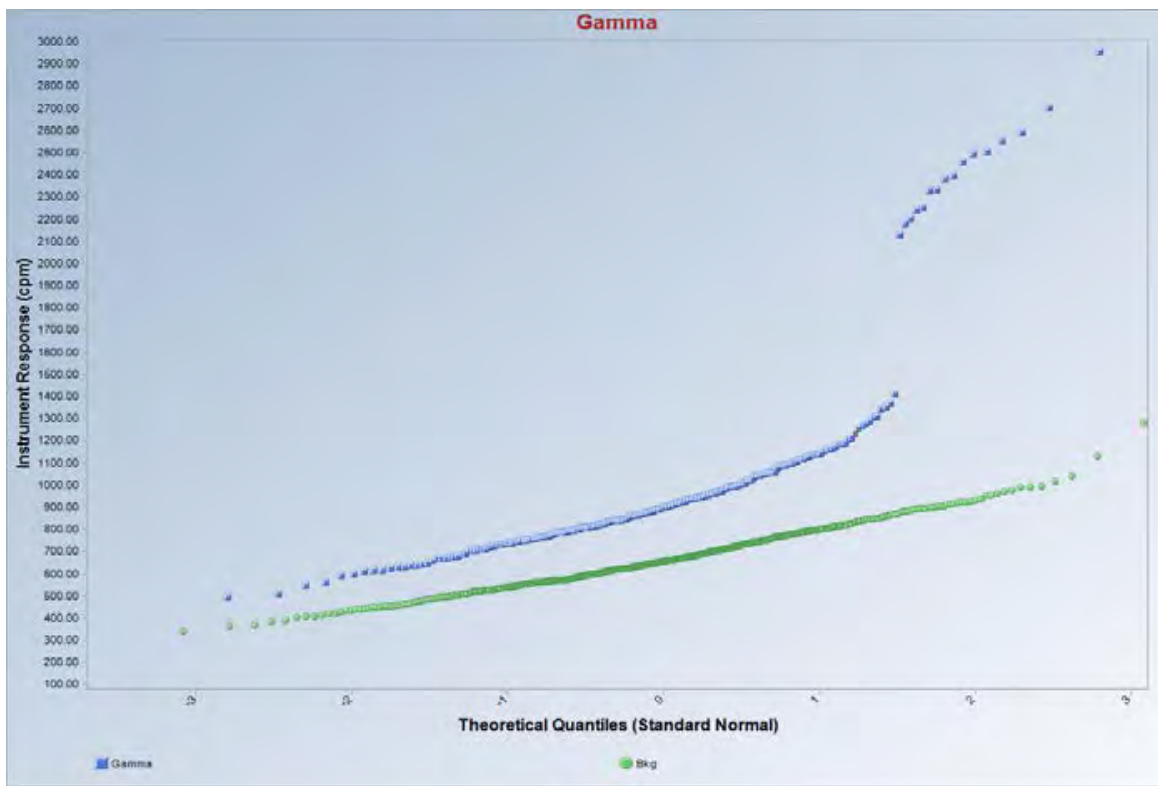




\section{MMR 2 Cooling Trunk}

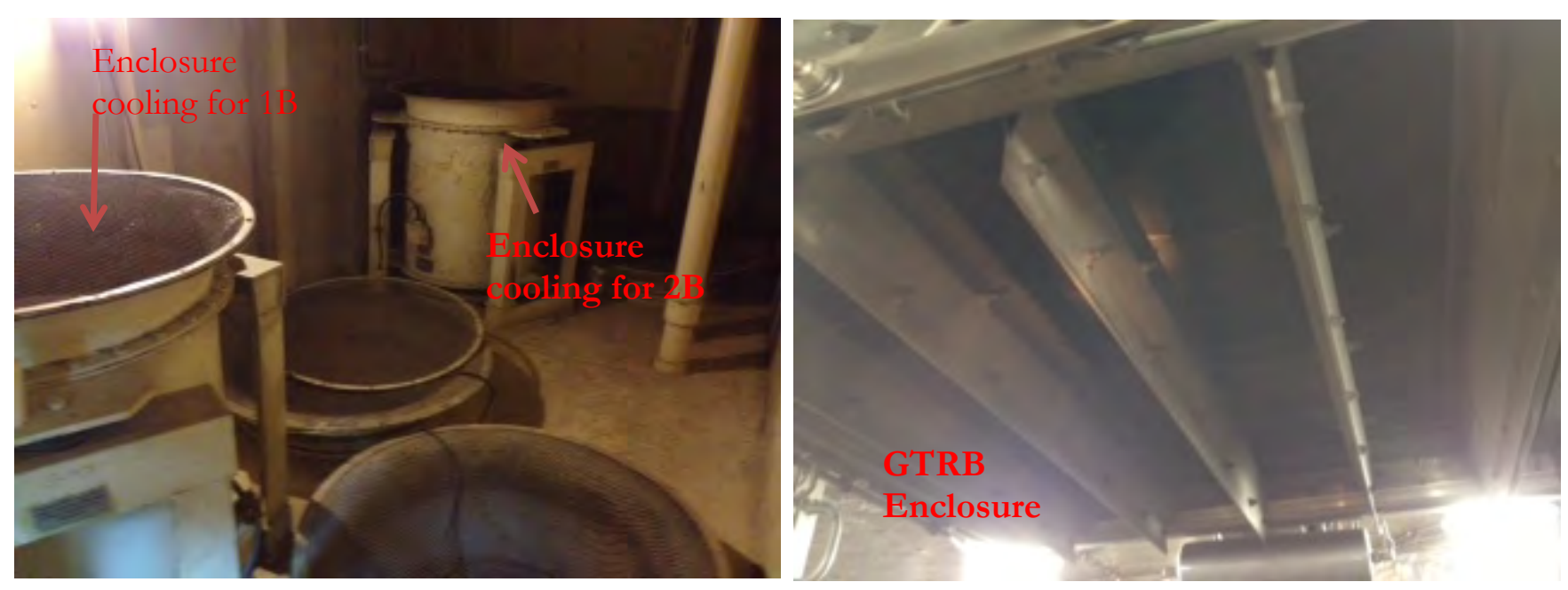

\begin{tabular}{|c|c|c|c|}
\hline \multicolumn{4}{|c|}{ MMR 2 Cooling Trunk Direct Measurements } \\
\hline GTRB & Item & ccpm /probe & $\mathbf{d p m} / \mathbf{1 0 0} \mathbf{~ c m}^{\mathbf{2}}$ \\
\hline 1A & Fan blade & 19 & 960 \\
\hline 1A & Plenum & 5 & 240 \\
\hline 1A & Plenum (accessed from enclosure) & -5 & -240 \\
\hline 1B & Fan blade & 53 & 2,700 \\
\hline 1B & Plenum & 86 & 4,400 \\
\hline 1B & Plenum (accessed from enclosure) & -1 & -74 \\
\hline
\end{tabular}




\section{MMR 2 Cooling Trunk Beta Scan}

Wilcoxon-Mann-Whitney Site vs Background Comparison Test for Full Data Sets without NDs

User Selected Options

From File

Full Precision

Confidence Coefficient

Substantial Difference

Selected Null Hypothesis

Alternative Hypothesis

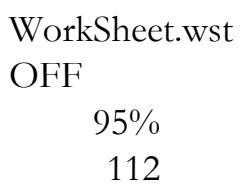

Site or AOC Mean/Median >= Background Mean/Median Plus Substantial Difference, S (Form 2)

Site or AOC Mean/Median Less Than Background Mean/Median Plus Substantial Difference, $\mathrm{S}$

Area of Concern Data: Beta

Background Data: Bkg

Raw Statistics

Number of Valid Observations

$\begin{array}{rc}\text { Site } & \text { Background } \\ 753 & 783 \\ 248 & 232 \\ 15 & 20 \\ 613 & 365 \\ 143.8 & 141.6 \\ 129 & 136 \\ 76.33 & 57.52 \\ 2.782 & 2.056\end{array}$

Number of Distinct Observations

Minimum

Wilcoxon-Mann-Whitney (WMW) Test

H0: Mean/Median of Site or AOC $>=$ Mean/Median of Background +112

Site Rank Sum W-Stat

346841

WMW Test U-Stat

$-26.68$

WMW Critical Value (0.050)

$-1.645$

P-Value

Conclusion with Alpha $=0.05$

Reject H0, Conclude Site $<$ Background +112.00

P-Value < alpha (0.05) 
GTRB 1A 
GTRB 1A

\begin{tabular}{|c|c|c|c|c|c|}
\hline \multicolumn{6}{|c|}{ Beta Scan of GTRB 1A Enclosure and Engine Surface } \\
\hline $\mathbf{n}$ & Min & Max & Mean & Median & SD \\
\hline \multirow{4}{*}{1730} & \multicolumn{5}{|c|}{$c$ m } \\
\cline { 2 - 7 } & 14 & 335 & 116 & 112 & 46 \\
\cline { 2 - 6 } & \multicolumn{5}{|c|}{$c$ cpm/probe } \\
\cline { 2 - 6 } & -21 & 27 & -6 & -6 & 7 \\
\cline { 2 - 6 } & \multicolumn{5}{|c|}{$d p m / 100 \mathrm{~cm}^{2}$} \\
\cline { 2 - 6 } & -95 & 123 & -27 & -29 & 32 \\
\hline
\end{tabular}

\begin{tabular}{|c|c|c|c|c|c|}
\hline \multicolumn{6}{|c|}{ Gamma Scan of GTRB 1A Enclosure and Engine Surface } \\
\hline $\mathbf{n}$ & Min & Max & Mean & Median & SD \\
\hline \multirow{3}{*}{1404} & \multicolumn{5}{|c|}{$c$ pm } \\
\cline { 2 - 6 } & 413 & 1,310 & 841 & 852 & 142 \\
\cline { 2 - 6 } & \multicolumn{5}{|c|}{$c c p m$} \\
\cline { 2 - 6 } & -253 & 644 & 175 & 186 & 142 \\
\hline
\end{tabular}
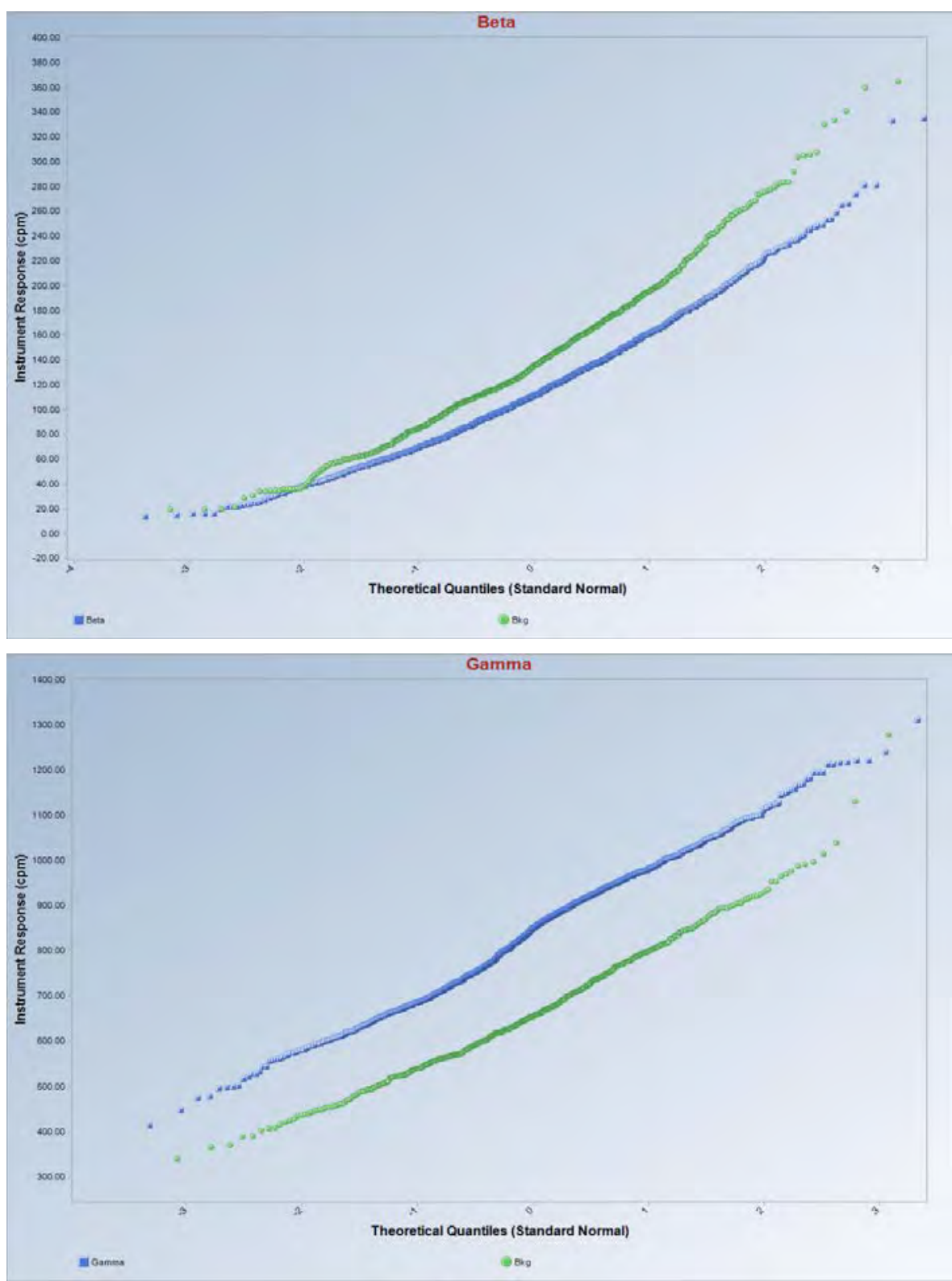


\section{GTRB 1A Engine Surfaces}
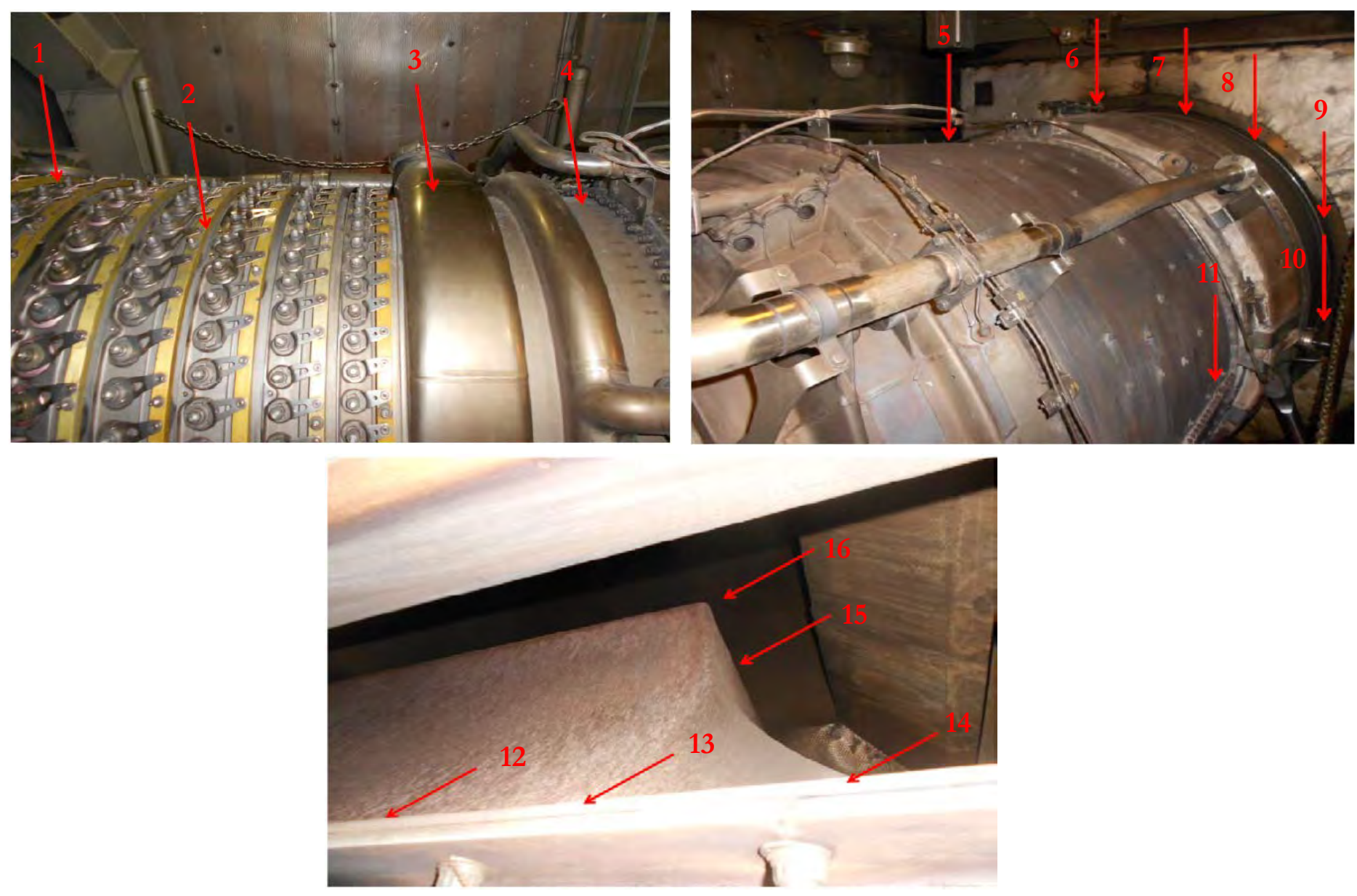

\begin{tabular}{|c|c|c|c|c|c|}
\hline \multicolumn{6}{|c|}{ GTRB 1A Engine Surface Direct Measurements } \\
\hline Location & ccpm /probe & $\mathrm{dpm} / 100 \mathrm{~cm}^{2}$ & Location & ccpm /probe & $\mathrm{dpm} / 100 \mathrm{~cm}^{2}$ \\
\hline 1 & -4 & -210 & 11 & -5 & -260 \\
\hline 2 & -4 & -210 & 12 & -10 & -510 \\
\hline 3 & -7 & -360 & 13 & 4 & 210 \\
\hline 4 & -4 & -210 & 14 & -1 & -42 \\
\hline 5 & -6 & -310 & 15 & -4 & -220 \\
\hline 6 & -4 & -210 & 16 & 1 & 65 \\
\hline 7 & 9 & 460 & ARP (pre) & -10 & -510 \\
\hline 8 & 0 & 0 & ARP (post) & 4 & 210 \\
\hline 9 & -5 & -260 & & & \\
\hline
\end{tabular}




\section{GTRB 1A Power Turbine}
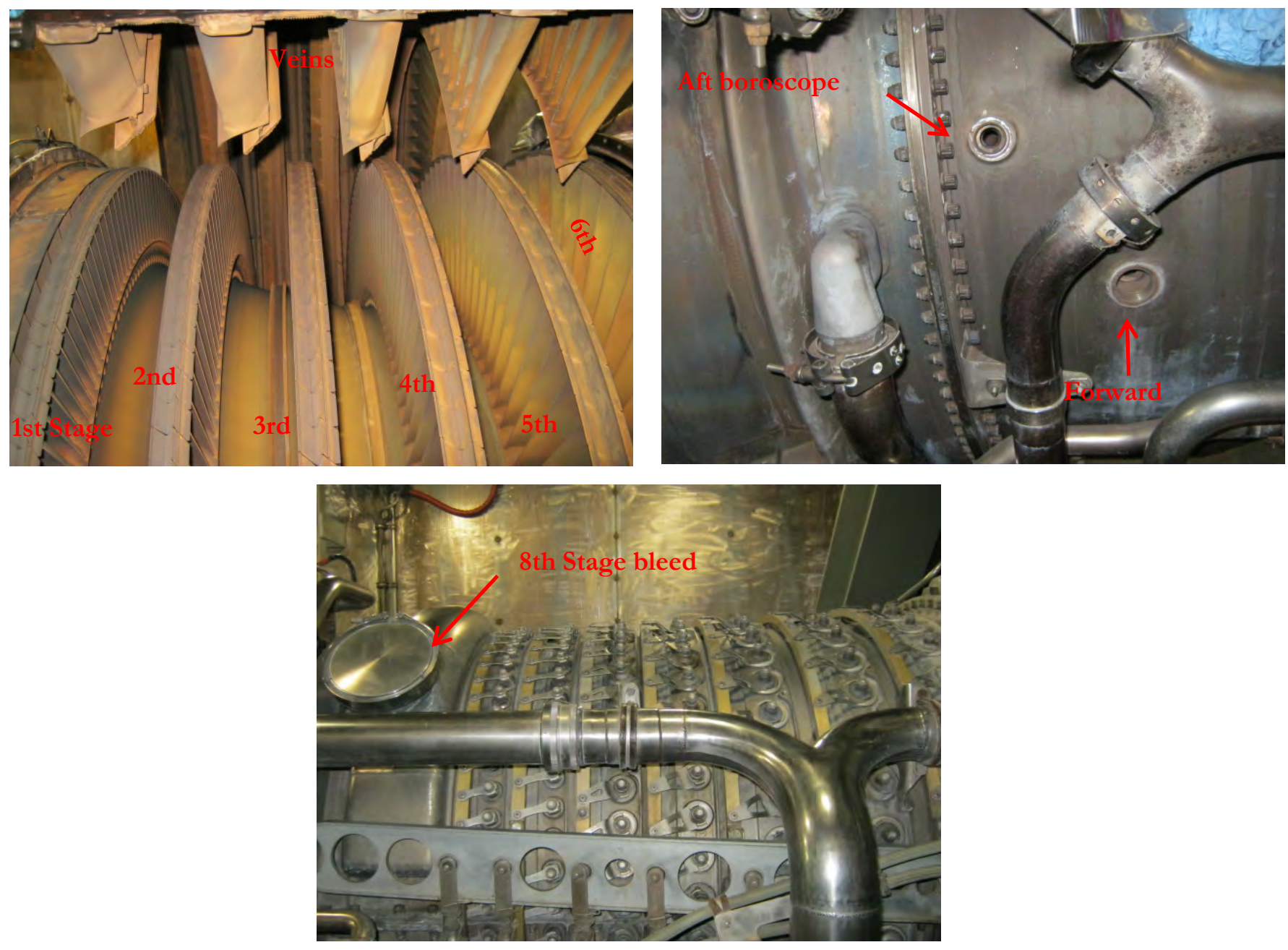

\begin{tabular}{|c|c|c|c|c|}
\hline \multicolumn{5}{|c|}{ GTRB 1A Power Turbine Direct Measurements } \\
\hline \multirow{2}{*}{ Location } & Total & & Removable & \\
\hline & ccpm/probe & $\mathrm{dpm} / 100 \mathrm{~cm}^{2}$ & ccpm & $\mathrm{dpm} / 100 \mathrm{~cm}^{2}$ \\
\hline Vein between 5 th $/ 6$ th stage & 31 & 1,600 & -2 & -8 \\
\hline 6th stage blade & 26 & 1,300 & 14 & 65 \\
\hline Aft boroscope port & -15 & -770 & & \\
\hline Forward boroscope port & -14 & -710 & & \\
\hline 8th stage bleed air & -1 & -51 & & \\
\hline
\end{tabular}




\section{GTRB 1A Exhaust}

\begin{tabular}{|c|c|c|c|c|}
\hline \multirow{2}{*}{ Location } & \multirow[b]{2}{*}{ ccpm/probe } & \multirow[b]{2}{*}{$\mathrm{dpm} / 100 \mathrm{~cm}^{2}$} & \multicolumn{2}{|c|}{ Removable } \\
\hline & & & ccpm & $\mathrm{dpm} / 100 \mathrm{~cm}^{2}$ \\
\hline Large Fin & 19 & 950 & 11 & 88 \\
\hline 6th Stage Blade & a & מ & 7 & 51 \\
\hline
\end{tabular}




\section{GTRB 1A Beta Scan}

Wilcoxon-Mann-Whitney Site vs Background Comparison Test for Full Data Sets without NDs User Selected Options

From File

Full Precision

Confidence Coefficient

Substantial Difference

Selected Null Hypothesis

Alternative Hypothesis

WorkSheet.wst
OFF
\[ 5 \% \% \]
112

Site or AOC Mean/Median >= Background Mean/Median Plus Substantial Difference, $\mathrm{S}$ (Form 2)

Site or AOC Mean/Median Less Than Background Mean/Median Plus Substantial Difference, $\mathrm{S}$

Area of Concern Data: Beta

Background Data: Bkg

Raw Statistics

Number of Valid Observations

Site $\begin{array}{rc}\text { Background } \\ 1730 & 783 \\ 224 & 232 \\ 14 & 20 \\ 335 & 365 \\ 116.2 & 141.6 \\ 112 & 136 \\ 46.26 & 57.52 \\ 1.112 & 2.056\end{array}$

Wilcoxon-Mann-Whitney (WMW) Test

H0: Mean/Median of Site or AOC $>=$ Mean/Median of Background +112

Site Rank Sum W-Stat

1535132

WMW Test U-Stat

$-37.96$

WMW Critical Value (0.050)

$-1.645$

P-Value

Conclusion with Alpha $=0.05$

Reject H0, Conclude Site $<$ Background +112.00

P-Value $<$ alpha (0.05) 
GTRB 1B 


\section{GTRB 1B}

\begin{tabular}{|c|c|c|c|c|c|}
\hline \multicolumn{6}{|c|}{ Beta Scan of GTRB 1B Enclosure and Engine Surface } \\
\hline $\mathbf{n}$ & Min & Max & Mean & Median & SD \\
\hline \multirow{4}{*}{1557} & \multicolumn{5}{|c|}{$c$ m } \\
\cline { 2 - 7 } & 17 & 426 & 164 & 156 & 66 \\
\cline { 2 - 6 } & \multicolumn{5}{|c|}{$c c p m / p r o b e$} \\
\cline { 2 - 6 } & -21 & 41 & 2 & 0 & 10 \\
\cline { 2 - 6 } & \multicolumn{5}{|c|}{$d p m / 100 \mathrm{~cm}^{2}$} \\
\cline { 2 - 6 } & -93 & 185 & 7 & 1 & 45 \\
\hline
\end{tabular}

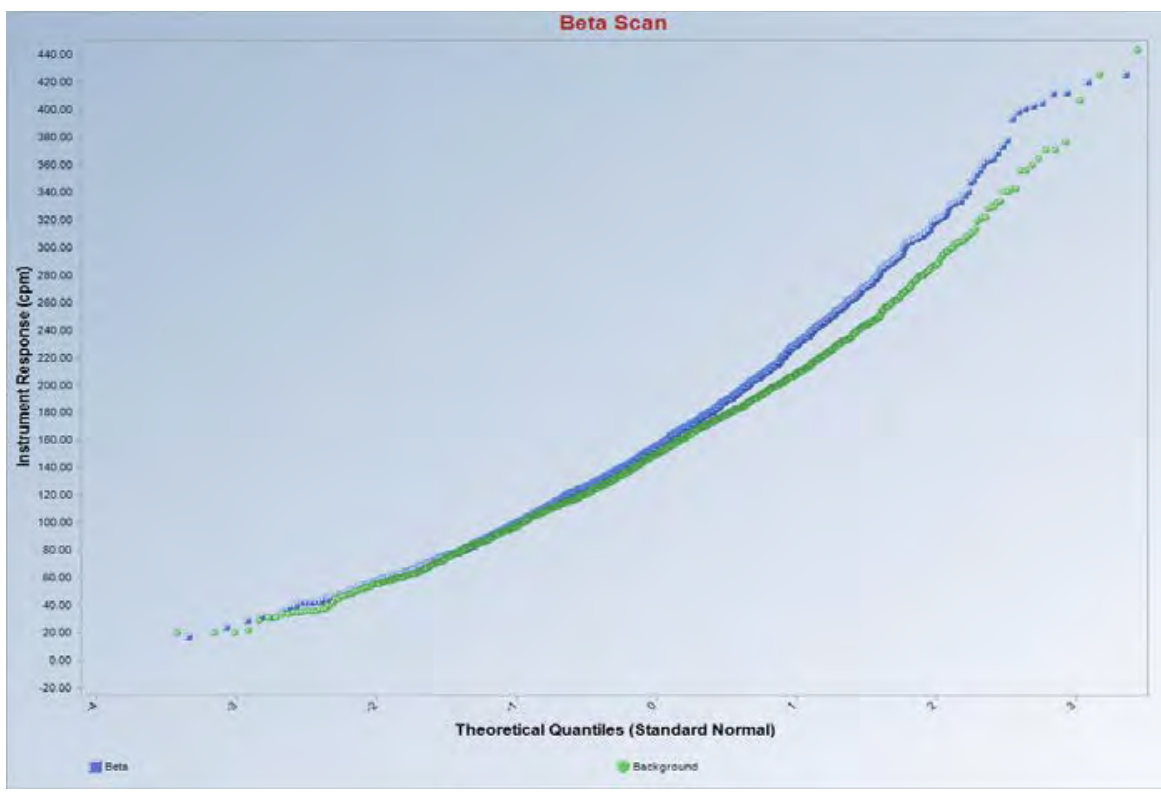

\begin{tabular}{|c|c|c|c|c|c|}
\hline \multicolumn{6}{|c|}{ Gamma Scan of GTRB 1B Enclosure and Engine Surface } \\
\hline $\mathbf{n}$ & Min & Max & Mean & Median & SD \\
\hline \multirow{3}{*}{1727} & \multicolumn{5}{|c|}{$c$ pm } \\
\cline { 2 - 6 } & 1,103 & 6,353 & 3,054 & 2,991 & 991 \\
\cline { 2 - 6 } & \multicolumn{5}{|c|}{$c c p m$} \\
\cline { 2 - 6 } & 437 & 5,687 & 2,388 & 2,325 & 991 \\
\hline
\end{tabular}

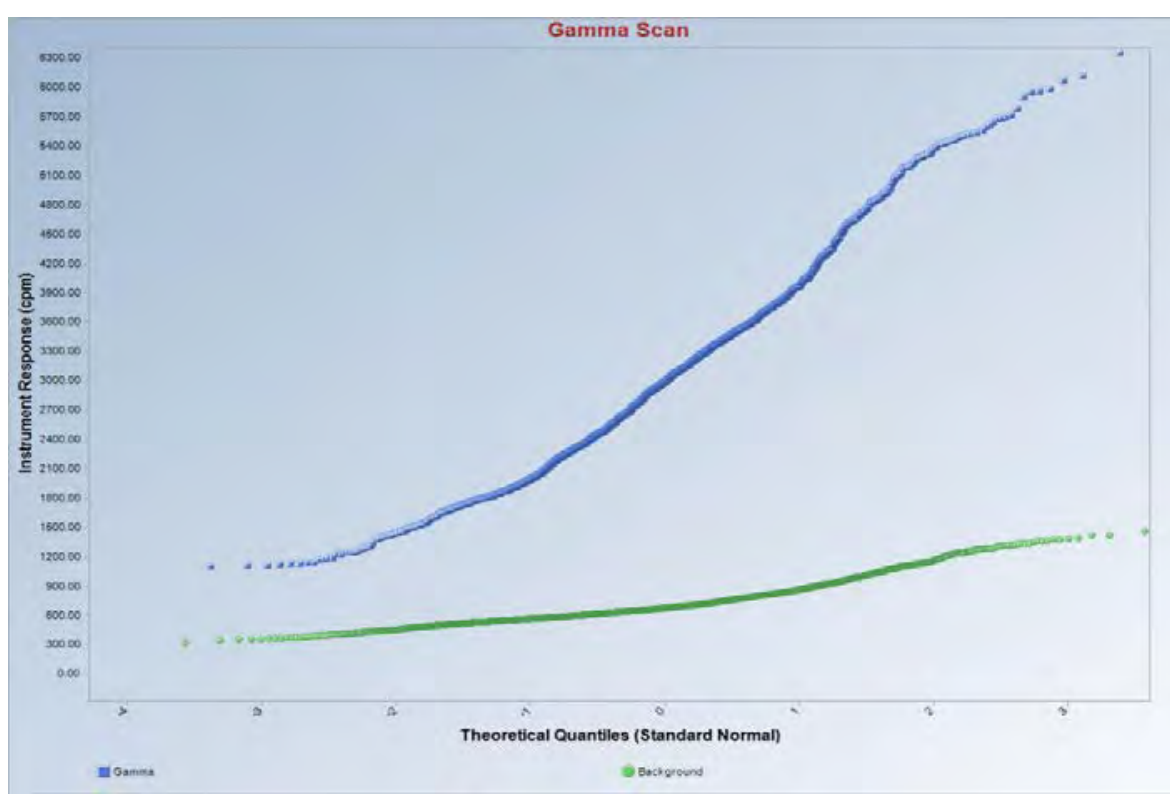




\section{GTRB 1B Engine Surfaces}
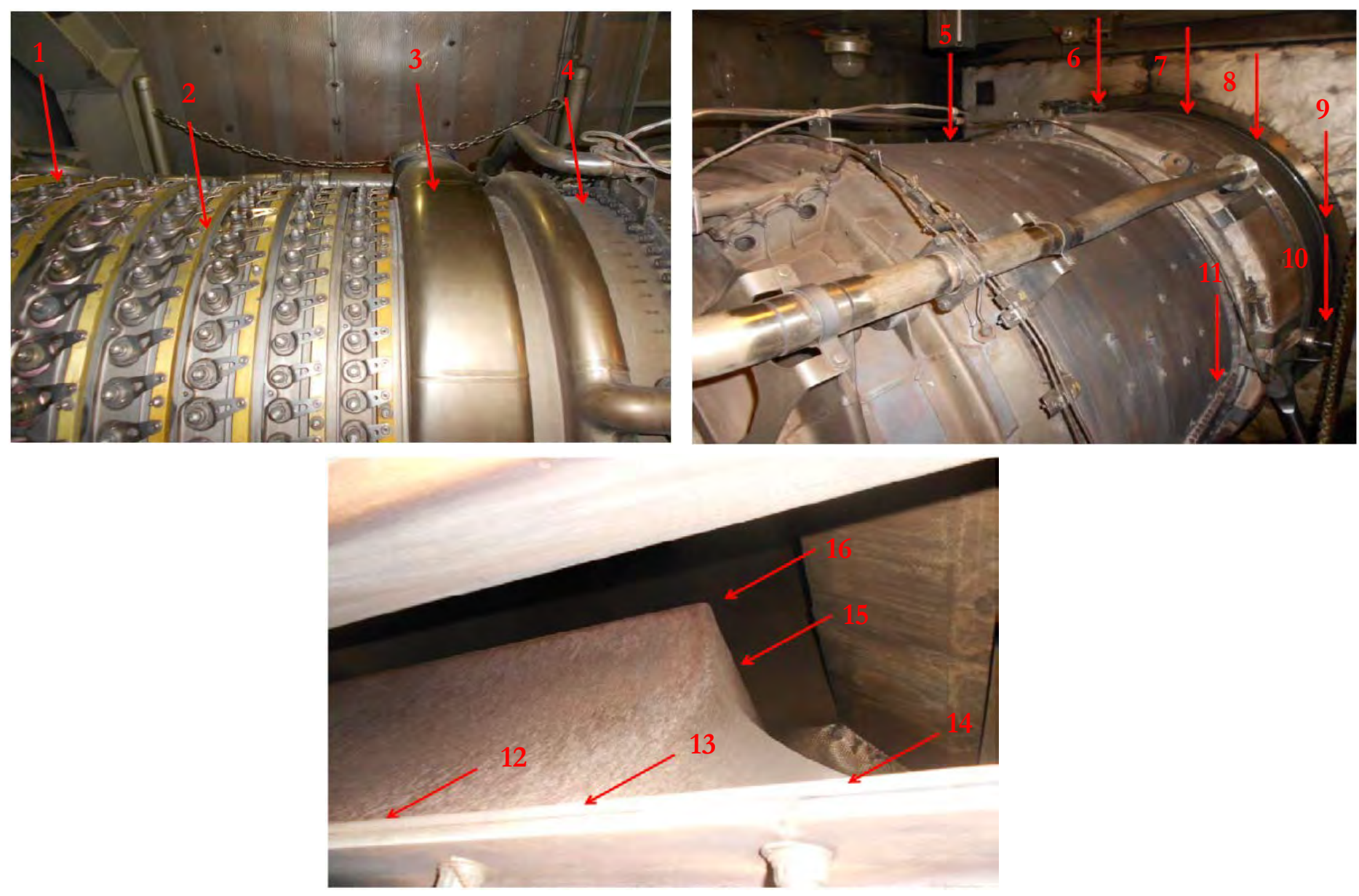

\begin{tabular}{|c|c|c|c|c|c|}
\hline \multicolumn{6}{|c|}{ GTRB 1B Engine Surface Direct Measurements } \\
\hline Location & ccpm /probe & $\mathrm{dpm} / 100 \mathrm{~cm}^{2}$ & Location & ccpm /probe & $\mathrm{dpm} / 100 \mathrm{~cm}^{2}$ \\
\hline 1 & 6 & 310 & 11 & 12 & 620 \\
\hline 2 & -6 & -310 & 12 & -13 & -60 \\
\hline 3 & 4 & 210 & 13 & -15 & -70 \\
\hline 4 & 15 & 770 & 14 & -26 & -120 \\
\hline 5 & 6 & 310 & 15 & -50 & -230 \\
\hline 6 & 3 & 150 & 16 & 92 & 430 \\
\hline 7 & 8 & 410 & ARP (pre) & -16 & -820 \\
\hline 8 & -4 & -210 & ARP (post) & 3 & 150 \\
\hline 9 & 3 & 150 & n & & \\
\hline
\end{tabular}




\section{GTRB 1B Power Turbine}
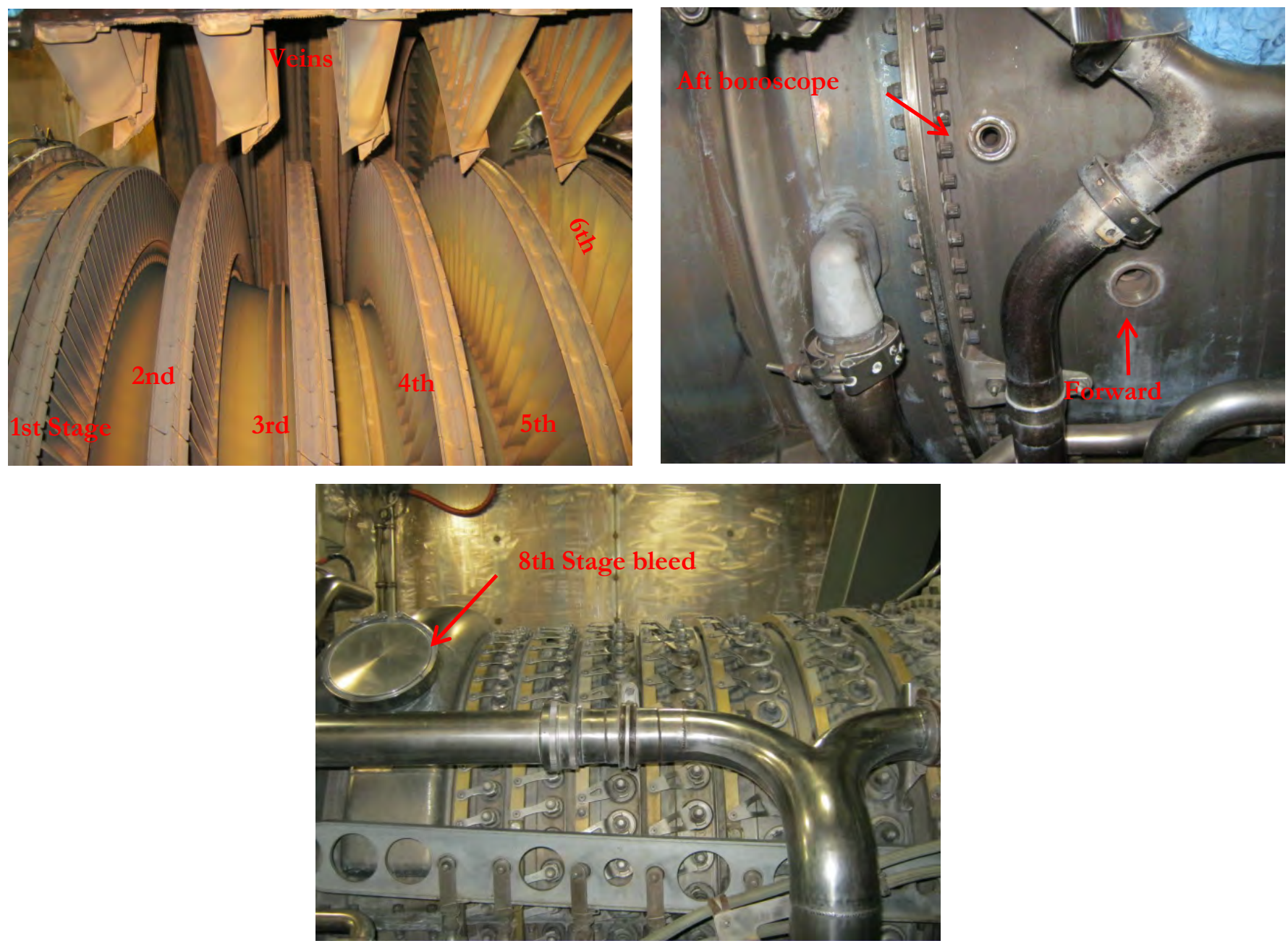

\begin{tabular}{|c|c|c|c|c|}
\hline \multicolumn{5}{|c|}{ GTRB 1B Power Turbine Direct Measurements } \\
\hline \multirow{2}{*}{ Location } & \multicolumn{2}{|c|}{ Total } & \multicolumn{2}{|c|}{ Removable } \\
\hline & ccpm/probe & $\mathrm{dpm} / 100 \mathrm{~cm}^{2}$ & ccpm & $\mathrm{dpm} / 100 \mathrm{~cm}^{2}$ \\
\hline 4th stage blade & 93 & 4,800 & -4 & -17 \\
\hline $\begin{array}{l}\text { Casing between } 5 \text { th } / 6 \text { th } \\
\text { stage veins }\end{array}$ & 170 & 8,600 & 18 & 84 \\
\hline Aft boroscope port & 3 & 150 & & \\
\hline Forward boroscope port & 7 & 360 & & \\
\hline 8th stage bleed air & 12 & 620 & & \\
\hline
\end{tabular}




\section{GTRB 1B Exhaust}

\begin{tabular}{|c|c|c|c|c|}
\hline \multicolumn{4}{|c|}{ GTRB 1B Exhaust Direct Measurements } \\
\hline \multirow{2}{*}{ Location } & \multicolumn{2}{|c|}{ Total } & \multicolumn{2}{c|}{ Removable } \\
\cline { 2 - 5 } & ccpm/probe & $\mathbf{d p m} / \mathbf{1 0 0} \mathbf{~ c m}^{2}$ & $\mathbf{c c p m}$ & $\mathbf{d p m} / \mathbf{1 0 0} \mathbf{~ c m}^{2}$ \\
\hline Shaft & 36 & 1900 & 7 & 56 \\
\hline Large Fin & 62 & 3200 & -3 & -23 \\
\hline Small Blade & \multicolumn{2}{|l|}{} & 57 \\
\hline
\end{tabular}




\section{GTRB 1B Beta Scan}

Wilcoxon-Mann-Whitney Site vs Background Comparison Test for Full Data Sets without NDs

User Selected Options

From File

Full Precision

WorkSheet.wst

Confidence Coefficient

OFF

Substantial Difference

Selected Null Hypothesis

$95 \%$

112

Site or AOC Mean/Median $>=$ Background Mean/Median Plus Substantial Difference, S (Form 2)

Site or AOC Mean/Median Less Than Background Mean/Median Plus

Alternative Hypothesis

Substantial Difference, $\mathrm{S}$

Area of Concern Data: Beta

Background Data: Bkg

Raw Statistics

Number of Valid Observations

$\begin{array}{rc}\text { Site } & \text { Background } \\ 1557 & 783 \\ 304 & 232 \\ 17 & 20 \\ 426 & 365 \\ 164.2 & 141.6 \\ 156 & 136 \\ 66.25 & 57.52 \\ 1.679 & 2.056\end{array}$

Number of Distinct Observations

Minimum

2.056

Wilcoxon-Mann-Whitney (WMW) Test

H0: Mean/Median of Site or AOC >= Mean/Median of Background + 112

Site Rank Sum W-Stat

1393021

WMW Test U-Stat

$-27.85$

WMW Critical Value (0.050)

$-1.645$

P-Value

Conclusion with Alpha $=0.05$

Reject H0, Conclude Site < Background + 112.00

P-Value $<$ alpha $(0.05)$ 


\section{GTRB 2A}




\section{GTRB 2A}

\begin{tabular}{|c|c|c|c|c|c|}
\hline \multicolumn{6}{|c|}{ Beta Scan of GTRB 2A Enclosure and Engine Surface } \\
\hline $\mathbf{n}$ & Min & Max & Mean & Median & SD \\
\hline \multirow{4}{*}{1447} & \multicolumn{5}{|c|}{$c$ m } \\
\cline { 2 - 6 } & 2 & 335 & 114 & 110 & 47 \\
\cline { 2 - 6 } & \multicolumn{5}{|c|}{$c$ cpm/probe } \\
\cline { 2 - 6 } & -23 & 27 & -6 & -7 & 7 \\
\cline { 2 - 6 } & \multicolumn{5}{|c|}{$d 00 \mathrm{~cm}^{2}$} \\
\cline { 2 - 6 } & -104 & 123 & -27 & -30 & 32 \\
\hline
\end{tabular}

\begin{tabular}{|c|c|c|c|c|c|}
\hline \multicolumn{6}{|c|}{ Gamma Scan of GTRB 2A Enclosure and Engine Surface } \\
\hline $\mathbf{n}$ & Min & Max & Mean & Median & SD \\
\hline \multirow{3}{*}{1459} & \multicolumn{5}{|c|}{$c$ mm } \\
\cline { 2 - 6 } & 453 & 1,049 & 726 & 736 & 111 \\
\cline { 2 - 6 } & \multicolumn{5}{|c|}{$c c p m$} \\
\cline { 2 - 6 } & -213 & 383 & 60 & 70 & 111 \\
\hline
\end{tabular}
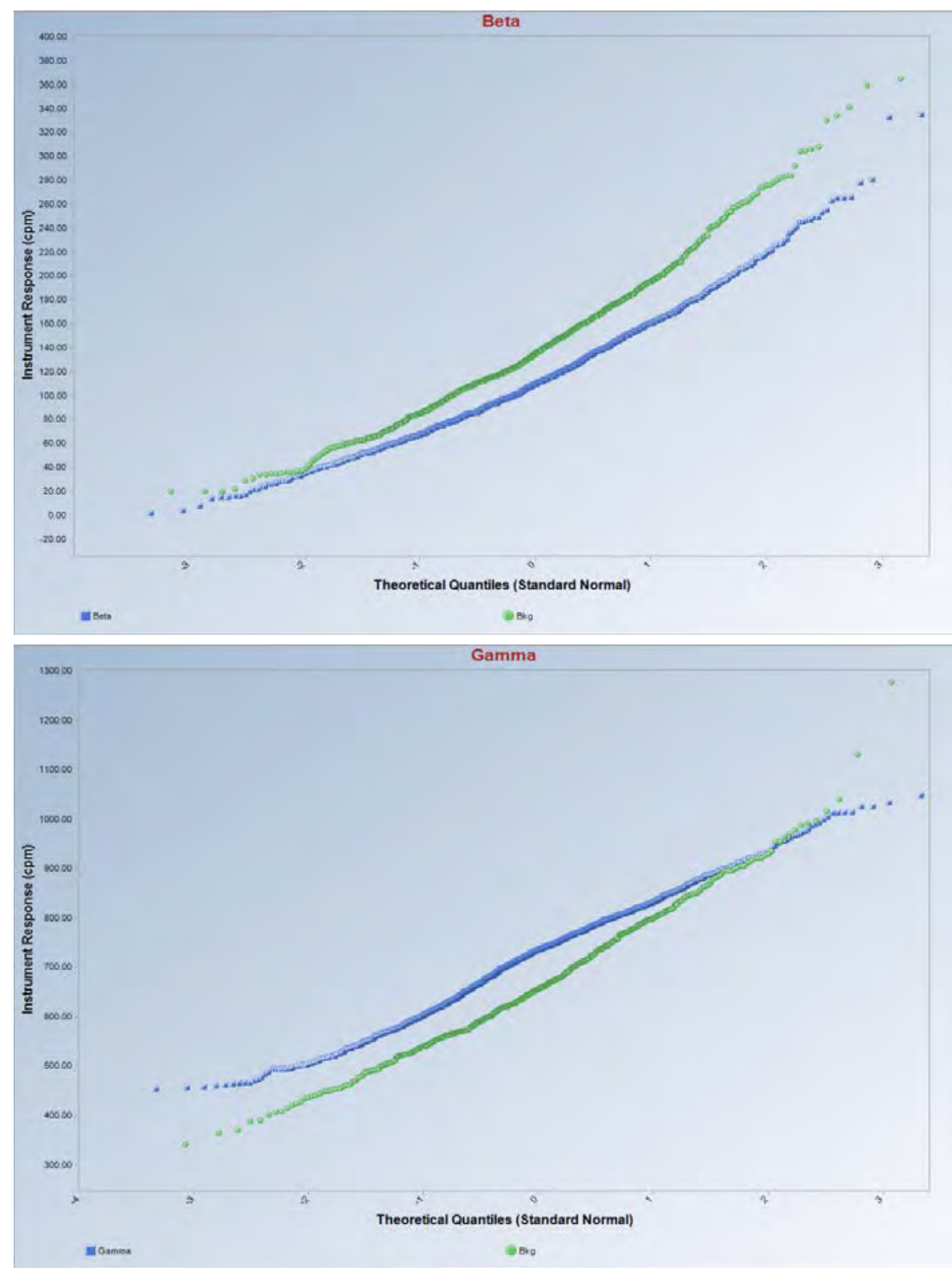


\section{GTRB 2A Engine Surfaces}
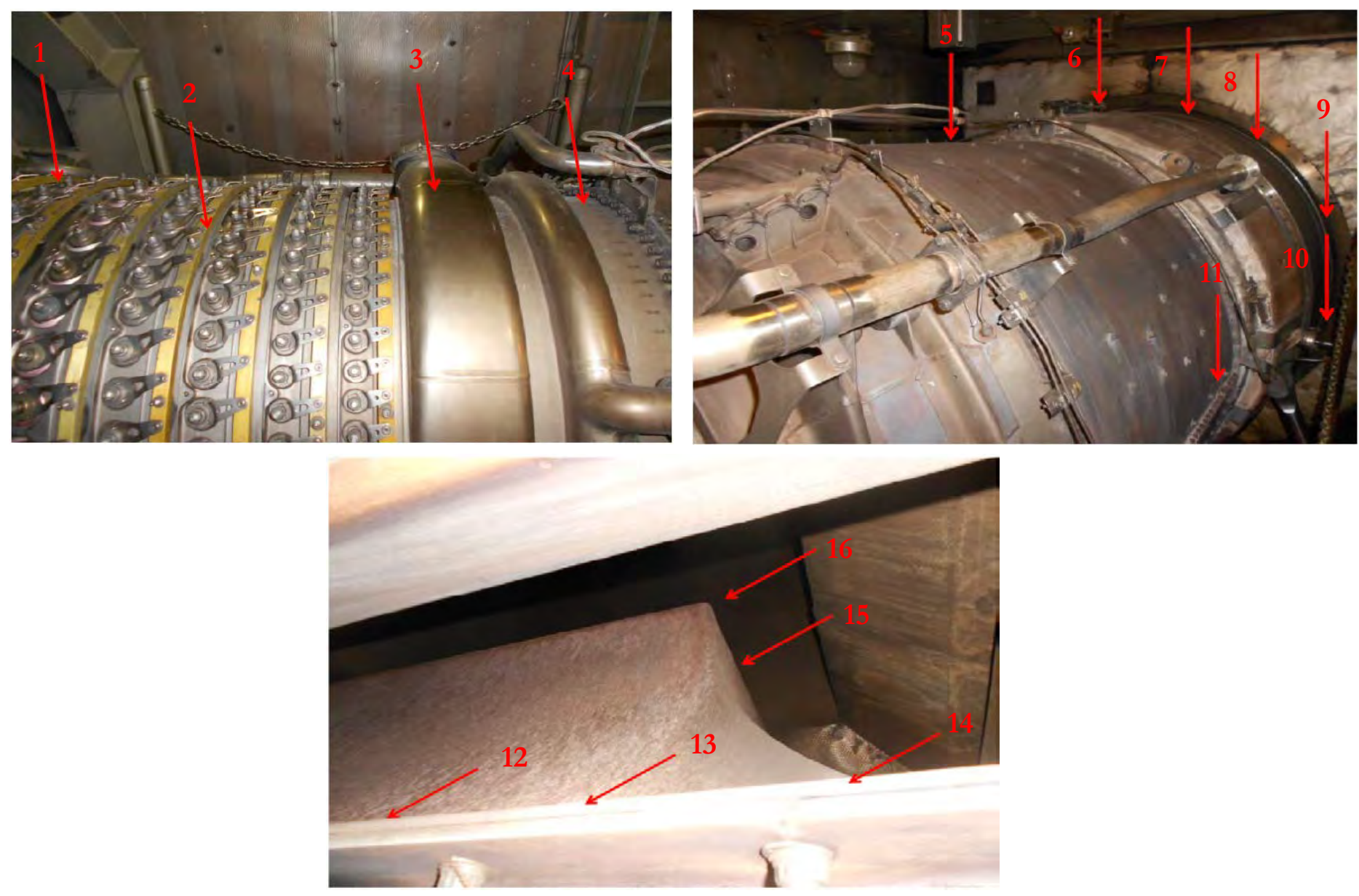

\begin{tabular}{|c|c|c|c|c|c|}
\hline \multicolumn{7}{|c|}{ GTRB 2A Engine Surface Direct Measurements } \\
\hline Location & $\mathbf{c c p m} /$ probe & $\mathbf{d p m} / \mathbf{1 0 0} \mathbf{~ c m}^{\mathbf{2}}$ & Location & $\mathbf{c c p m} / \mathbf{p r o b e}$ & $\mathbf{d p m} / \mathbf{1 0 0} \mathbf{~ c m}^{\mathbf{2}}$ \\
\hline 1 & -7 & -360 & 10 & 0 & 0 \\
\hline 2 & -3 & -150 & 11 & -4 & -5 \\
\hline 3 & -10 & -510 & 12 & 1 & 65 \\
\hline 4 & -10 & -510 & 13 & 1 & 47 \\
\hline 5 & -4 & -210 & 14 & 3 & -160 \\
\hline 6 & 0 & 0 & 15 & -4 & -220 \\
\hline 7 & -2 & -100 & 16 & -10 & -510 \\
\hline 8 & -2 & -100 & ARP (pre) & -12 & -610 \\
\hline 9 & -9 & -460 & ARP (post) & 3 & 150 \\
\hline
\end{tabular}




\section{GTRB 2A Power Turbine}
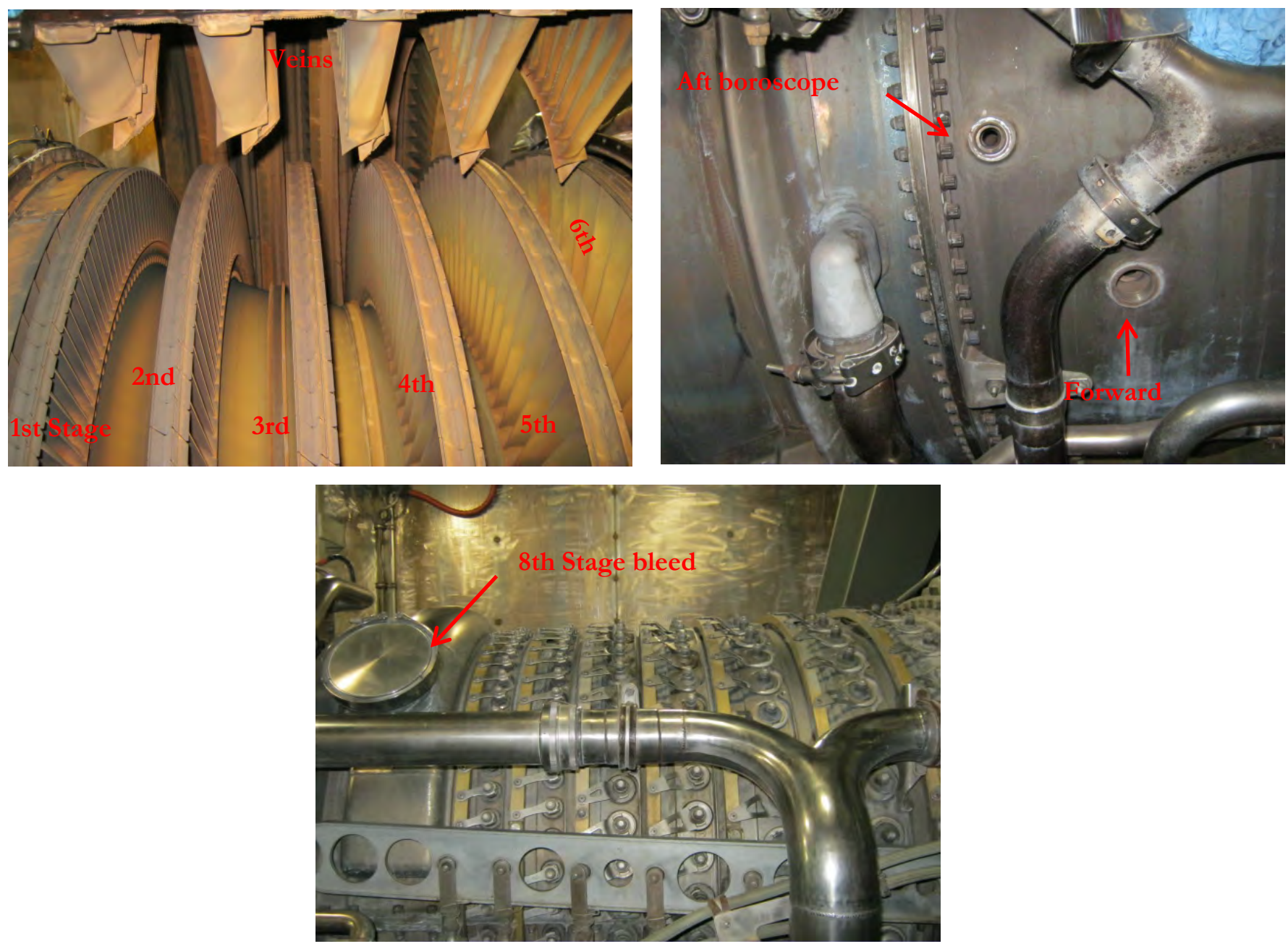

\begin{tabular}{|c|c|c|c|c|}
\hline \multicolumn{5}{|c|}{ GTRB 2A Power Turbine Direct Measurements } \\
\hline \multirow{2}{*}{ Location } & \multicolumn{2}{|c|}{ Total } & \multicolumn{2}{|c|}{ Removable } \\
\hline & ccpm/probe & $\mathrm{dpm} / 100 \mathrm{~cm}^{2}$ & ccpm & $\mathrm{dpm} / 100 \mathrm{~cm}^{2}$ \\
\hline 6th stage blade & 31 & 1,600 & 4 & 17 \\
\hline Aft boroscope port & -7 & -360 & & \\
\hline Forward boroscope port & 5 & 260 & & \\
\hline 8th stage bleed air & -8 & -410 & & \\
\hline
\end{tabular}




\section{GTRB 2A Exhaust}

\begin{tabular}{|c|c|c|c|c|}
\hline \multirow{2}{*}{ Location } & \multicolumn{2}{|c|}{ Total } & \multicolumn{2}{|c|}{ Removable } \\
\hline & ccpm/probe & $\mathrm{dpm} / 100 \mathrm{~cm}^{2}$ & ccpm & $\mathrm{dpm} / 100 \mathrm{~cm}^{2}$ \\
\hline Large Fin & 15 & 770 & 17 & -130 \\
\hline 6th Stage Blade & \multicolumn{2}{|c|}{ a } & 12 & 92 \\
\hline
\end{tabular}




\section{GTRB 2A Beta Scan}

Wilcoxon-Mann-Whitney Site vs Background Comparison Test for Full Data Sets without NDs User Selected Options

From File

Full Precision

Confidence Coefficient

Substantial Difference

Selected Null Hypothesis

Alternative Hypothesis

WorkSheet.wst
OFF
\[ 5 \% \]
112

Site or AOC Mean/Median >= Background Mean/Median Plus Substantial Difference, $\mathrm{S}$ (Form 2)

Site or AOC Mean/Median Less Than Background Mean/Median Plus Substantial Difference, $\mathrm{S}$

Area of Concern Data: Beta

Background Data: Bkg

Raw Statistics

Number of Valid Observations

Site $\begin{array}{rc}\text { Background } \\ 1730 & 783 \\ 224 & 232 \\ 14 & 20 \\ 335 & 365 \\ 116.2 & 141.6 \\ 112 & 136 \\ 46.26 & 57.52 \\ 1.112 & 2.056\end{array}$

Wilcoxon-Mann-Whitney (WMW) Test

H0: Mean/Median of Site or AOC $>=$ Mean/Median of Background +112

Site Rank Sum W-Stat

1535132

WMW Test U-Stat

$-37.96$

WMW Critical Value (0.050)

$-1.645$

P-Value

Conclusion with Alpha $=0.05$

Reject H0, Conclude Site $<$ Background +112.00

P-Value $<$ alpha (0.05) 


\section{GTRB 2B}




\section{GTRB 2B}

\begin{tabular}{|c|c|c|c|c|c|}
\hline \multicolumn{6}{|c|}{ Beta Scan of GT'RB 2B Enclosure and Engine Surface } \\
\hline $\mathbf{n}$ & Min & Max & Mean & Median & SD \\
\hline \multirow{4}{*}{1108} & \multicolumn{5}{|c|}{$c$ pm } \\
\cline { 2 - 6 } & 100 & 266 & 168 & 164 & 31 \\
\cline { 2 - 6 } & \multicolumn{5}{|c|}{$c$ cpm/probe } \\
\cline { 2 - 6 } & -8 & 17 & 2 & 1 & 5 \\
\cline { 2 - 6 } & \multicolumn{5}{|c|}{$d \mathrm{pm} / 100 \mathrm{~cm}^{2}$} \\
\cline { 2 - 6 } & -37 & 76 & 9 & 7 & 21 \\
\hline
\end{tabular}
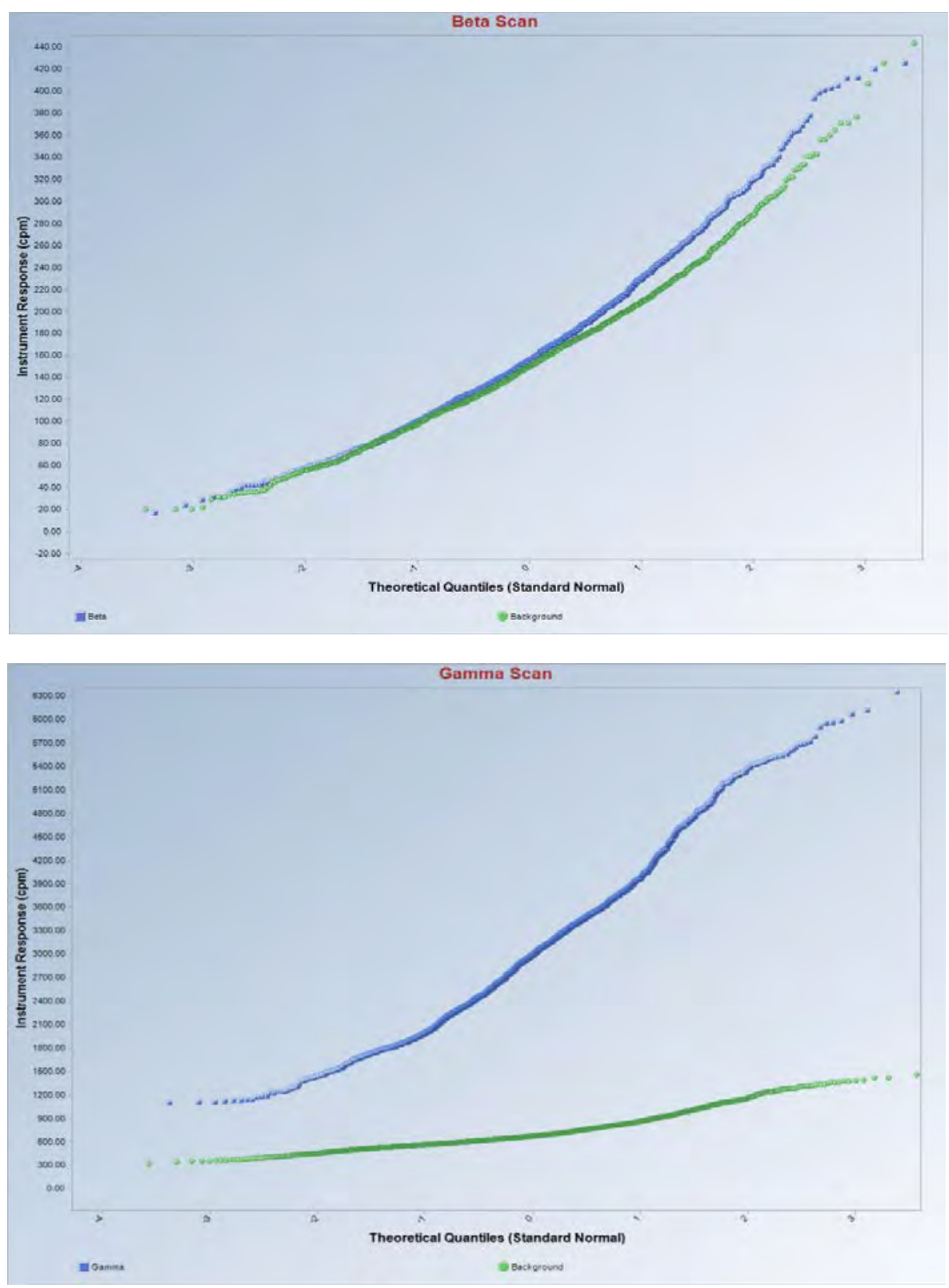


\section{GTRB 2B Engine Surfaces}
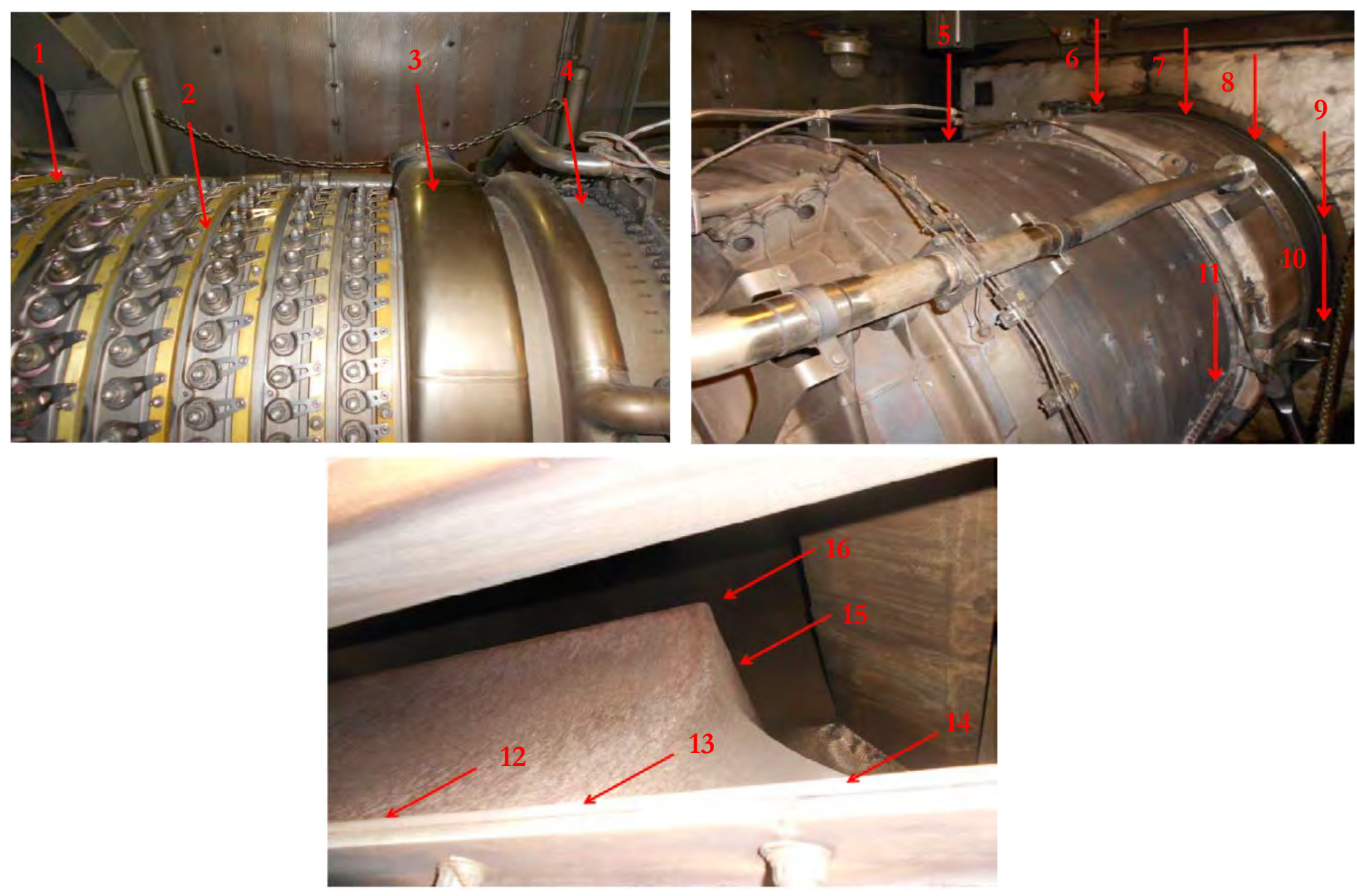

\begin{tabular}{|c|c|c|c|c|c|}
\hline \multicolumn{6}{|c|}{ GTRB 2B Engine Surface Direct Measurements } \\
\hline Location & ccpm /probe & $\mathrm{dpm} / 100 \mathrm{~cm}^{2}$ & Location & ccpm /probe & $\mathrm{dpm} / 100 \mathrm{~cm}^{2}$ \\
\hline 1 & 0 & 0 & 11 & 3 & 150 \\
\hline 2 & 3 & 150 & 12 & -1 & -37 \\
\hline 3 & 4 & 210 & 13 & -2 & -93 \\
\hline 4 & 7 & 360 & 14 & -1 & -33 \\
\hline 5 & 19 & 970 & 15 & -4 & -190 \\
\hline 6 & -3 & -150 & 16 & 10 & 510 \\
\hline 7 & -2 & -100 & ARP (pre) & 3 & 150 \\
\hline 8 & -5 & -260 & ARP (post) & 23 & 1200 \\
\hline 9 & -5 & -260 & & & \\
\hline
\end{tabular}




\section{GTRB 2B Power Turbine}
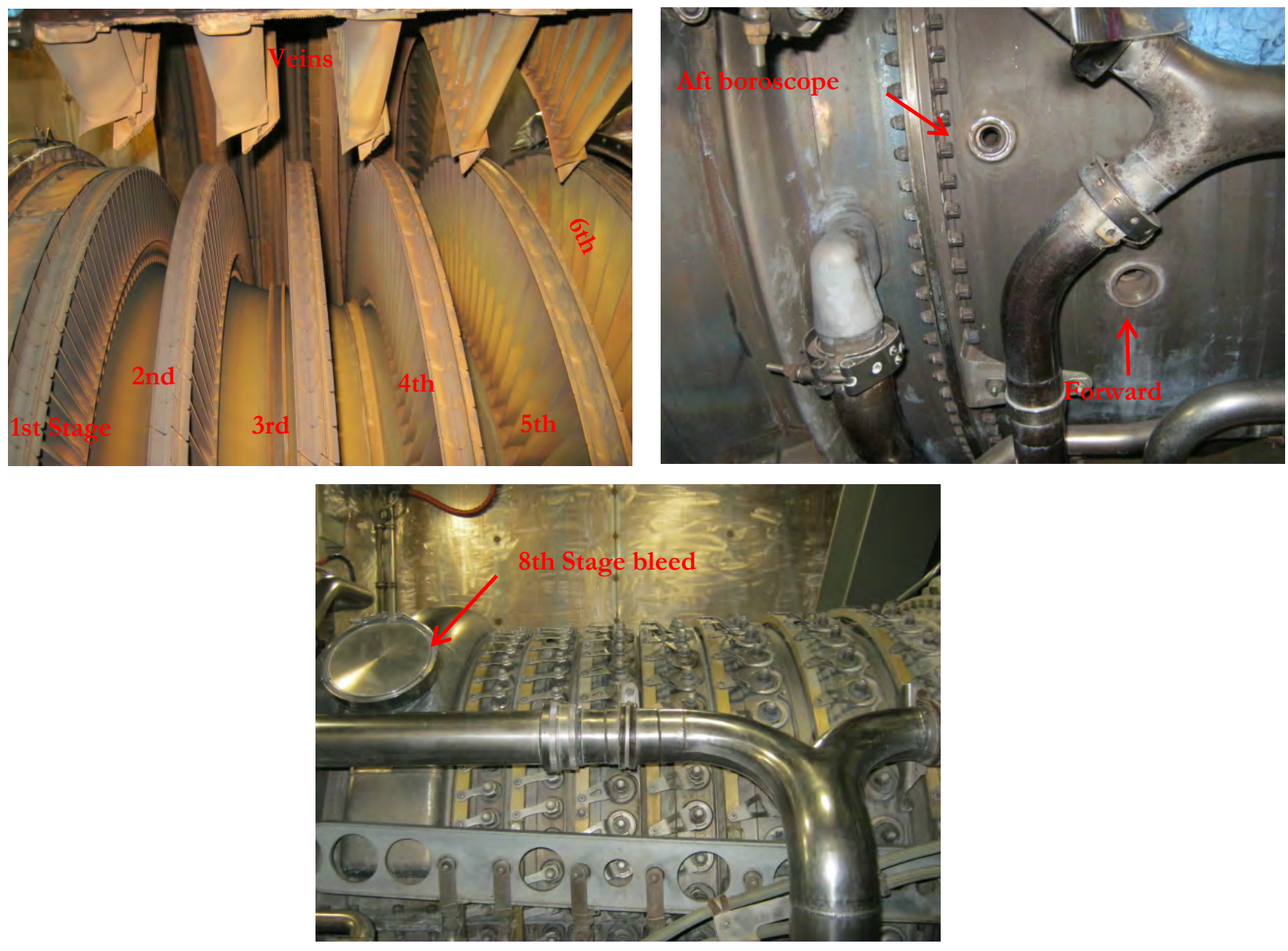

\begin{tabular}{|c|c|c|c|c|}
\hline \multicolumn{5}{|c|}{ GTRB 2B Power Turbine Direct Measurements } \\
\hline \multirow{2}{*}{ Location } & \multicolumn{2}{|c|}{ Total } & \multicolumn{2}{|c|}{ Removable } \\
\hline & ccpm/probe & $\mathrm{dpm} / 100 \mathrm{~cm}^{2}$ & ccpm & $\mathrm{dpm} / 100 \mathrm{~cm}^{2}$ \\
\hline 6th stage blade & 120 & 5,900 & 21 & 98 \\
\hline 2nd stage vein & 100 & 5,200 & 14 & 65 \\
\hline $\begin{array}{l}\text { Casing between 5th/6th } \\
\text { stage veins }\end{array}$ & 160 & 8,000 & 8 & 39 \\
\hline Aft boroscope port & 7 & 630 & & \\
\hline Forward boroscope port & 9 & 460 & & \\
\hline 8th stage bleed air & 11 & 564 & & \\
\hline
\end{tabular}




\section{GTRB 2B Exhaust}

\begin{tabular}{|c|c|c|c|c|}
\hline \multicolumn{5}{|c|}{ GTRB 2B Exhaust Direct Measurements } \\
\hline \multirow{2}{*}{ Location } & \multicolumn{2}{|c|}{ Total } & \multicolumn{2}{|c|}{ Removable } \\
\hline & ccpm/probe & $\mathrm{dpm} / 100 \mathrm{~cm}^{2}$ & ccpm & $\mathrm{dpm} / 100 \mathrm{~cm}^{2}$ \\
\hline Large Fin & 41 & 2084 & 16 & 121 \\
\hline Wall, adjcent to fin & 42 & 2153 & -1 & -5 \\
\hline 6th stage blade & m & an & 3 & 23 \\
\hline
\end{tabular}




\section{GTRB 2B Beta Scan}

Wilcoxon-Mann-Whitney Site vs Background Comparison Test for Full Data Sets without NDs

User Selected Options

From File

Full Precision

WorkSheet.wst

Foll Precision

Confidence Coefficient

OFF

Substantial Difference

Selected Null Hypothesis

$95 \%$

112

Site or AOC Mean/Median $>=$ Background Mean/Median Plus Substantial Difference, $S$ (Form 2)

Site or AOC Mean/Median Less Than Background Mean/Median Plus

Alternative Hypothesis

Substantial Difference, $\mathrm{S}$

Area of Concern Data: Beta

Background Data: Bkg

Raw Statistics

Number of Valid Observations

$\begin{array}{rc}\text { Site } & \text { Background } \\ 1557 & 783 \\ 304 & 232 \\ 17 & 20 \\ 426 & 365 \\ 164.2 & 141.6 \\ 156 & 136 \\ 66.25 & 57.52 \\ 1.679 & 2.056\end{array}$

Number of Distinct Observations

Minimum

2.056

Wilcoxon-Mann-Whitney (WMW) Test

H0: Mean/Median of Site or AOC >= Mean/Median of Background + 112

Site Rank Sum W-Stat

1393021

WMW Test U-Stat

$-27.85$

WMW Critical Value (0.050)

$-1.645$

P-Value

Conclusion with Alpha $=0.05$

Reject H0, Conclude Site < Background + 112.00

P-Value $<$ alpha (0.05) 